\title{
DEVELOPMENT OF THE
}

Filucay

\section{ENVIRONMENTAL DATA STORAGE} AND RETRIEVAL SYSTEM

MARCH 1968

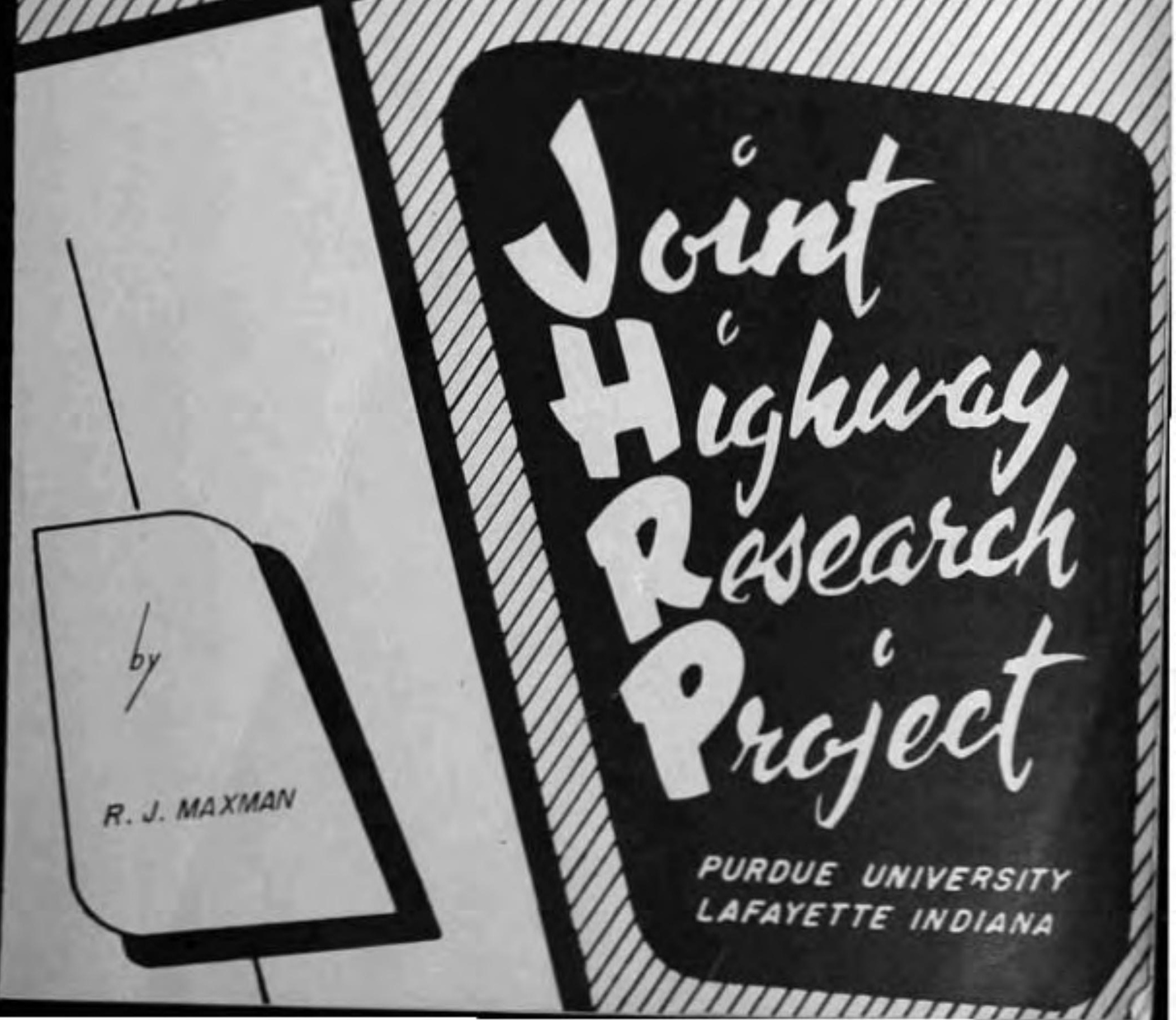




\section{DEVBLOPAEYT OF THE ENVIROERENAL.}

DATA STORAGE ADO RETR ZBVAL SYSNEA

то:

G. A. Leonsrda, Director

Joint Highway Reaesrch Project:

FrOA: H. L. Wichael Associate Director Joint Eighway Research Project
Hay 9, 1968

File No: 3-7

The attached research report is presented to the Advisory Board for information. The report, "Developiest of the Eavironmental Data storage and Retrleval Syatea" wss authozed by Mr. Robert J. Moxaun, a Graduste Trainee in the Eavironsentel Binslth Institute of Purdue Vnivereity. Mr. Muxmen also ured the regearch for hiv $\mathrm{kSCB}$ thesis research at Purdue and performed it under the direction of Professor W. L. Grecco.

The research reported herein was not conducted by the Joint Bighway Research Project but by the Bavironments 1 Hesith Institute of Purdue Dniverelcy with funda fonthe Public Health Service. It. 1s reported to the Bourd because of its strong relationship to urban trensportation planning. The results heve direct application in the continuiug transportation planning process required for all matropolitan areas in Indianu of more than 50,000 populstion.

The report is presented to the Board as informotion.

Hבx:

Attachuent

Copy:
R. E. Herre11

v. R. Harvey

3. A. Havers

J. F. Mcleughlin

7. B. Nendenha11

R. D. Miles

J. C. Oppenlander
Respectfully subaitted,

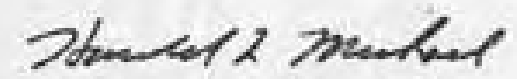

Harold $\mathbf{l}$. Michae 1 Associate Director
C. F. Scholer
M. B. Scott
W. T. Spencer
H. R, J. Waloh
z. B. Woods
Z. J. Yoder 


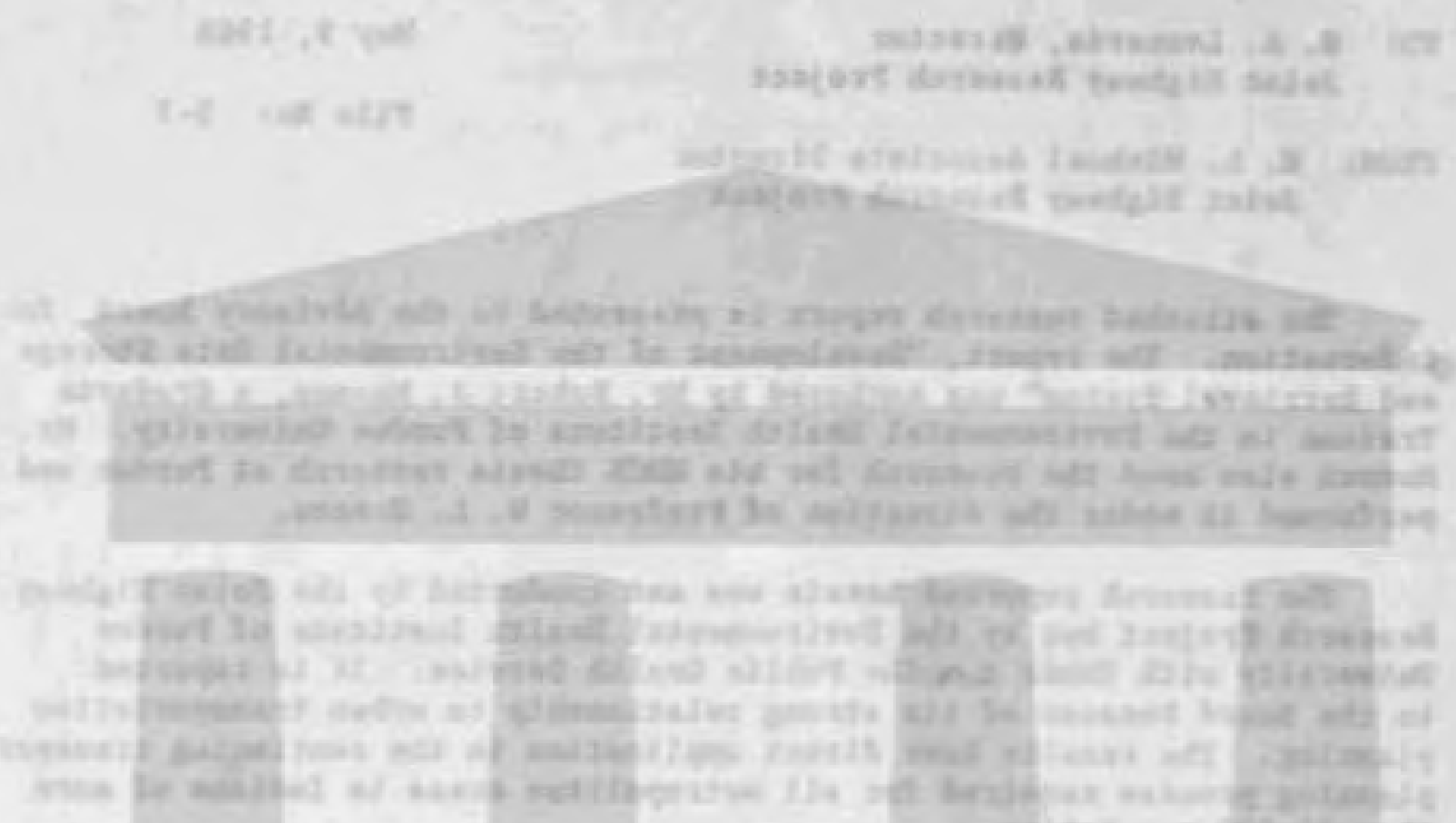

Digitized by the Internet Archive in 2011 with funding from LYRASIS members and Sloan Foundation; Indiana Department of Transportation

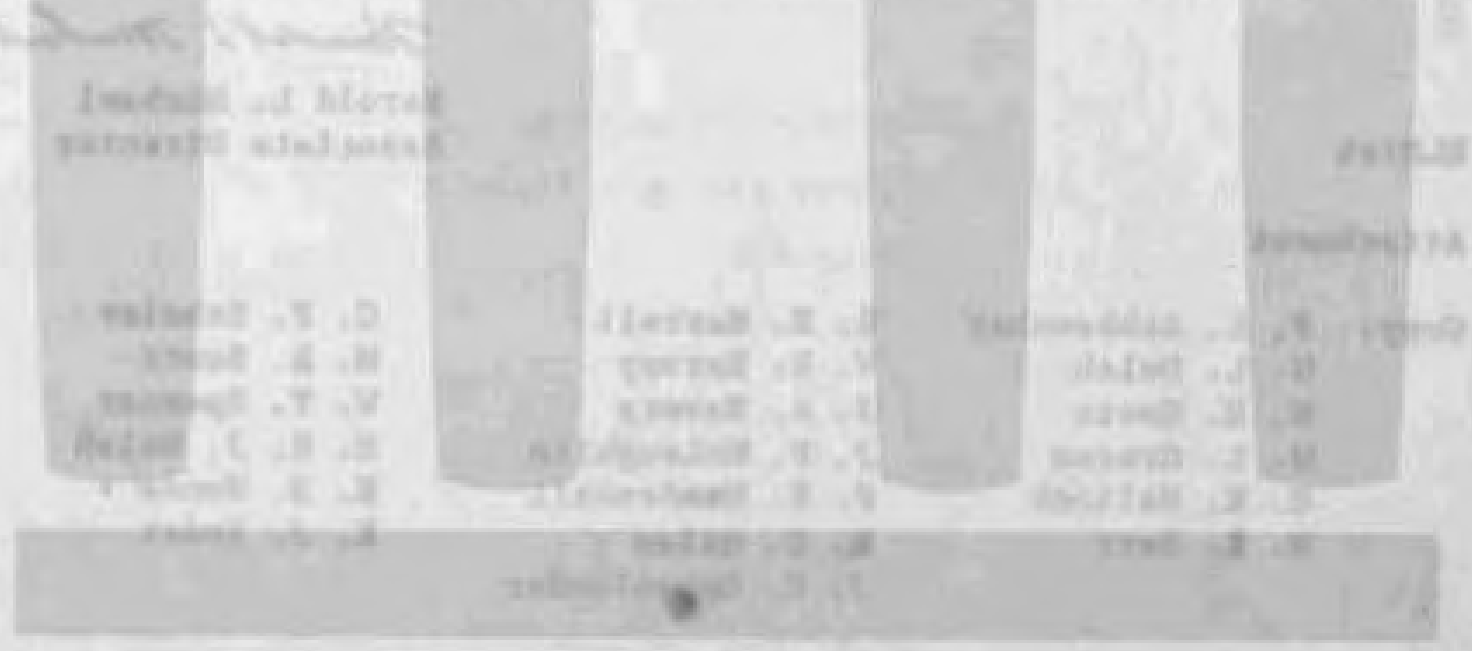


Informetional Report

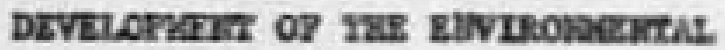

DATA STORACE AID RETRETAL. STSWM

by

Robert J. Kaxoun

Greduate Trainee

Eaviroanentel Eeelth Iaotitute, Purdue Dalverefty

Thts Copy Provided by

Joint Bighray Research Project

zile Xos 3-7

Purdue University

Lafeyette, Indiena

Kay 9, 1968 
ACKNOWL EDGNENTS

The author wishes to express his sincere thanks to Dr. W. L. Grecco, Professor of Civil Engineering for his guidance and advice in the developnent of this project and for his review of the manuscript. The Lafayette and Kest Lafayette City Engineers' offices; Mr. E. H. Worley, Director of the Tippecanoe County Area Plan Commission; Mr. E. Katerstraat, Director of the Lafayette Area Redevelopment Connission, Professor H. L. Nichael, Professor X. L. Grecco and $\mathrm{Mr}$. J. Fletcher, Director of the Greater Lafayette Area Transportation Study are acknowledged for their help and guidance in choosing data itens and data fornat. Thanks are also extended to Professor H. L. Nichael for his review of the manuscript and his constructive advice throughout the project. Professor N, R. Baker is also thanked for his review of the manuscript.

The author is grateful to the Environmental Health Institute of Purdue University, whose financial assistance made this project possible.

Sincere thanks are extended to Miss Peg Maxwell for her untiring assistance in manuscript preparation, typing and reproduction. 
TABLE OF CONTENTS

Page

LIST OF FIGURES $\ldots \ldots \ldots \ldots \ldots \ldots \ldots \ldots \ldots \ldots \ldots \ldots \ldots \ldots \ldots$ vi

ABSTRACT. . . . . . . . . . . . . . . . . . . . . . . . vi

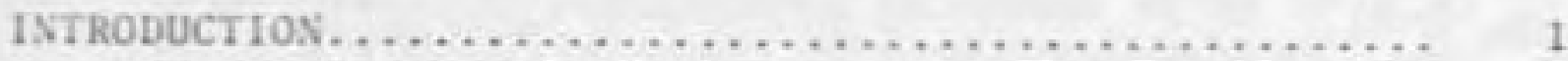

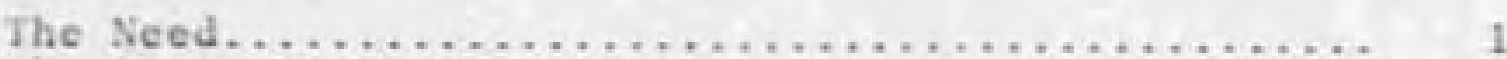

The Scope................................

URBAN DATA BANE CONCEPT, .................. 5

Inforation Theory........................ 5

Information Hierarchy, ...................

Levels of Sophistication................. 5

Use of An Information Systen............... 8

Application of Information Theory to Urban

Information Systens..................... 8

Urban Data System Developnent. . . . . . . . . . . . . 9

System Facilities........................ 9

System Requirements..................... 10

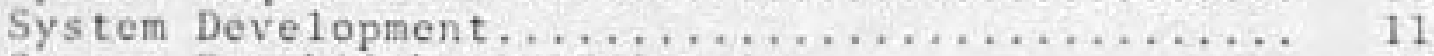

System Establishment Critoria.............. 12

Standardization and Coordination of Data....... 14

Data Coordination Methods.................... 14

Choice of Data Module....................... i?

Data Dimensions......................... 18

Organization of Parcel Information.............. 20

List of Data Items by General Category ........... 23

Data Maintenance, Retrieval and Updating........... 27

Definition of Data...................... 27

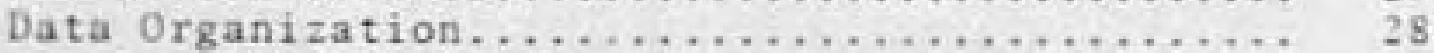

Retrieval Mechanisms...................... 29

Adaptation of Concepts................... 31

DEVELOPMENT OF THE ENVIRONMENTAL DATA STORAGE

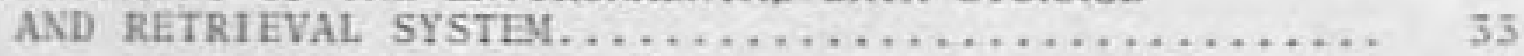

Level of Data Sophistication................ 33

Level of Systen Sophistication.................. 33

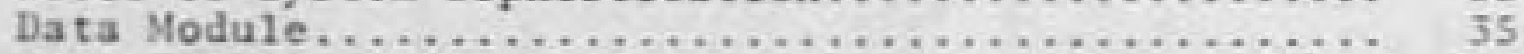

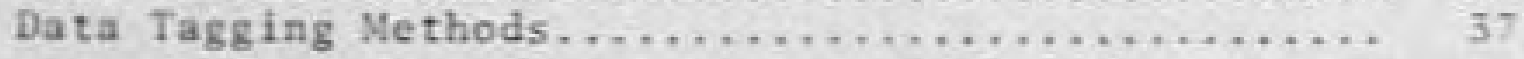


TABLE OF CONTENTS (continued)

Page

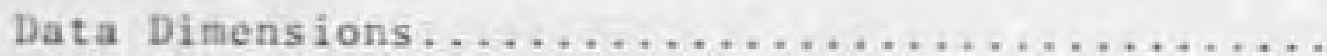

Data Items.............................

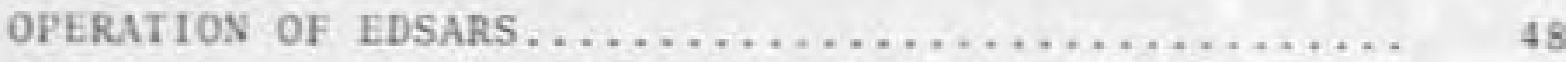

Data File Characteristics................. 48

General Progran Infornation.................. 49

Data File initialization.................... 50

Parcel Number-Grid Coordinate-Address File.... 50

General Data File....................... 53

Zone-Grid Coordinate File................ 50

Read Prograns............................ 58

Update Programs.......................... 58

Updating the Parcel Nunber-6rid Coordinate-

Address File.......................... 59

Updating the General Information File........ 60

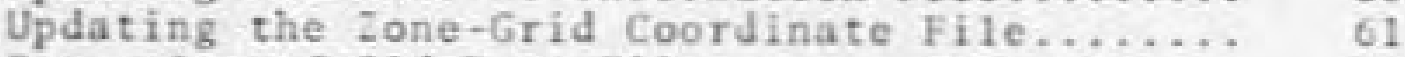

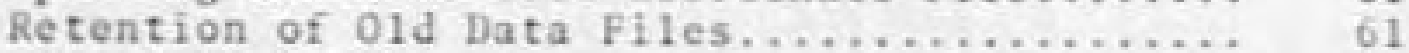

Retrieval Prograns........................ 62

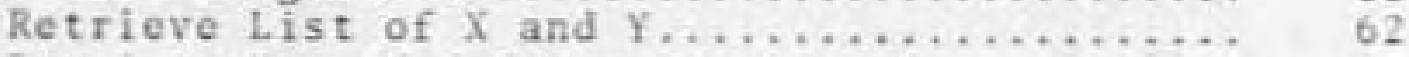

Retrieve Sum of $Y$ for a Specific X........... 63

Retrieve List of $Y$ for a Specific X.......... 63

Retrieve $X$ for Specific Parcel Numbers....... 64

Retrieve Parcel Number for Specific

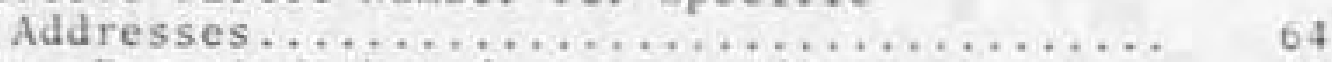

Retrieve Parcel Number for a Specific Zone....... 65

Flexibility of Prograns................... 66

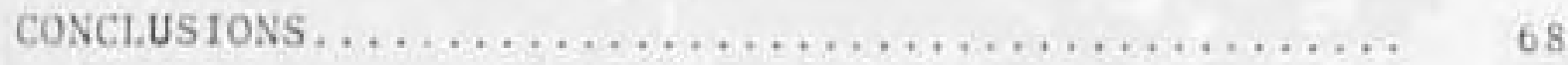

RECOMMENDATIONS FOR FURTHER RESEARCH........... 70

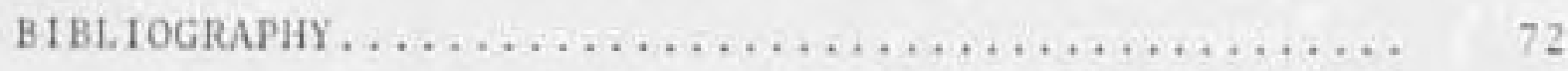

List of References..................... 72

Genera1 References....................... 75

APPENDIX I. DATA ITEMS: DESCRIPTION, USE,

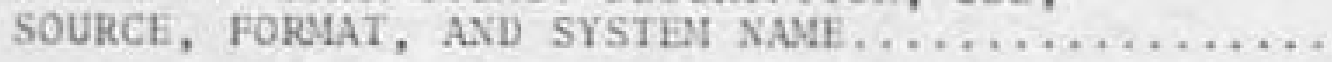

Section A: General Data Itens............... 78

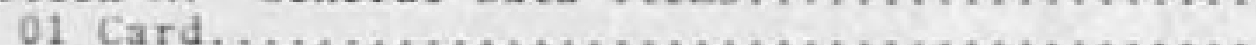

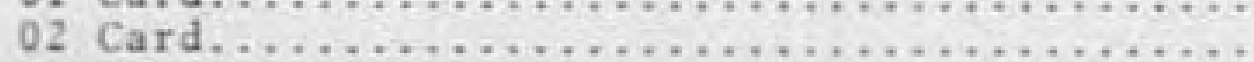

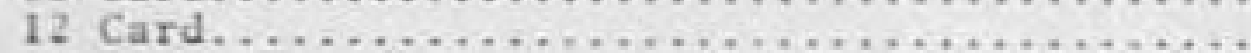

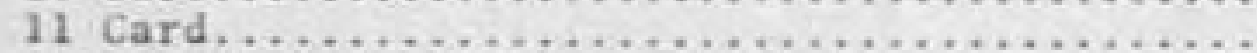

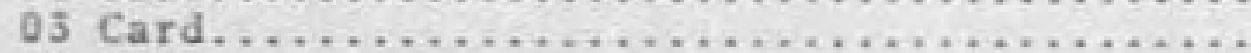

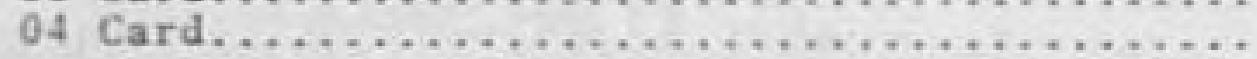

78

91

95

103

105

112 
TABLE OF CONTENTS (continued)

Page

Section B: Zone Name-Grid Coordinate File...... 119

Section C: Parcel Number-Grid Coordinate-

Address File.......................... 122

APPENDIX II. DATA CODES .................. 126

APPENDIX III. PROGRAM DESCRITTION AND LISTING...... 148 


\section{LIST OF FIGURES}

Figure

Page

1. Separating an Area into Parcels for Data Coding..................................

2. Fornat of Zone Nane-Grid Coordinate Card and Fornat of Parcel Number-Grid Coordinate Card........................ 52

3. Fornat of General Data Cards............... 54

4. Zone Divided Into Triangles for Data Coding..... 57 


\section{ABSTRACT}

Maxman, Robert James. MSCE, Purdue University, June 1968. Development of the Environmental Data Storage and Retrieval System. Major Professor: W. L. Grecco.

The wealth of data collected on the urban area by a multiplicity of people for a multiplicity of purposes has led to an inefficient, disorganized utilization of resources for data handling. Until recently, most of the information collected has been gathered by a specific group for a specific purpose. This information was not useable by other than the primary data recipient because of its narrow definitions and specific characteristics.

This project provides a system whereby data that is collected only once is useable by all segments of the urban environment. Universally compatible definitions, aggregation unit, and procedures are developed. Computer programs are developed to handle the data for the system. The data system (EDSARS) will make a useful tool for all segments of the urban environment by putting all generally useable data in one place with one set of definitions and aggregated on one useful module, utilizing one set of data handling procedures. 
The basic unit of data collection was established on a parcel basis, thereby providing a high degree of flexibility in data aggregation.

The conceptual development of information theory as it applies to urban data systems is first explored. The actual conceptual development of EDSARS is explained next, followed by the operational procedures needed to utilize the EDSARS system. An explanation of the computer programs utilized in the operation of EDSARS is discussed in the operations chapter. The actual data definitions, codes and computer program listings are found in the appendices. 


\section{INTRODUCTION}

\section{The Need}

The rapid growth that has occurred in this country since World War II has led to a genuine concern for the urban decision making process. It has been recognized that better data are needed in order to make appropriate decisions in the changing urban environment. As a result, a wealth of information has been gathered about the urban area. Almost every facet of urban life has been examined. Data have been collected on many aspects, from the health of the individual to the number of trips he makes. Until recently, most of this information has been gathered by a specific agency or committee for its own use. Individual definitions for data characteristics have prevailed. Definitions of land use density, for example, can range from trips generated per acre to people per square foot of floor space. The definition has depended upon the information user. The result of this multiplicity of data definitions and uses is a hodgepodge of data, collected many times by many agencies without knowledge of each other's efforts (1).* Public agencies gather much of their data for normal operations; these data are potentially very useful to other

* Numbers in parenthesis refer to numbers in list of references 
agencies at little additional cost, if only common definitions and parameters could be established. Without these common definitions and parameters each agency sees the urban environment only in the perspective of its narrowly defined information requirements (1).

Each urban area has developed a multiplicity of plans to channel the growth of the area in a manner that is deemed best for the community as a whole. Up to the present, just as the different agencies collect and use their own data, so do the various urban studies. While a Recreational or School Plan may use much of the data collected in a Transportation Study, the difference in data definitions and aggregation units makes the information nearly useless for any study other than the one that collected the data.

Many segments of the urban environment desire information on the community. The present means of getting this information is to go out into the urban area and collect the data directly. Any company, organization, or group that now wants data on the community must collect the information itself or accept the narrow definitions of data now established by existing governmental groups or studies that have collected data for their own purposes. 
In order to facilitate the use of data by other than the primary information receiver, a set of universally compatible definitions is needed. This set of definitions is not impossible to develop if one attempts to direct the collection of "pure" data. The term "pure" simply means that the information should not be aggregated before collection. For instance, when square feet of space is collected, it should be recorded as square feet, not square feet per some other dimension. For example, square feet per employee ' may be useful to an industry, but square feet of building and number of employees is much more useful for planning purposes while still serving the purpose originally intended. The data system that is developed below seeks to develop a tool for urban decision making that utilizes data from many sources and makes this information available and useable by other sectors of the urban community.

\section{The Scope}

This project involves the development of an urban data system for an area of approximately 100,000 population. The Lafayette-West Lafayette area is used to demonstrate application. The first developmental problem involves choosing the degree of sophistication needed for such a system. This involves choosing a particular level in a hierarchy of data 
system complexity. Once the level of sophistication has been decided, the basic data collection and aggregation module must be chosen. The data to be used will be decided along with specific definitions for each data item. How these data can be entered into the system will be developed along with updating procedures to keep information current. A logical and easily useable means of data storage and retrieval will be developed to facilitate the use of the system by a wide variety of users.

This project will explain, in detail, the conceptual background of an information system and will describe the application of these concepts to the Environmental Data Storage and Retrieval System (EDSARS). The data items to be collected are then defined. The format for these data is explained along with detailed instructions on the initialization, updating and retrieval procedures. All the computer work for EDSARS is done on the Purdue University Computer Science Center Control Data Corporation Model 6500 computer. The coordinate digitizing procedures that are outlined use the spatial coordinate digitizer of the Joint Highway Research Project at Purdue University, which is a BensonLehner V Digital Coordinautograph. 
THE URBAN DATA BANK CONCEPT

\section{Information Theory}

The applied science now known as information theory applies concepts of systems analysis, mathematical and statistical analysis, and computer programming to the storage, retrieval and analysis of information. The term "information" is used in a general sense, for information theory actually concerns itself with a hierarchy of information.

\section{Information Hierarchy}

The first stage of this information hierarchy is known as raw data; these raw data include numbers, symbols, lines, etc., general1y on paper, that are not yet organized into a machine record. The second state is banked data; these data are organized on cards or tape, and are machine processable. The third state is a data library where the data are edited and established in machine records; these are manipulated into a format amenable to updating, search, and retrieval as organized information (2).

Levels of Sophistication

Just as a hierarchy of data exists so do various levels of system sophistication. An information system may 


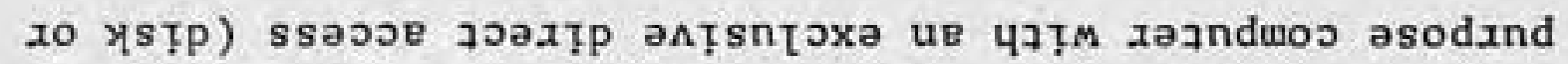

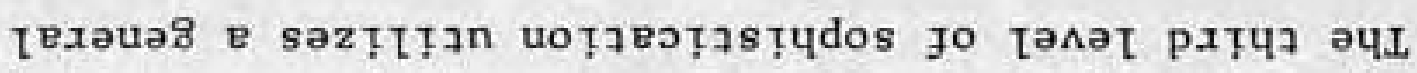

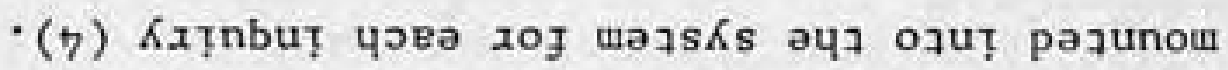

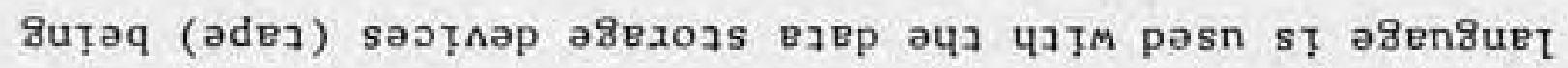

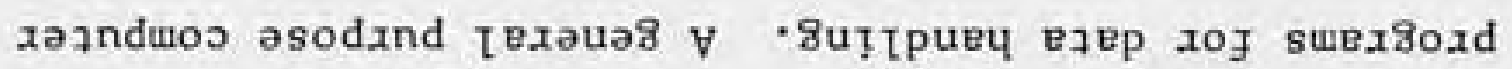

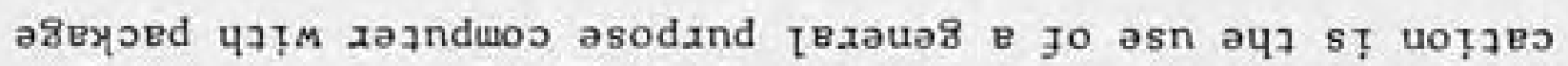

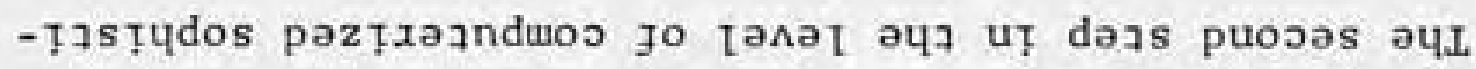

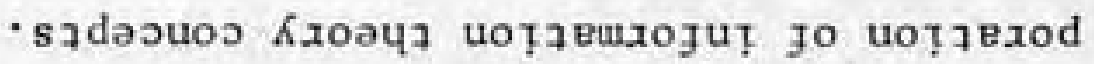

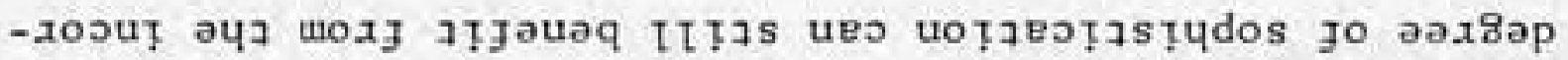

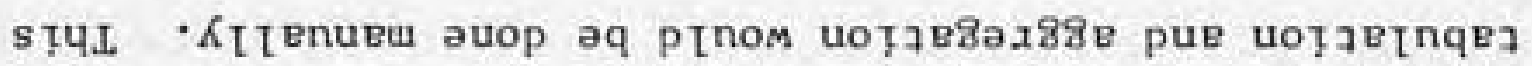

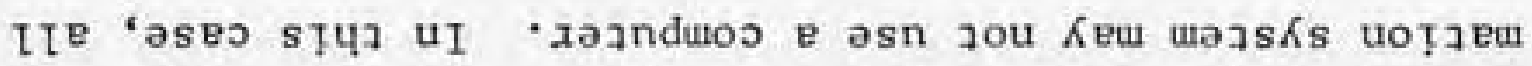

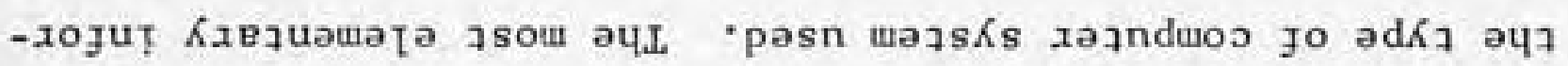

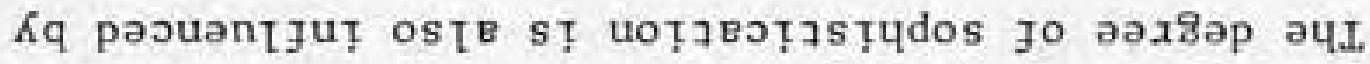

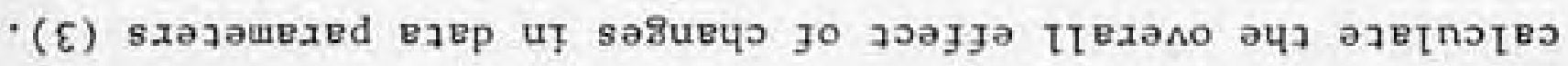

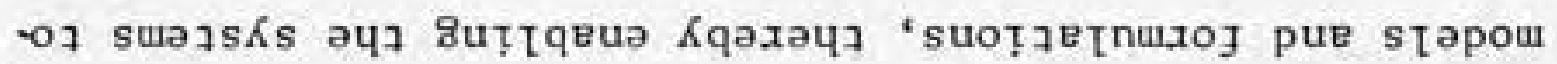

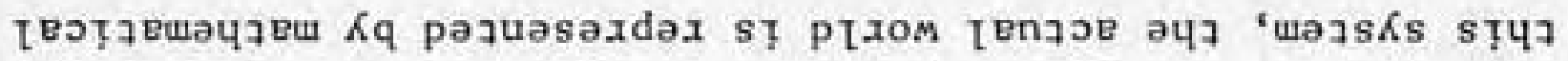

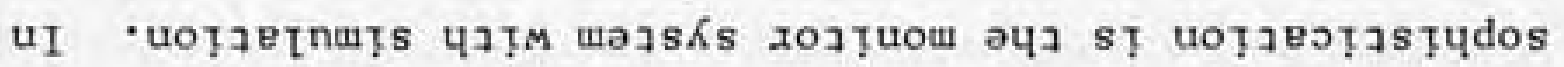

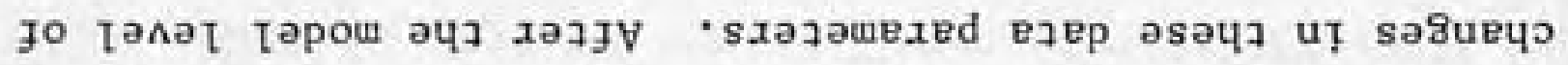

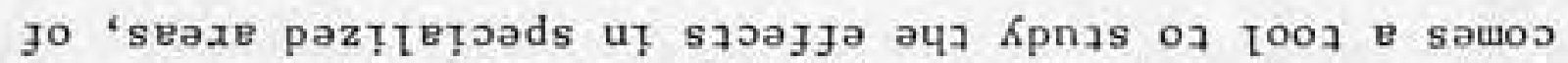

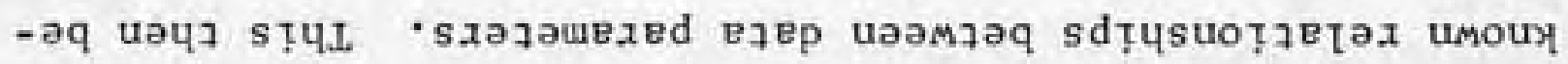

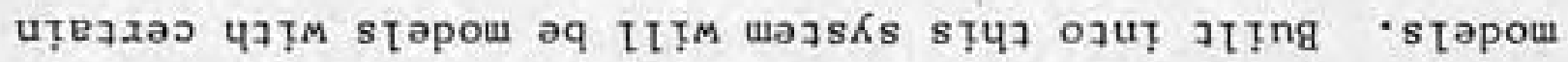

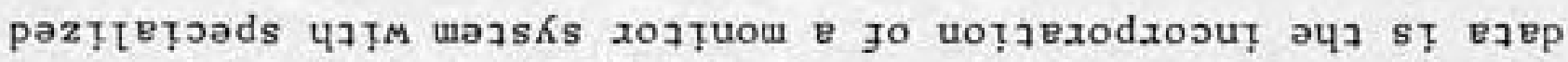

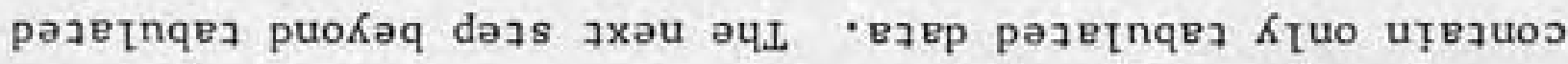


drum) storage. A problem oriented computer language is utilized. An information system with this level of computer sophistication enables file manipulation, data retrieval, and reporting with relative ease (4).

The fourth level of sophistication incorporates an on-line, time-shared computer system. Time-sharing enables many users to have direct access to the computer at the same time. Utilizing a file-oriented and problem-oriented programming language, this type of system has direct access to computer storage (4).

The fifth level utilizes a special purpose on-line computer system. This type of system is special purpose with respect to the type of data incorporated and to the program and query language used. Large data processing jobs can be accomplished by a system at this level (4). The sixth level of sophistication incorporates specially designed hardware and software and an on-line Cathode Ray Tube (CRT). The physical computer installation and programs to utilize the computer are specifically designed for the job at hand. The Cathode Ray Tube enables direct digitizing of coordinate data and facilitates higher efficiency in the handling of spatial data (4). 
Use of An Information System

An information system should give access to its data that is both logical and functional. Without these characteristics of access the system would not be useable. Functional access involves the efficient location and retrieval of subsets of the stored information, and also involves the ability to aggregate, combine and transform data. This facility is essential so that the user of the system can mold the data into a form useable for a particular purpose. Logical access insures that a comprehensive scheme for data description and documentation exists $(5,6)$.

\section{Application of Information Theory}

\section{to Urban Information Systems}

In the development of an information system for use by the urban planning community, the specific users of the system should first be ascertained (5). The system should be useroriented, that is, people in the urban environment without a computer programming background should be able to use the system. The data incorporated into the information system should be based on the theoretical formulations that best explain the ecological system to which they belong (7).

In developing the facility of a user-oriented urban information system, many computer languages have been developed 
to enable a non-programmer to access the system. SPAN, Statistical Processing and Analysis System, is such a language. SPAN was developed for the Penn-Jersey Transportation Study (now called the Delaware Valley Transportation Study) by the Systems Development Corporation. Mark III File Management System from Informatics, Inc.; COLINGO, Compile On Line and Go, from the Mitre Corporation; Integrated Data Store, from General Electric; GIS, Generalized Information System, from IBM; are general data handling languages that are not designed specifically for urban studies but might perhaps be adapted to this purpose. A new language for the urban study community called QUEST, Query of Spatial-Temporal Data, is now under development and should broaden the scope of data handling abilities for urban information system $(8,9,4,10)$.

\section{Urban Data System Development}

System Facilities

A data system for urban studies can utilize the following facilities:

1. A data library organized for easy search, access, retrieval, editing, and expansion of the data base.

2. A library of mathematical programs by which data can be analyzed and manipulated.

3. A set of graphical procedures for representation of results. 
4. A data structure by which to describe urban problems and designs.

5. A set of orders and procedures which would help in the design and operation of experiments and simulations.

6. A repertory of programs and a facility for programming to help in the evaluation of plans and decisions (11).

\section{System Requirements}

In order to develop an urban data system, certain basic functional requirements must be met. The requirements are:

1. Develop a list of data items that are required by the system users for operations and decision making. Select only items available on a continuing basis. This list is not meant to be final; the system should be arranged so that data can be added or deleted later.

2. Develop a set of standard definitions for the data; each potential user should be aware of the exact definition of each data item.

3. Provide for cross-reference systems which link data in different parts of the system.

4. Establish specific collection responsibility to each department.

5. Coordinate the data flow of the entire system (1). 
An urban data system, while being designed primarily for the planning function, must be amenable to a wide variety of users. As the system becomes used by more segments of the urban environment, the system itself will grow in power and usefulness. Each potential user is also a potential data source, and cooperation between the source groups is paramount in the success of the system (1).

System Development

The actual development of the data system should follow a logical procedure. An outline of this development could be:

1. Establish data collection and file maintenance procedures prior to file creation. This eliminates from consideration data that cannot be updated.

2. Establish data control procedures to edit data. Information from the system must be accurate. Inaccuracy in data can lead to distrust in the system and eventual elimination.

3. Test the system by inserting a limited amount of data and running a test problem. Testing should grow from using a relatively small amount of data to using larger quantities in steps - with checks for internal and external consistency being made at each interval. 
4. Consider expansion and use of new technical advances and techniques. The system should be flexible enough to incorporate these changes without major modification (1).

\section{System Establishment Criteria}

In developing the information system, certain criteria must be considered for establishment. These criteria lead to the specific choice of system sophistication and actual data to be incorporated. The criteria are as follows:

1. The purpose of the information and its relationship to the goals and objectives of the users.

2. The essentiality of the information.

3. The cost of the information.

4. The maintenance of the information.

5. Reduction of data to useful terms.

6. Applicability of the data to the policies, plans, programs and effectuation of the system users.

7. Relation to sophistication of tools available.

8. Receptivity of planning group and policy makers.

9. Relation of the planning body to decision makers (3). In establishing the data system, the goals and objectives of the community, and of the information system should be thoroughly established and understood. Once the 
goals and objectives are established, the entire environmental system should be monitored. Measurement units for the data can then be established: individual, family, census block, parcel, census tract, school districts, etc., are all candidates for measurement units. Norms for geographical entities must be established in order to understand the significance of the data collected. Once the entire environmental system is understood, the measurement unit established, norms established, and level of sophistication chosen, then the decision on exactly what data is to be collected is ready to be approached (3).

Three developmental approaches exist for the organization of the spatial data required in an urban information system. The first approach involves taking an inventory of the kinds of data that are presently being collected and incorporate these data into a unified system with multiple functions. The second approach concerns itself with the enumeration of questions to be asked of the data system and then the design of a system which can provide the answers. The third approach is that of conceiving generalized capabilities for handling classes of data and answering classes of questions (9). The approach that is used depends upon the other criteria and factors that must be considered for system development. 
Standardization and Coordination of Data

In developing an urban data system, the paramount consideration is to establish the modulus of data collection and insure the coordination of data. In order to standardize and coordinate data, the specific data to be collected must be understood. The data to be collected, however, can depend on the modules of collection and methods of aggregation. These two considerations - module establishment and data to be collected - must be considered simultaneously. Both intimately depend upon the development and establishment considerations mentioned above. Understanding the environmental system is the overwhelming requirement.

\section{Data Coordination Methods}

Coordinating data in an urban information system is accomplished by tagging the data. The tag given to a piece of data identifies it as a unique entity thereby enabling the information to be used and coordinated with other unique pieces of data in the system. Alternative methods of tagging data can be categorized into two broad areas: name method, and location method. In the name method of tagging, all data is keyed to a particular module name such as a street address. Characteristics of the name method are such that it may not have full territorial coverage, it may have 
unequal module areas, irregularly shaped areas or areas of unequal population size. The name method could be an address code of dwelling units or a consecutive numbering of zones. All data would be keyed to a particular address or zone number. This method need not have any internal logic, e.g. street names usually have no logical order, zones could be randomly numbered. No direct computations for coordination can be established using the name method because of lack of internal logic. Any areal computations must have external logic applied to coordinate the name and the locations of a module. The name method enables data to be described on a basis that is directly understandable to the user, i.e. political district, planning area, census tract, street address, etc. Developmental boundaries must be established before actual data collection. Aggregation is automatic in the name method, since all data are directly keyed to the module $(12,13,14)$.

The location method of tagging data involves spatially locating each data bit within the development area. An example of location coding is an $\mathrm{X}-\mathrm{Y}$ grid superimposed over an area; this would enable any point in the area to be described by a set of $X-Y$ coordinates. A $Z$ coordinate could be added for coding height. The characteristics of the location method of tagging data are such that: boundary 
conditions are secondary, one can furnish coordinates to refer to any location, and coordinates tell precisely where a point is located. The location code gives almost automatic statements of density; the coordinates could be chosen so that exactly one square mile is enclosed - any aggregation would then give "per square mile" figures directly. Full territorial coverage of the geographical universe is easily obtained by the location method. Points can be added or deleted without altering the reference value of the system; by virtue of its nature the location method is a built-in indicator of the location of a point within the development area. Mathematical measurements of distance, direction, area, proximity, and centrality can be obtained inherently from a system utilizing the location method $(12,13,14)$.

The two methods, name and location, can and probably should both be used. The location method is more flexible; boundaries can be stated after data collection; the name method provides for direct aggregation because all data are gathered on this basis. Many queries of the system will be made on a name basis; street addresses are the most common description of a parcel or a dwelling unit. In order to make the information broadly useable, the name and location methods should be coordinated; an example of this would be the establishment of a street address - geographical code index 
which would relate all addresses to location coordinates $(12,14)$.

By combining the two tagging methods, the computational advantages of the location method can be realized while still having the advantages of the widely used descriptions of street address or zone number (name method). The location code will enable a particular urban data system to become compatible with systems of other areas. As state and national geographical code systems become operational, an urban data system utilizing the location method can be adapted to the larger system by simple mathematical coordinate changes. The key here is to join mathematical efficiency and user understanding in the tagging system $(13,14)$.

\section{Choice of Data Module}

In the urban data banks that were studied, the module of collection most used was the parcel. The parcel was chosen from a long list of possible modules. The census block, census tract, street block, block face, transportation zone, etc., are all possible candidates for collection module. The parcel was chosen because it provides a flexible, multi-purpose base from which to work. The physical and social data incorporated in an urban data system can easily be keyed to the parcel. Both tagging methods, name and location, can be readily adapted 
to the parcel; street address can suffice for the name tag and grid coordinates of the parcel centroid are adequate for the location tag. Most data incorporated in an urban information system originates at the parcel level so that the parcel becomes a natural unit of aggregation. The parcel is defined as all contiguous land under one ownership and one general land use $(1,15)$.

\section{Data Dimensions}

With the data module chosen, attention must now be focused on the dimensions of the data to be collected. Basic dimensions of data fall into three broad categories: phenomena dimension, location dimension, and time dimension. In a grid coordinated data system, the location dimension is determined by the grid interval. The time dimension of the data in an urban data system should be current since all of the information should be updatable. The phenomena dimension, then, is the only dimension of major concern at this point (9).

In order to preserve flexibility in the data system, information must be gathered in terms of several dimensions. The type of data dimensions that are needed in this case are termed "pure dimensions;" "pure" simply means that no 


$$
\text { - oja 'jaaxas-jzo "umozumop }
$$

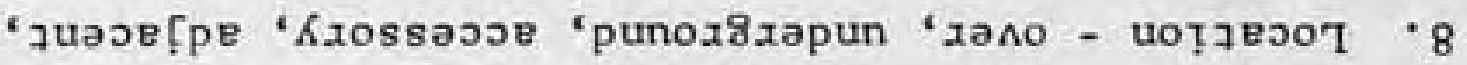

-sjuamanoxdurt pue puet jo anten tejoueuta * $L$

$$
\text { *כaว 'saţtitan - saotnxas otiqnd *9 }
$$

• งวa 'szueuวnos 'guțuoz

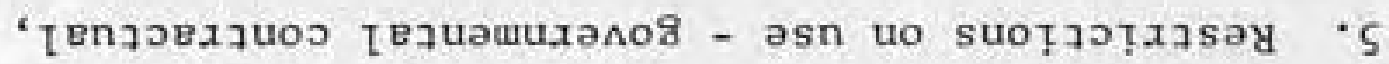

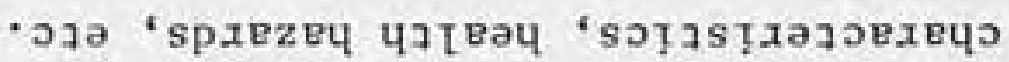

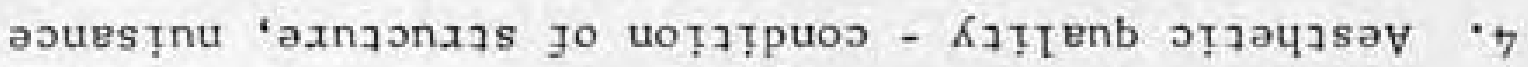

$\cdot 273$

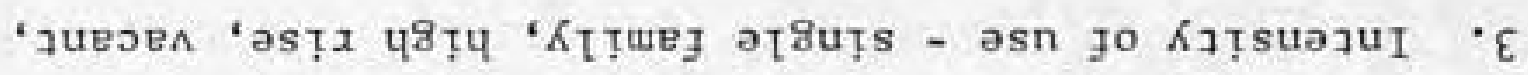

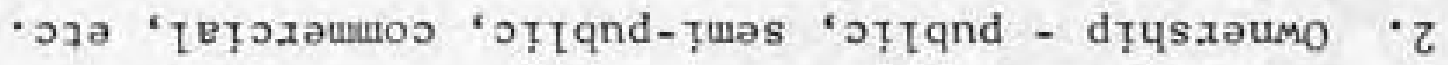

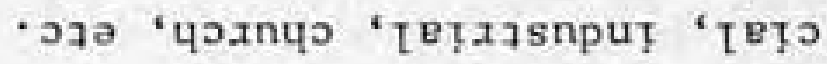

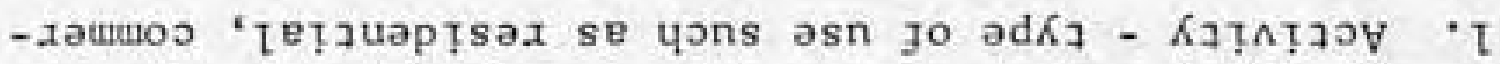

: sadəouos 8ิuт̣moltog әчว uт̣вวuos

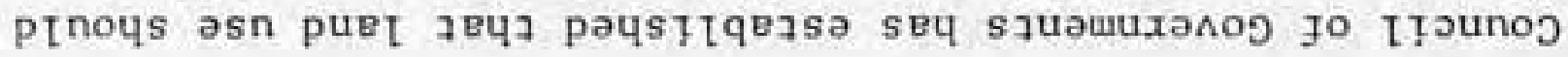

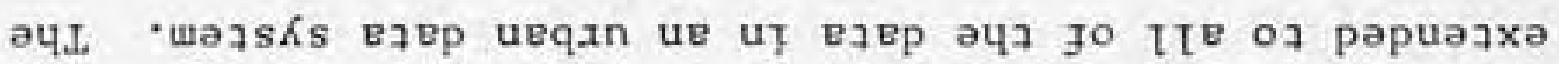

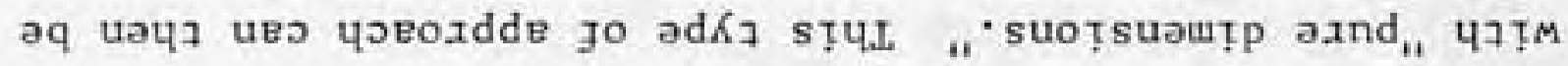

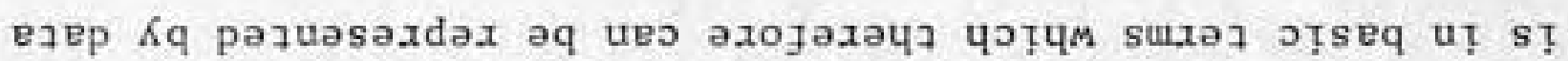

деч asn puet jo uotaţutgap e padotanap sey sauauuxanos jo

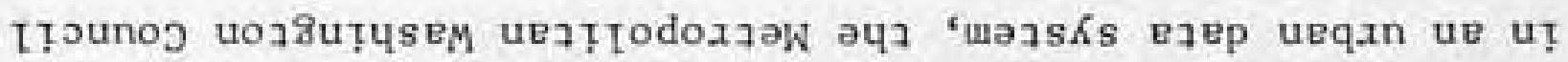
"suotsuautp axnd

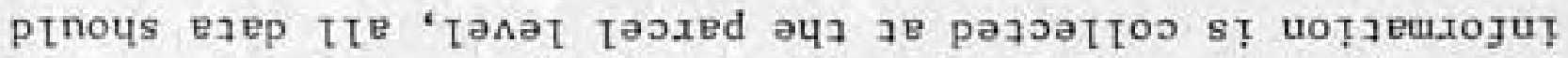

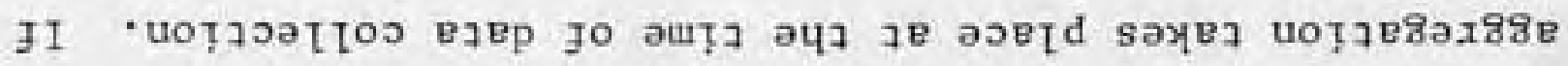


9. Type of structure - detached, high rise, walk-up, etc.(13).

By incorporating these basic concepts, data can be collected that can be aggregated in different ways for different uses, thereby giving the information system its needed flexibility. This conceptual definition of land use leads to data with the following "pure dimensions:"

1. Type of activity

2. Type of structure

3. Type of ownership

4. Intensity of use

5. Restrictions on use

6. Aesthetic quality

7. Nuisance characteristics

8. Economic functions (13)

\section{Organization of Parcel Information}

In determining the information to be incorporated into the system, one can catalog the components of change in the urban area and determine the data needed to describe this change. The components of change can be broken down in the following way:

A. Physical Change

1. Private

a. Housing supply 
b. Number of industrial plants

c. Mining activities

d. Commercial activities

e. Private open land changes

f. Transportation changes

g. Etc.

2. Public

a. Schools, playgrounds

b. Other comunity facilities

c. Streets and highways

d. Etc.

B. Economic Change

1. Public

a. Urban renewal investment

b. Effect of change in family income

c. Property values

d. Tax revenue

e. Public investment

f. Etc.

2. Private

a. Housing expenditures

b. Mobility

c. Land value

d. Etc. 
C. Social Change

1. Education needs

2. Population

a. Number

b. Characteristics

3. Social problems

4. Pub1ic Policies

5. Welfare

6. Etc. (3)

Other components of urban change include: accessibility, time, communication, and visual and aesthetic qualities. Accessibility directly influences the potential growth of an area. The passage of time must be recognized as gross changes occur in the community. Changes in transportation and other types of communication cause rapid change in an urban area. Visual and aesthetic qualities directly influence the growth of an area; visual depressants and stimulants must be recognized ( 3 ).

With these components in mind the actual organization of the data at the parcel level can now be accomplished. The Metropolitan Data Center Project organizes the parcel record into three categories:

1. Parcel information

2. Land use information 
3. Space use information (1)

The parcel information will contain data on the land itself, the type of ownership, restrictions, etc. Land use information describes the structure or structures on the parcel. Space use information explains the uses and characteristics of establishments within each structure. These levels of information will become clearer as the exact information to be collected is explained (1).

\section{List of Data Items by General Category}

The Metropolitan Data Center Project is again representative of many of the data systems that were studied. The list below is not exhaustive, but points to the specific type of information under consideration. A list of this information is as follows:

I Parcel Information

A. General parcel information

1. Location information

a. Parcel number

b. Grid coordinates

c. Address

2. Political jurisdictions

a. Municipality

b. School district 
3. Planning statistical area
a. Census block
b. Census tract
c. Community
d. Urban renewal project
e. Industrial district
f. Origin - destination zone

B. Parcel Characteristics

1. Size
a. Average depth
b. Average width
c. Area
d. Frontage

2. Tax and economic factors
a. Business personal property value
b. Date of last sale
c. Dollar amount of exemptions
d. Improvement value
e. Tax exempt status
f. Total value

3. Other characteristics

a. Distance from front of parcel to center of street 
b. Landmark

c. Neighborhood characteristics

d. Presence of nuisances

e. Site characteristics

f. Street area

g. Street classification

h. Utilities

C. Parcel Use Data

1. Comprehensive plan use

2. Customer off-street parking spaces

3. Employee off-street parking spaces

4. Land use code

5. Year of new water meter connection

6. Year of building permit

D. Zoning Data

1. Current zoning

2. Current zoning area

3. Previous zoning

4. Zone change request number

5. Zone variance case number

II Land Use Information

A. General Building Data

1. Building condition

2. Building location 
3. Building setback

4. Estimated cost of rehabilitation

5. Frontage of building

6. Number of elevators

7. Number of rooms

8. Presence of plumbing

9. Type of construction

10. Year built

B. Building Floor Data

1. Area of first floor

2. Gross floor area

3. Net floor area

4. Family income

5. Number of floors

6. Number of dwelling units

7. Number of residents

8. Number of rooms for rent

9. Presence of a basement

III Space Use Information

A. Non-residential data

1. Attributable parcel acreage

2. Conmercial off-street parking spaces

3. Establishment location code 
4. Establishment name

5. Floor level

6. Floor space utilized

7. Number of employees

8. Number of establishments

9. Peak shift number of employees

10. Space use code

11. Vacancy

B. Residential Data

(Collected in summarized form under Land Use Information)(1)

This 1 ist defines what data were collected by the Metropolitan Data Center Project and in what general category these data were placed. The exact classification of some of the data differs from other data systems but the approach is genera11y representative $(1,15)$.

\section{Data Maintenance, Retrieval and Updating}

Definition of Data

Before any information can actually be collected and placed in a data system, it must be definitely and exhaustively defined. If the data is to be stored in numerical form, as is generally the case in existing data systems, then non-numerical data must be given a numerical code. The numerical code is directly dependent upon the exact definition of 
the data. Each unique definition is given a numerical code which can later be keyed back to that specific meaning (15, $16,17)$.

After data has been defined and converted to a numerical code, then initialization procedures can be developed. At this point, the data handling programming languages mentioned previously become applicable $(14,9,4,10)$.

\section{Data Organization}

Data must be organized so that the system can be initialized, but also so that the information can be maintained, updated, and retrieved. The organization of data for retrieval (and the other functions) can take one of two alternative paths:

1. Location addressing

A mapping function is derived which relates a piece of data and its storage address within the data system 2. Serial files

A list of data is developed and data are found by their relative position in the 1 ist. The 1 ist may be unordered or ordered; the ordered list may be ordered on some property which will increase the efficiency of search. One can test against this property to determine position in the list $(10)$. 
The efficiency of the data files can be improved by providing a parallel file where a property or piece of data is stored sequentially with a correlation to the entire data entity. This parallel piece of data can be searched and when the desired characteristic is found, the correlation will give the location of the rest of the information on this data module. A list structure that links one piece of data to the next can also improve efficiency in data handling. Each data item contains a pointer to the next data item, and also an indication of the previous item in the list. This, then, gives the list the facility of being able to branch out. Two lists can also be merged by this method; also, physical sequence is not necessary as in the non-linked list $(10,18)$.

The establishment of the data organization leads to the development of updating procedures. Updating the information involves utilizing the available programming languages (or the development of a new language) to exchange old data for new as current and more complete information becomes available.

\section{Retrieval Mechanisms}

Retrieval mechanisms based on the type of data incorporated and the file structure can now be established. Retrieval must be facilitated on a logical and a spatial basis. Logical retrieval involves the retrieval of data based on a 
characteristic other than spatial; an example would be the retrieval of information on all parcels with a particular land use. This type of retrieval must be provided for in the internal logic of the data system.

Spatial retrieval can involve three place types of retrieval regions:

1. Coordinate region

"Coordinate regions are an exhaustive partitioning of the study surface into uniform spatial areas whose dimensions equal the fineness or accuracy of the coordinate region" (9). An example of retrieval based on a coordinate region would involve obtaining information on a parcel with coordinates $(\mathrm{X}, \mathrm{Y})$.

2. Query region

"Query regions are arbitrarily delineated places. These regions are expressed as polygons and are a grouping of coordinate regions" ( 9 ). A transportation zone defined by the coordinates of its boundaries is an example of a query region with the parcels within the transportation zone being the coordinate regions.

3. Uniform data region

"Uniform data regions are arbitrary areas that are defined to be homogenous and relate a single phenomenon to places" (9). A11 land under a particular ownership is an example of a uniform data region. 
Conceptual procedures for spatial data retrieval have been developed in varying degrees of complexity. Dueker, Shirmat, Dial, and Loomis have each developed a procedure to test if a particular coordinate pair (coordinate region) is within a given polygon (query region). The usefulness and complexity of each of the methods differs. The usefulness being dependent upon the computational accuracy needed (10).

\section{Adaptation of Concepts}

The conceptual background and information on existing urban data systems is quite large. The existing systems do not seem to be abreast of the newest concepts, however. The task undertaken by this project is to apply the concepts of information theory to a new and conceptually sound urban data system. The data system developed below is the result of an evaluation of past successes and failures in existing data systems. It is the result also of a definitive review of applicable theory. The Environmental Data Storage and Retrieval System (EDSARS) that is developed below is conceptualized from the point of view of the planning community. Application of the system is meant to encompass a much wider scope than just the planning function, however; the developmental approach will follow nearly the same outline as the 
conceptual development. System complexity will be chosen first. Decisions on system development, data coordination, data modules, exact data to be collected, data definitions, initialization, storage, retrieval and updating will be made respectively along with explanations of the conceptual and pragmatic reasoning for each decision. An explanation of the physical operation will then be outlined which will, hopefully, render EDSARS operationally feasible for any interested community or organization. 
DEVELOPMENT OF THE ENVIRONMENTAL DATA STORAGE AND RETRIEVAL SYSTEM

\section{Level of Data Sophistication}

The decisions in actually developing an urban data system follow approximately the same format as the conceptual development. The information used in EDSARS is taken from the level in data hierarchy of a data library. Banked data, which is another level in the information hierarchy, are organized into machine records but need not be functional or logical in format. The data library information is logical and functional in format and can be updated, searched, and retrieved; these requirements are essential for any urban data system.

\section{Level of System Sophistication}

The three levels of system sophistication vary in the complexity of models incorporated. The first level uses no models, the second utilizes specialized models, while the third level uses simulation. EDSARS, being an attempt at developing the initial phase of an urban data system, utilizes the first level of sophistication. The system contains tabulated data but no specialized or simulation models. It is felt that the model requirements will evolve from the 
demands of the users on the data system. The addition of models to the system can be made within the present format; the data in the system will directly feed any models developed in the future.

The computer hardware that is incorporated also influences the level of system sophistication. EDSARS utilizes the CDC 6500 computer at Purdue University. This is a general purpose computer; the programming language used is Chippewa Fortran. The data system can be initialized and information retrieved or updated by merely submitting the correct program deck to the computer science center. The updating retrieval or initialization will be run just as any other job that is submitted to the computer. The information for EDSARS is now stored on tape. As the system is initialized and the amount of stored information grows, the incorporation of a "disk pack" will become feasible. A "disc pack" is a mountable disc storage device that enables direct random access of information. This direct access feature will save valuable computer time when the system searches large quantities of data.

The decisions on the level of system sophistication were the result of many factors. Models were not incorporated into the system because of the necessity of actual data to test the validity of a model. This project outlines the 
initialization of EDSARS without actually inserting real data. The amount of data needed to initialize the system makes initialization another entire project of at least one to two years in duration. Once the initialization is complete, then the addition of models can be considered.

The decision of using the $\operatorname{CDC} 6500$ computer was made in light of the hardware available. Purdue University now has an IBM 7094 computer which could handle a data system such as EDSARS. However, the 7094 is a second generation computer; this type of computer is now in the process of being phased out by many organizations; being replaced by a "third generation" computer such as the CDC 6500 computer. Any work done in the future on data systems will most probably be done on the more advanced equipment such as the CDC 6500 . The use of Chippewa Fortran was the result of the author's knowledge of the language and the fact that the Fortran developed for the CDC system is quite efficient in its data handling capabilities.

\section{Data Module}

The data module chosen for EDSARS is the parcel. This aggregation module seems to be almost the universal choice by existing urban data systems. The parcel provides a flexible, multi-purpose base from which to work. The data to be incorporated into an urban data system are easily keyed 
to the parcel. The tagging methods, which will be discussed below, work well with the parcel module. The parcel forms a very useful aggregation unit in that it is the largest common denominator that can be used to build zones. Any zone in an urban area can be represented fairly accurately, by a composite of parcels. This gives the system maximum flexibility in the designation of zones while containing a minimum number of data units.

The parcel in EDSARS is defined as all contiguous land under one ownership and one general land use. This definition closely parallels the parcel used in assessors records. If two adjacent pieces of land are owned by the same person and used for the same purpose, they would be listed as one parcel. If two adjacent parcels had different uses, they could be listed as two parcels. This definition, being general, allows a certain measure of ambiguity in the designation of a parcel; the system has the facility, however, of being able to join two or more parcels into one new parcel, or break up one parcel into two or more parcels. This facility for redefining parcels allows the system to establish its own equilibrium as the data are used and reevaluated.

A special definition of the parcel is utilized when coding rights-of-way. Each street segment and utility right-of-way is coded just as any other parcel. A street or 
right-of-way is broken down into block long segments if the block length is 500 feet or less; if the block length is longer than 500 feet, the block is broken down into segments of 500 feet or less. An intersection is taken as a street parcel. The parcel boundaries are defined as the right-ofway line for the street segments. An example of an area divided into parcels can be found in Figure 1.

\section{Data Tagging Methods}

EDSARS uses both the name method and location method of tagging data. The name tag utilized is the street address of the parcel. The street number, name and type (e.g. Drive, Street, Lane, etc.) are all noted in the name tag of the parcel. For rural areas, the street number is replaced by the rural route number, and the street name is replaced by "Rural Route". The name method of tagging gives the system the facility of locating data for the user on a basis thet is familiar to all segments of the urban environment. Street addresses are universally known and understood, and, therefore, enable all potential users to be familiar with at least one retrieval method.

Street segments are coded by the street name and the number (in hundreds) of most of the houses on the street segment. A street segment along a street called Main Street, where house numbers go from 100-225 would be coded as 


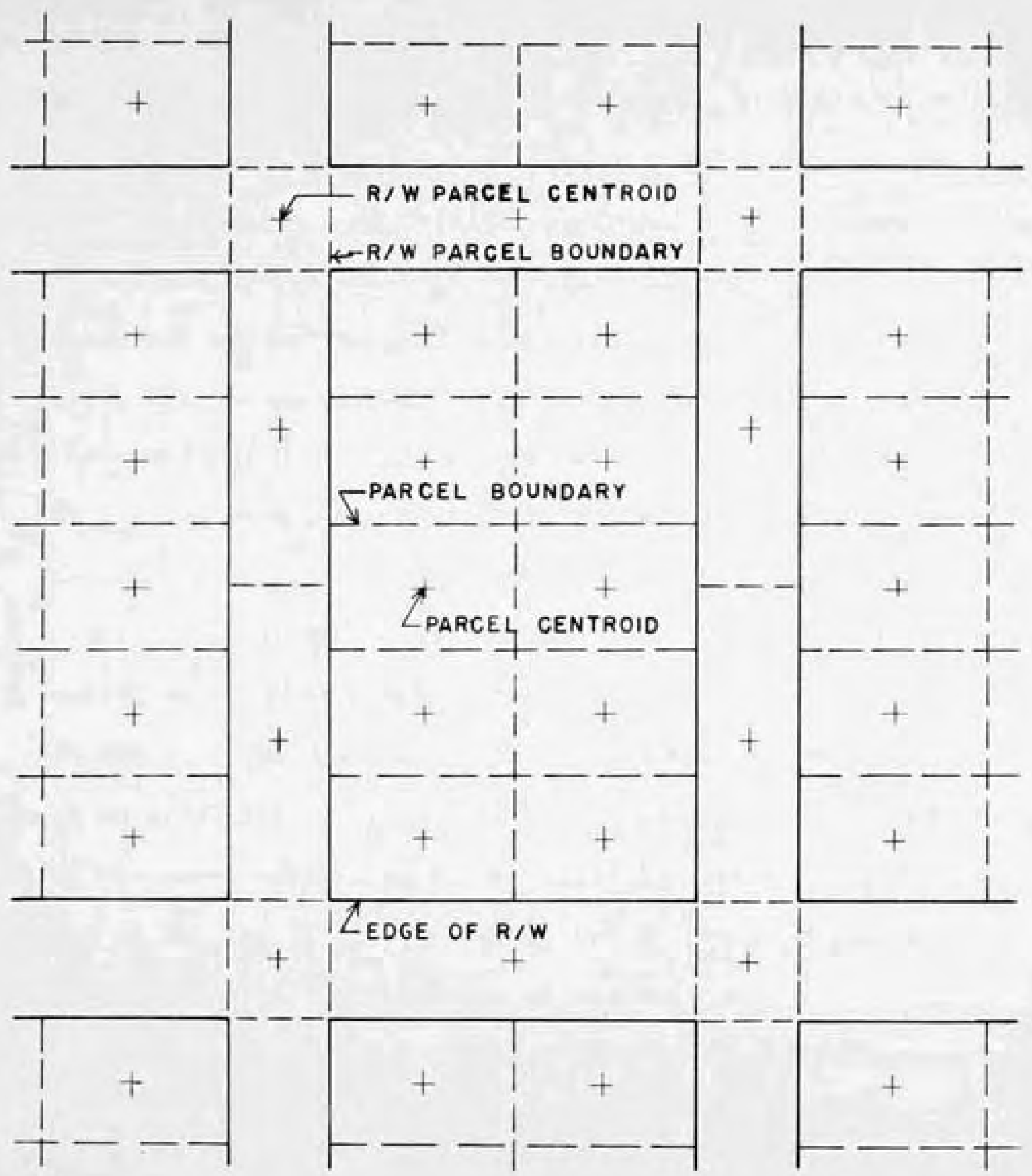

FIGURE I. SEPARATING AN AREA INTO PARCELS FOR DATA CODING 


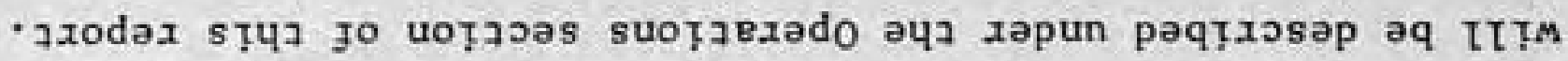

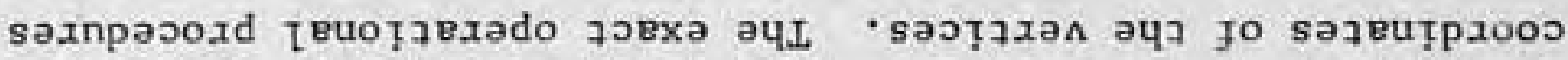

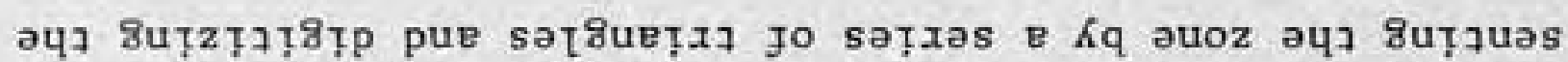
-axdax Kq paystiduoose sț sțul. Kaepunoq sat jo sazeutpaoos

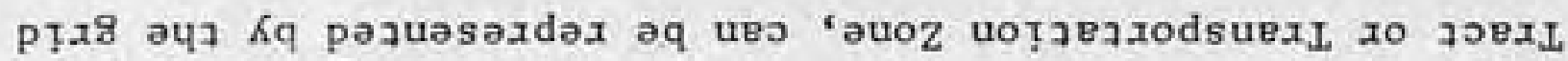

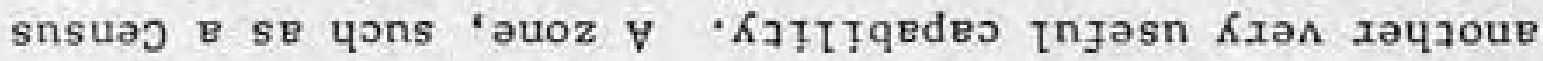

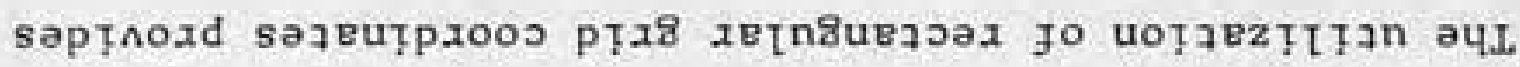

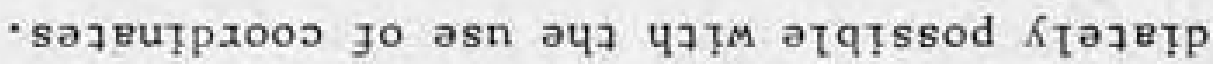

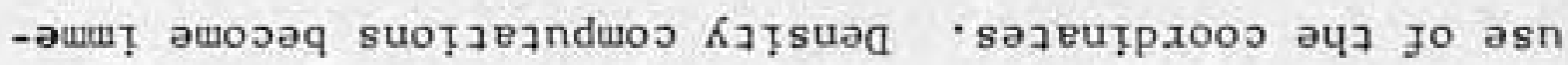

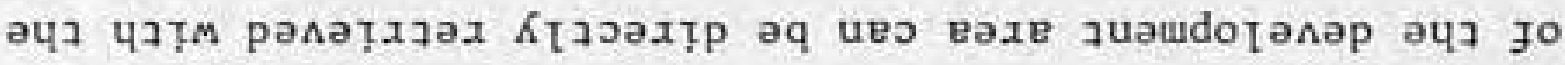

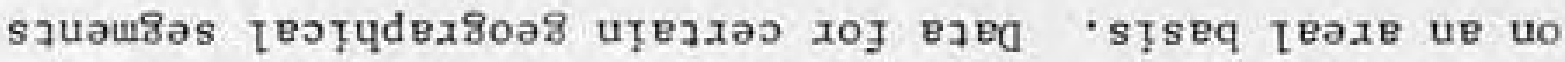

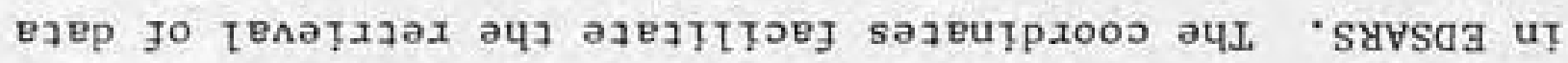

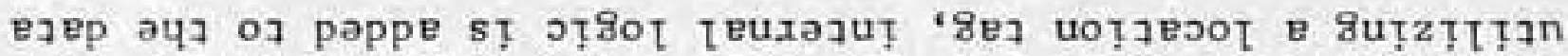

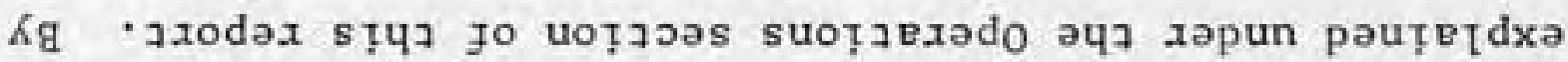

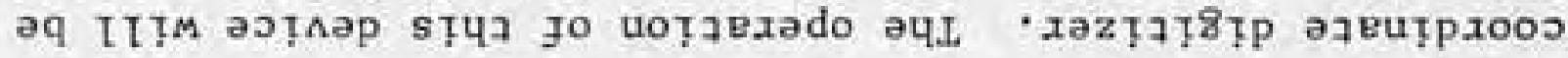

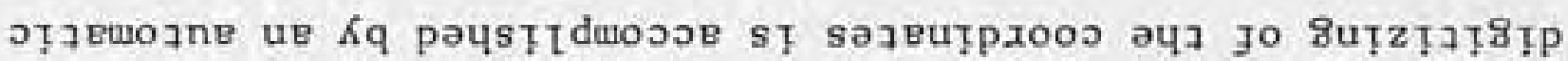

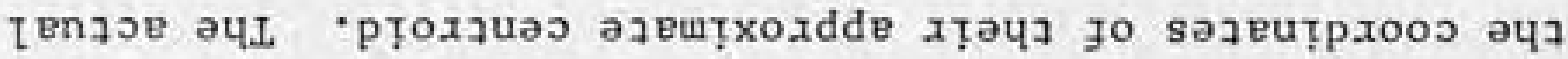

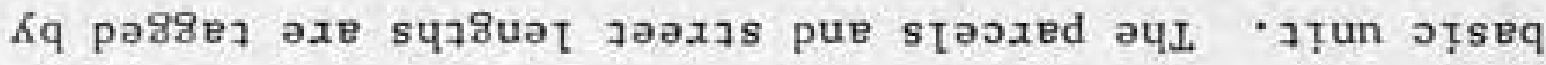

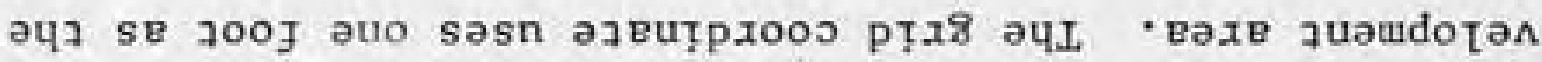

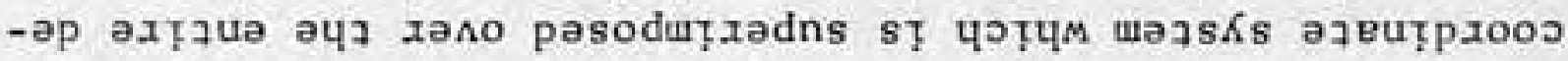

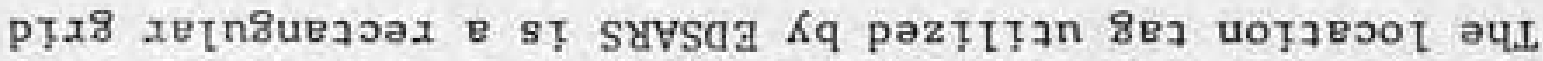

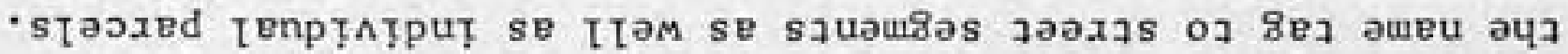

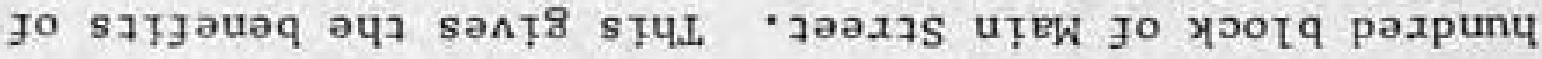

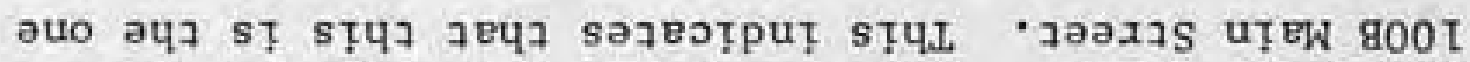


By representing zones in this way, a dictionary of zone names and grid coordinates is developed. When any information is desired on a zonal basis, the coordinates of the zone are read and each parcel is tested to establish whether or not it lies within the zone in question. The information for each parcel within the zone is then retrieved and aggregated thereby giving information on the desired zonal basis.

In order to coordinate the actual data incorporated into the system and the tags for each parcel, a dictionary with the parcel number, street address (or block number for street segments), and grid coordinates is developed. The actual data are stored in conjunction with a parcel number. The data are related to the name and location tags through the parcel number-street address-grid coordinate dictionary. The parcel number is merely a unique number of 1 to 6 digits given to each parcel. The numbers need not be consecutive or have any logical order. The only requirement is that each parcel have one and only one unique number.

\section{Data Dimensions}

The definition of land use developed by the Metropolitan Washington Council of Governments was utilized to aid in determining the data needed to define the different areas of land use. Data were examined in the light of how well 
they defined:

1. Type of activity

2. Type of structure

3. Type of land use

4. Intensity of use

5. Aesthetic qualities

6. Restrictions on use

7. Nuisance characteristics

8. Economic functions (13)

In order to completely describe the urban environment, the information on each parcel is broken down into three categories :

1. Parcel Information - information on the parcel itsself, including dimensions, restrictions, zoning, use, etc.

2. Building Information - information on each building on a parcel, including age, value, type of construction, con dition, size, etc.

3. Establishment Information - specific information on each unit within a building such as a business, a dwelling unit, etc., including space use, number of employees, number of residents, age of residents, number of vehicles, etc. 


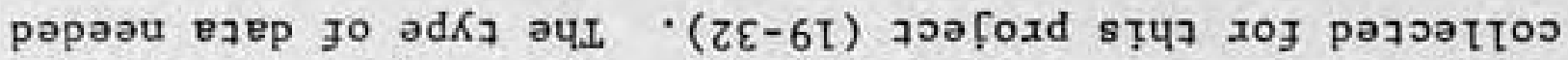

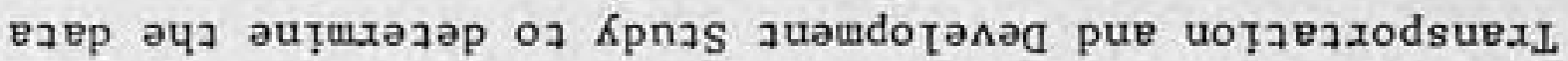

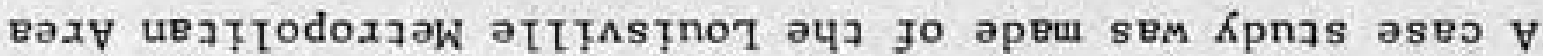
-pauțuexa uayz SeM 8uțuue [d ueqan jo saseyd II

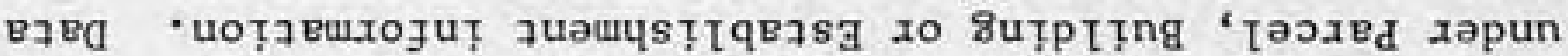

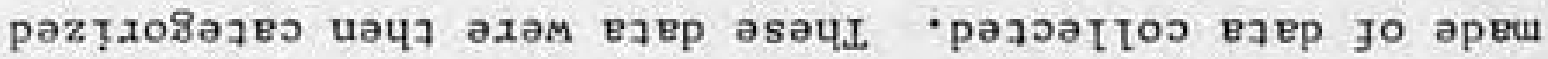

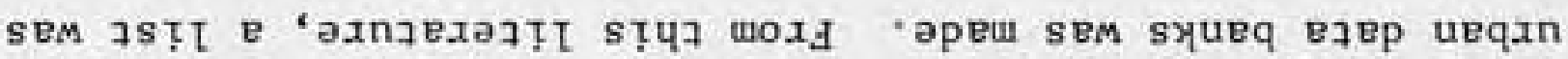

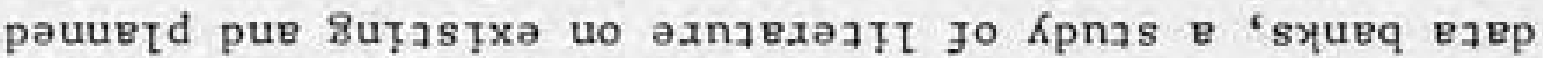

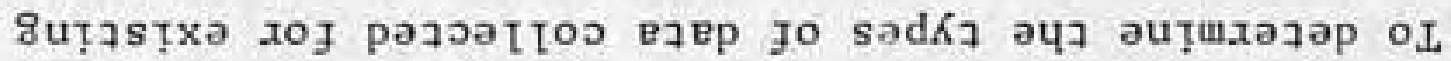
-pazepdn aq oz KațtTqe

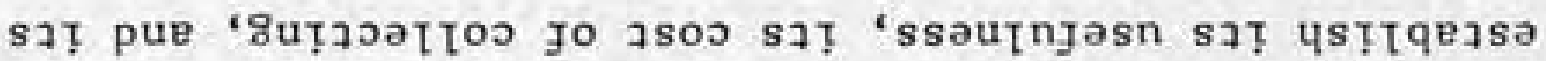

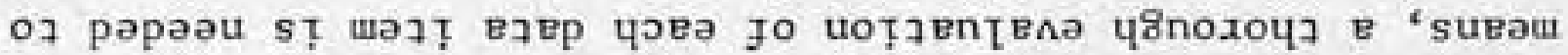

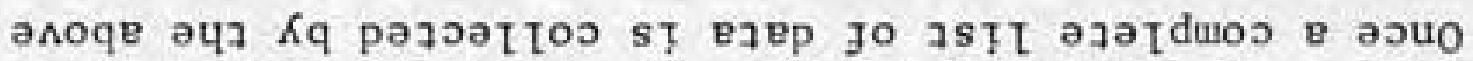

- Sựuue ${ }^{d}$ pue

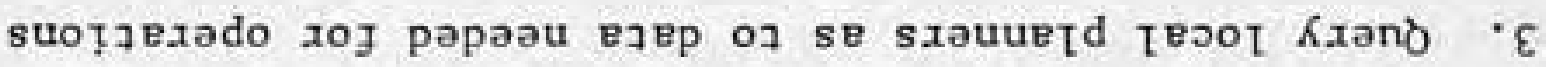
•suoțzoung

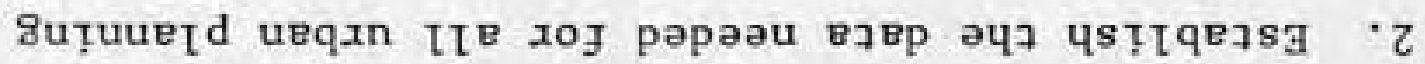

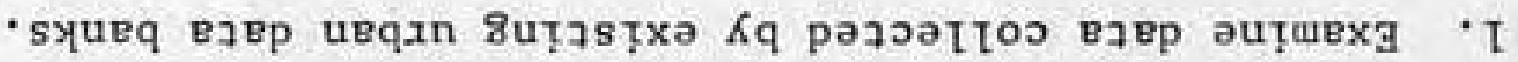

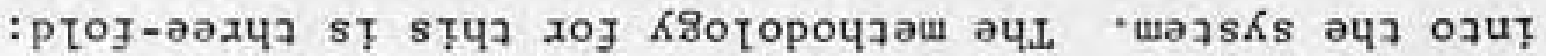

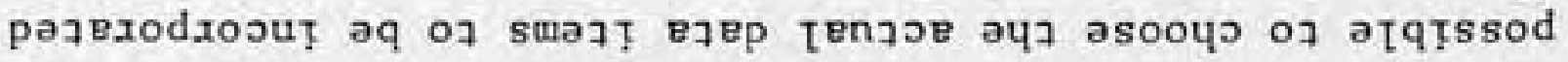

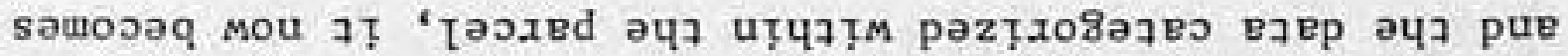

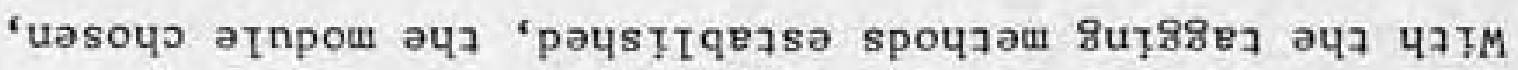


for a comprehensive Environmental Health Plan was determined (33). General notes on the data collected for other urban studies, including a Recreational Plan, School Plan, Urban Renewal Plan, Major Thoroughfare Plan, Transportation Plan, Land Use Plan, and an Economic Development Plan, were studied for the data needed (34). All listed data items were then appraised by local planners. The data incorporated, listed by general category, are as follows:

\section{Parcel Information}

1. Land use

2. Ownership

3. Frontage

4. Area

5. Year of subdivision

6. Assessed value of land

7. Easement

8. Landmark

9. Neighborhood characteristics

10. Land appearance

11. Number of structures

12. Year of zoning change

13. Zoning

14. Zone change request number

15. Variance number 
16. Comprehensive Plan use

17. Utilities

18. Parking spaces

19. Loading area

20. Assessed value of improvements

21. Total assessed value

22. Sale date

23. Sale price

24. Nuisances

(The following data are collected for street segnent parcels)

25. Intersection

26. Length of segment

27. Right-of-way width

28. Pavement width

29. Functional class

30. Structural composition

31. Per cent grade

32. Average daily traffic

33. Number of accidents

34. Traffic control signs and signals

35. Speed limit

36. Curb parking regulations

37. Curb type

38. Sidewalks 
39. Number of lanes

40. Loading zone

41. Bus route

42. School route

43. Access control

44. Condition

II Building Information

1. Year built

2. Type of construction

3. Type of structure

4. Building condition

5. Year of latest building permit

6. Cumulative cost of building permits

7. Number of floors

8. Total floor area

9. Basement

10. First floor area

11. Number of dwelling units

12. Buflding setback

13. Required Setback

14. Rehabilitation cost

15. Type of building code violation

16. Number of building code violations

17. Number of establishments 
III Establishment Information

1. Space use

2. Total number of employees

3. Peak shift number of employees

4. Optimum total employment

5. Number of rooms for rent

6. Number of residents by sex and age group

7. Family income

8. Vehicles owned

9. Police calls

10. Fire calls

11. Welfare payment

12. Number of communicable diseases

13. Type of comunicable diseases

14. Rent

A complete 1 ist of all data incorporated along with its possible source, use, and description can be found in Appendix I. Each piece of data that was entered into the system was judged to be important to the planning conmunity, able to be updated, and relatively easy to collect. Data that were too expensive to collect or not updatable were not incorporated into the system. 
47

With this developmental background now complete it becomes possible to explore the actual operation of EDSARS. The following section can be considered as the "Operations Manual" for this data system. All phases of initialization and utilization of the system are discussed in detail. It is assumed that with the general background given in the presvirus sections and the specific operational procedure explained in the following section that EDSARS can be initialized by any interested community or organization. 


\section{OPERATION OF EDSARS}

\section{Data File Characteristics}

The data in EDSARS are established in three separate files. The first data file contains parcel numbers, parcel grid coordinates and parcel addresses. Each parcel is given a unique number to identify it as a data entity; this number is correlated to the grid coordinates of the approximate parcel centroid and the street address of the parcel by the Parcel Number-Grid Coordinate-Address File. The second data file contains the parcel number and all general data on that parcel. The data for each parcel are correlated to the street address and grid coordinate via the parcel number. The third data file contains zone names and the coordinates of the zone boundary.

These three data files make up the data storage portion of EDSARS. The actual data is stored on tape and can be manipulated by a set of package programs. The first set of programs is used to initialize the system by reading cards and writing the information on tape. The second set of programs is used to incorporate more data items when they become available. The third set of programs is used to read the data tape and write on paper. This set of programs is used to check the other program sets and to give a complete 
list of all data in the system. The fourth set of programs is used to update the values of data items in the system when current information becomes available. The fifth and final set of programs is used to retrieve information from the system for special user purposes. The following is an explanation of the package programs and procedures for using them in EDSARS.

\section{General Program Information}

Each of the programs discussed below is used to manipulate the data in EDSARS. When data cards are to be read into the system, a card with "7, 8 and 9" punched in column one must follow the main body of the program and precede the actual data cards. When reading General Data cards, the last card should have a "99" in columns seven and eight. This indicates end-of-data to the system. The last data card in the Zone-Grid Coordinate File, and the Parcel NumberGrid Coordinate-Address File should be blank to indicate end-of-data to the system. The last data card is followed by a card with " $6,7,8$, and 9 " punched in column one. This indicates end-of-program to the computer. If no data cards are used in a program, the " $6,7,8$, and 9 " card immediately follows the main body of the program. 
The actual format of the data in the system is explained in Appendix I. Appendix I has a complete list of all information in the system along with a brief description of the data item, possible source, system name for the data item, system format for the item, and its possible use. Appendix II explains all codes used for data items in EDSARS.

\section{Data File Initialization}

Parcel Number-Grid Coordinate-Address File

The initialization of the Parcel-Number-Grid CoordinateAddress File occurs first. To initialize this file, the coordinate digitizer of the Joint Highway Research Project at Purdue can be utilized. An accurate base map of the entire development area is placed on the digitizer and a point 1,000 feet south and 1,000 feet west of the southwestern corner of the development area is set as point $(0,0)$. Key points on the base map are then digitized; the digitizer will give readings in inches and these readings are then converted to feet; the conversion depends upon the scale of the map utilized.

The key points that are digitized should be the intersection of street center lines if these are available. The actual digitizing of parcel coordinates will take place on more accurate maps. The key points that are located on the 
base map are digitized on the more accurate maps, and the coordinates of these key points serve as reference coordinates for the digitizing of all parcels.

Each map to be digitized, other than the base map, should first be broken up into parcels and approximate centroids located as shown in Figure 1. Consecutive parcel numbers are then written on the map for each parcel. The map is placed on the digitizer, its key point located (for coordinate conversion to the base system), and then each parcel centroid can be digitized. The digitizer will punch the parcel number and the grid coordinates on an IBM card which can then be fed into the computer for coordinate conversion.

The data cards for actual initialization of this data file are read into the system via Program I, Appendix III. The data cards for this file should have the format shown in Figure 2. This figure can also serve as a sample coding sheet. The parcel number is placed in columns 1-6. The $\mathrm{X}$ coordinate is placed in columns $8-13$, and the $Y$ coordinate in columns 15-20. The street or rural route number of the parcel is placed in columns $22-27$. If the parcel is a street segment, the block number is placed in columns $20-26$ with a "B" in column 27 to indicate "street block". A1l of these 


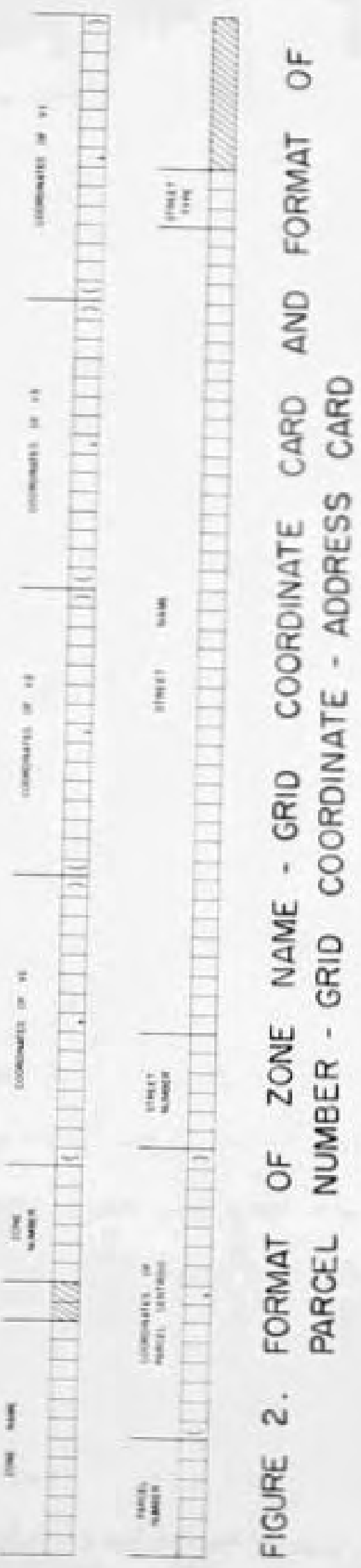


numbers should be right justified. Columns 30-69 contain the street name or "Rural Route". The name should start in column 30 and be punched on the card just as it appears in the town directory with one column between each word in the name. The type of street is coded in columns 70-72. An explanation of this code can be found in Appendix II. When more information becomes available, Program 2, Appendix III is used to read more data cards into the system. This data file locates all of the parcels in the development area and coordinates the parcel location and street address to a particular parcel number. This number is the identifying tag in the system used to locate all data that pertain to this particular parcel.

\section{General-Data File}

The file for general data is initialized after each parcel in the development area has been given a unique number. The format for General Data cards can be found on Figure 3 ; this figure can also serve as a sample coding sheet. The 01 card is used for every parcel in the development area. The 02 card is used where the parcel has a use other than right-of-way. A 12 card is used in place of the 02 card when a parcel is a right-of-way. If the parcel has multiple land use, zoning or comprehensive land use, an 11 


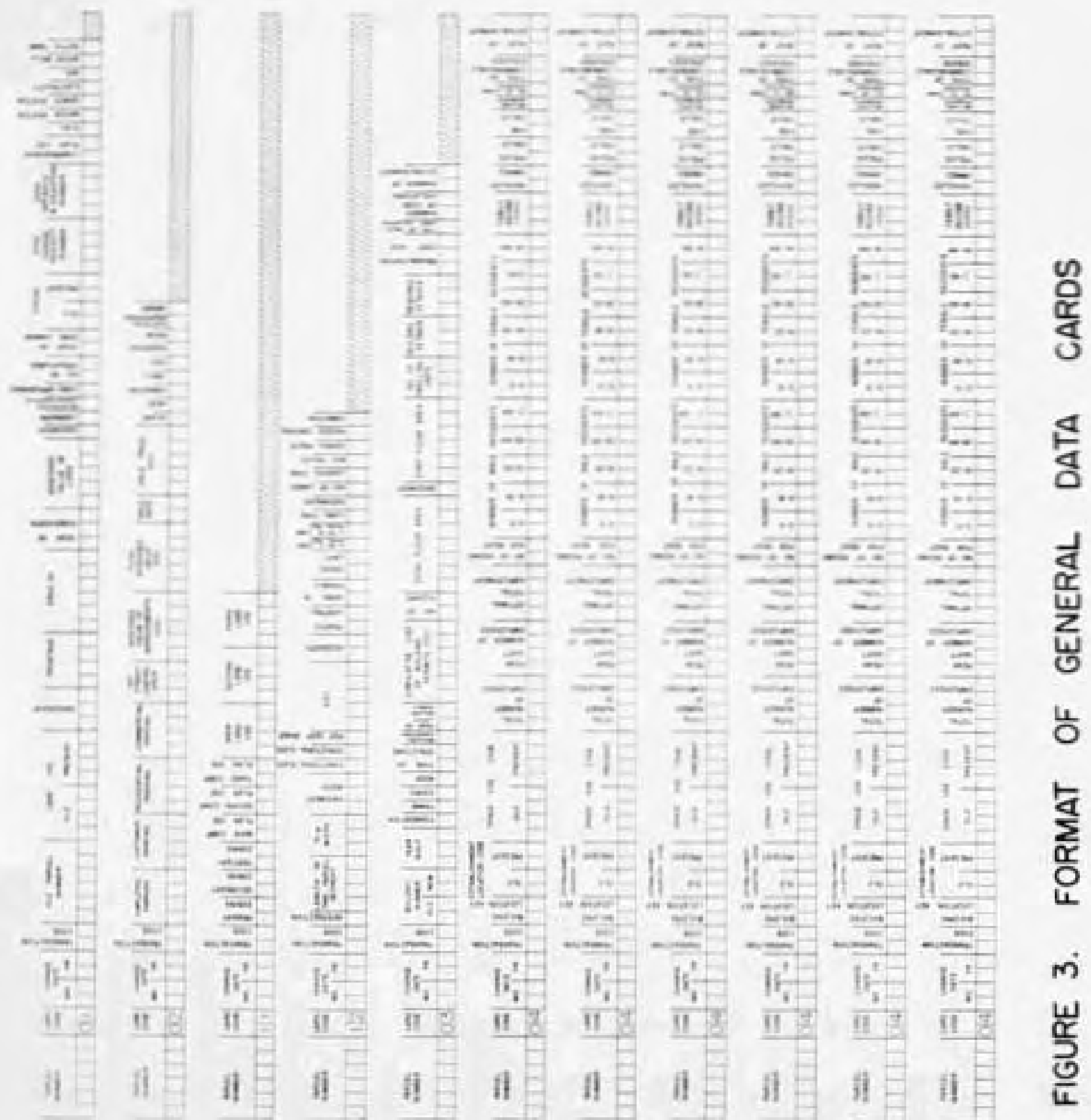


card is used to supplement the 01 and 02 cards. Each building on a parcel is represented by the information on the 03 card, and each establishment (dwelling unit, business, office, etc.) in a building is represented by an 04 card. The information in the General Data File is broken into three categories. The first category is land use information and is represented by the 01,02 , or 12 , and 11 cards; the second category is building information which is represented on the 03 card, and the third category is establishment information which is represented on the 04 card.

Each data item in the system is given a specific name. This name is used to refer to the particular data item within the system.

A detailed explanation of these data with definitions, location, format and data item name can be found in Appendix I. The format for these data cards is shown on Figure 3 .

Each building on a parcel is given a number to uniquely identify it; if four buildings exist on one parcel, they would be numbered 1-4. Each establishment within a building is also given a unique number to identify it. Building numbers start at one, with each separate parcel; establishment numbers start at one, with each separate building. Program 3, Appendix III is used to initialize this data file 
by reading data cards and writing the information on tape and paper as a check. Program 4, Appendix III is used to read in more information as it becomes available.

\section{Zone-Grid Coordinate File}

The last file to be initiated is the Zone-Grid Coordinate File. To define a zone, its boundary is located in the development area by the grid coordinate system. The zone is broken up into triangles and the grid coordinates of each of the three vertices are coded on data cards. The card format is shown in Figure 2. An example of a zone broken into triangles can be found in Figure 4. The coordinate of the vertices are placed on the data card by numbering the vertices 1-3. Point one is coded first, followed by point two, point three, and point one again. The first and last coordinate must be the same in order to close the triangle. The identifying zone name is placed in columns 1-12, the zone number is placed in columns 15-20. The coordinates of the vertices are placed in columns $22-80$ in the format shown on Figure 2. The zone name starts in column 1. The zone number and grid coordinates are right justified. Program 5, Appendix III is used to initialize this file by reading data cards and writing the data on tape, and paper as a check. Program 6, Appendix III is used to read more information into 


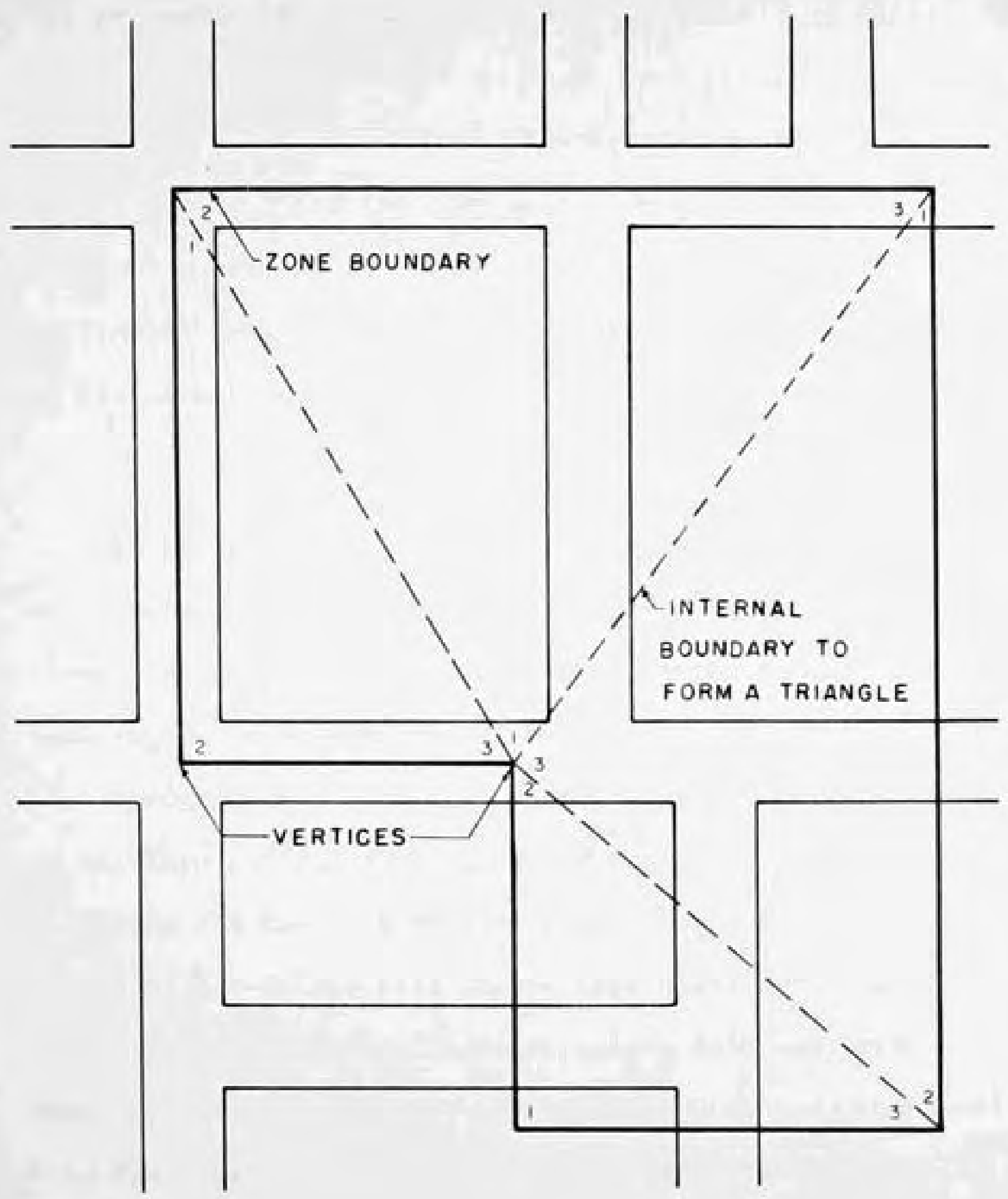

FIGURE 4. ZONE DIVIDED INTO TRIANGLES FOR DATA CODING 
the system as it becomes available. It should be noted that this file can contain as many zonal systems as required by the users. Census Tracts, Transportation Zones, School Zones, etc. are all examples of possible zonal systems that could be incorporated into this file. The inclusion of a particular zonal system is dependent upon the potential use of its parcel aggregation.

\section{$\underline{\text { Read Programs }}$}

There is a general class of programs in EDSARS that will read the data file tape and print the information on paper. These programs should be used after reading in more data or updating the system to check the accuracy of the tape file. These programs can also be used to obtain a complete 1 ist of all information on the tape. Program 7, Appendix III will read the Parcel Number-Grid Coordinate-Address file and print a complete list of the tape file. Program 8 , Appendix III will read the General Data file and print a complete 1ist. Program 9, Appendix III will read the ZoneGrid Coordinate file and print a complete listing of this information.

\section{Update Programs}

In order to change any of the information in the system or update the information, a set of update programs has been developed to replace the old information with the new. This 
is accomplished by using the initializing programs to make a tape file of the new information. This new information file and the original file are then used to initialize a new tape file with all of the new information incorporated into it.

All of the update programs require that the new data cards be identical to the original in format. The new cards should be complete - all information that is not changed should still be punched on the update card. The new information is punched on the card replacing the old in the same format. These cards are then used to form the update file. Any data card that has no data changed need not be entered into the update file, but any card that has any piece of information changed must be completely repunched with all of the new and unchanged information.

Updating the Parcel Number-

Grid Coordinate-Address File

In order to update this file, Program 1 is used to read the new data cards and write a New Information File. These data cards must be in the same format as the original and be complete with the new information inserted in place of the old. The New Information File, the original file, and the tape which will become the updated file are then mounted on 
the computer and Program 10, Appendix III is run to update the file. This program changes only the data that are to be updated. All data that are still valid from the original program are written in their original form on the updated file. This means that if street numbers were changed for only one block in the development area, new cards would be made only for that particular block. These new cards would be read into a New Information File and then by using Program 10, Appendix III this new information would be incorporated into the total file giving a complete updated file where the only information that was changed was for the block in question. Program 7, Appendix III should then be used to print a listing of the updated file to insure its accuracy.

Updating The General Information File

To update this file, Program 3, Appendix III is used to read the new information and write a New Information File. This New Information File and the original file are then used to write a new General Data File. The updating program for this file is Program 11, Appendix III. Program 8, Appendix III is then used to make a listing of the updated data file to insure its accuracy. 
Updating The Zone-Grid Coordinate File

This file is updated by reading the new information and writing it on tape via Program 5, Appendix III. The New Information File, along with the existing tape file are used by Program 12, Appendix III to write an updated Zone-Grid Coordinate File. Program 9, Appendix III should then be used to check the accuracy of the updated file by writing out a complete listing. The updating of this file can take place by redefining the boundaries of a particular zone for a specific zonal system. If a zone name is changed, an entirely new file must be written by Program 5 without the cards from the deleted zone and with cards for the new zone.

\section{Retention of 01d Data Files}

A decision on how many old data files should be kept needs to be approached at this time. Data files represent current data for a certain period of time. The comparison of data files for different time periods can yield useful information on trends that exist in the development area. It is felt that files should be updated at least once a year. These yearly files should be retained for at least a period of five years. The final decision on this policy is, of course, up to the initializing agency. 


\section{RETRIEVAL PROGRAMS}

To retrieve information from the data files for special purposes, there are a set of programs in EDSARS which give specific information for the special purposes of the user. Programs 7-9 will give a complete listing of an entire data file, but this is quite often no more useful than the raw data cards. Programs 13-18, Appendix III are designed to be general in their characteristics so that specific user needs can be satisfied. The programs are flexible enough so that they can be modified as user needs permit. The first four programs discussed below retrieve information from the General Data File; the next two retrieve information from the Parcel Number-Grid Coordinate Address File. The last program retrieves information from the Zone-Grid Coordinate File.

\section{Retrieve List of $\mathrm{X}$ and $\mathrm{Y}$}

Program 13, Appendix III will retrieve a list of any two parameters from the General Data File. All information will, of course, be on a parcel basis. With this program the user can retrieve a list of land use and customer parking spaces, for instance, to determine the trend in types of 1 and use providing parking for customers. The format for each parameter ( $\mathrm{X}$ and $\mathrm{Y}$ ) is entered into this program. The variable name is also entered into the general program along with the 
maximum number of items in the list and the data card type that the information is on. The listing of this program in Appendix III indicates where these parameters must be entered. The variable name, format and card type are explained in Appendix I for each data item.

Retrieve Sum of $\mathrm{Y}$ for a Specific X

If a parameter is to be summed for a particular value of another parameter, Program 14, Appendix III is used. An example of application would be to sum customer parking spaces for local business type of land use. The value of the $\mathrm{X}$ parameter which the sum is to be taken over is entered into the program along with the variable name being summed and the variable name being summed over. The data card that each parameter is on is also entered into the main program along with the format of each variable. The format for these entries is clarified by the program listing in Appendix III.

Retrieve List of $\mathrm{Y}$ for a Specific $\mathrm{X}$

A program that can provide a list of one data item based on a particular value of another data parameter is often useful. The list of residents by parcel with residential land use is a possible application of this type of program. Program 15, Appendix III will list any variable Y, for any 
specific value of another variable $X$. The variable name for $\mathrm{X}$ and $\mathrm{Y}$, and their format, along with the specific value of $\mathrm{X}$ that is listed over, and the maximum size of the list are entered into the main body of the program. With these parameters the program will then give the desired list. The program listing in Appendix III indicates where the proper information is to be entered.

Retrieve $\mathrm{X}$ for Specific Parcel Numbers Any data parameter can be retrieved for a specific parcel number by using Program 16, Appendix III. The variable name to be listed and its format, along with the number of parcels in the list are entered into the main program. With this information the program will retrieve the desired data. This program is used in conjunction with the next two programs which yield parcel numbers based on other data parameters.

\section{Retrieve Parcel Number for Specific Addresses}

The parcel number for a parcel with a specific address will be retrieved by Program 17, Appendix III. This program will read addresses that are submitted to it and will print out the address, parcel number and grid coordinates for each specific parcel. The address cards that are fed to this program must start the street name in column 7 with one space 
between words in the name. The street number should be right justified in columns 1-6; the street type should be coded in columns 49-51. Any number of addresses can be fed to this program and the parcel number and grid coordinates will be retrieved. The number of addresses being searched must be entered into the main body of the program as shown in Appendix III. The output cards from this program can be fed directly to Program 16, which retrieves General Data based on parcel numbers. These two programs give the system the facility of retrieving general data on a street address basis.

Retrieve Parcel Number

for a Specific Zone

Program 18, Appendix III will give a complete listing of zones and the parcels that are within these zones. The inputs for this program are the Zone-Grid Coordinate File and the Parcel Number-Grid Coordinate-Address File. The output from this program can be fed selectively to Program 16 thereby giving the system the capability of retrieving general data on a zonal basis. 


\section{Flexibility of Programs}

The programs discussed above are general in nature and are meant to be a start of a complete retrieval package. More programs will certainly be added to the retrieval package as user needs become evident. The programs that have been outlined here are meant to be flexible and easily changed for specific user needs. Any of the retrieval programs that retrieve on the basis of a data parameter being equal to a certain value can be changed to retrieve data for a parameter greater than or less than a certain value by merely changing the statement that tests the $\mathrm{X}$ parameter. These statements now read IF(X.EQ.TEST) which means "if $X$ equals test." If this statement is changed to IF(X.GE.TEST) the program will retrieve information for $\mathrm{X}$ greater than or equal to a certain value (TEST). If information is required for $X$ less than or equal to a certain value, the expression would be IF(X.LE.TEST). Many different programs can be built from the basic six retrieval routines explained above. Consultation of any basic Fortran manual will reveal how this can be done. This does not mean that one need be a programmer to use or change the programs, however; the manual can usually give the needed information even if one does not know the Fortran language. 
In order to run these programs, the users manual for specific computer must be consulted. Each particular installation has different requirements for control cards; these are explained in the users manual.

After examining the conceptual development and the operational characteristics of EDSARS, it is felt that an organization or community could use the work presented here as the basis for an urban data system. Specific needs and capabilities will probably change some details, but the approach and application explained above should be broadly applicable to the task of initiating a unique planning tool that should greatly increase the efficiency of handling planning data while making this information available to a much broader segment of the urban environment. 


\section{CONCLUSIONS}

The following conclusions about EDSARS and its potential can be made:

1. EDSARS should facilitate efficient and economical handling of planning data for the area of about 100,000 population.

2. The utilization of a general purpose computer and general purpose programing languages should make EDSARS available to most metropolitan areas in the United States.

3. The concept of a unified data system is the most important contribution of EDSARS.

4. The data proposed for EDSARS is the most useable and easily obtainable information available to the urban area.

5. The incorporation of a flexible method of representing zones by their location is essential to an efficient urban data system such as EDSARS.

6. The information for an urban data system should be in three separate files so that one file can be updated and improved without disturbing the other files.

7. Zone names and boundary locations should comprise one file; parcel numbers, parcel location, and street address should compromise another file, and the third file should be 
made up of general data.

8. The best unit for data collection is the parcel.

9. The data system should be flexible so that improvements can be made as use and technology increase.

10. The streets and rights-of-way should be represented as special parcels in order to insure full territorial and information coverage.

11. All data incorporated should be potentially useful and updateable.

12. Utilization of applicable theory and practical experience of existing data systems are needed to develop a useful, efficient and improved data system.

The concepts that are represented by these conclusions when tied together into an urban data system such as EDSARS give the planning community and the urban environment as a whole a flexible and useful tool which should make more information available to more people at a much lower cost and with much less effort. 


\section{RECOMMENDATIONS FOR FURTHER RESEARCH}

EDSARS, and most other urban data systems can be improved most effectively by the development of a programing language that can handle urban data more efficiently. A computer language is needed that can be understood by the planner and have the capability of efficient data handing. The multitude of data to be incorporated into EDSARS makes research in this area a highly profitable undertaking in terms of time and money saved in handling data. As EDSARS becomes operational, models should be incorporated into the system. At first the models could be specific in nature. When the specific models have been developed, they could be incorporated into a more sophisticated simulation model. The ultimate type of model that can be forseen at this time, which could be incorporated into EDSARS, would be a model which automatically could give changes in predictable parameters as the system is updated. An example might be a simulation model that, among other things, would give the change in future land use caused by the change in data read in as update information today. This model could be sensitive to changes in population, land use, etc., and would be able to detect these changes at each update cycle and predict the effect of these changes on future land use. 
As EDSARS is used and specific retrieval procedures become common, these procedures should be made more efficient by the use of special purpose programs. The present programs are general in purpose and therefore serve all purposes adequately, but certainly more efficient methods for specific uses could be derived.

EDSARS should be a dynamic system from its inception. As common uses and retrievals become evident they should be made more efficient; as new technology in programming or data handling is developed, it should be incorporated. It should be remembered that EDSARS is not a series of computer programs, it is a concept of information handling made operational; if the concept is remembered, then EDSARS and other systems like it will exist and grow long after the initial crude methods of data handling have been discarded for better and more efficient methods. 
BIBLIOGRAPHY 


\section{LIST OF REFERENCES}

1. Metropolitan Data Center Project, Tulsa, Oklahoma, February 1966

2. Horwood, Edgar M., "A Fundamental Look at Urban Information Systems," Urban Information and Policy Decisions, Clark D. Rogers, ed., University of Pittsburgh, September 1964 .

3. Hamilton, Calvin S., "Monitor Systems for Urban Planning," Urban Information and Policy Decisions, Clark D. Rogers, ed., University of Pittsburgh, September 1964.

4. Dueker, Kenneth, Spatial Data Systems: Organization of Spatial Data, Volume 2, Northwestern University, December 1966 .

5. Almendinger, Vladimir U., "Span: A System for Urban Data Management," Urban Information and Policy Decisions, PP 189-194, Clark D. Rogers, ed., University of Pittsburgh, September, 1964.

6. Almendinger, Vladimir U., "Span: A System for Urban Data Management," Urban Information and Policy Decisions, PP 195-210, Clark D. Rogers, ed., University of Pittsburgh, September, 1964.

7. Webber, Melvin M., "The Policy Sciences and the Role of Information In Urban Systems Planning," Urban Information and Policy Decisions, Clark D. Rogers, ed., University of Pittsburgh, September, 1964.

8. Dueker, Kenneth, "Application of Information System Concepts to Transportation Planning," Highway Research Record 194, 1967

9. Dueker, Kenneth, Spatial Data Systems: Organization of Spatial Data, Volume 1, Northwestern University, December 1966. 
10. Dueker, Kenneth, Spatial Data Systems: Organization of Spatial Data, Volume 3 , Northwestern University, December 1966.

11. McKains, W. and A. Fleischer, "A Computer System For Urban Studies" A Report for the Highway Research Board, January, 1967.

12. Barraclough, R. E., "Geographic Aspects of Information Retrieva1," Urban Information and Policy Decisions, Clark D. Rogers, ed., University of Pittsburgh, September, 1964.

13. Interim Report: Metropolitan Planning Data From Loca1 Governments, Metropolitan Washington Council of Governments, August, 1966.

14. Horwood, Edgar M., "Urban Information Systems and Transportation Planning," Highway Research Record 194, 1967.

15. A Manual For Establishing and Maintaining a Basic Data File for Pulaski County, Arkansas, Metropolitan Area Planning Comission of Pulaski County, Little Rock, Arkansas, June, 1964.

16. A Data Storage System for Land Use Analysis, Technical Report 62-1, Department of Planning, E1 Paso, Texas, Apri1, 1962.

17. Metropolitan Planning Data, From Local Governments, The Metropolitan Washington Council of Governments, July, 1967.

18. Dueker, Kenneth, "Organization For The Retrieval of Spatially Distributed Data: A Land Use Data System (LUDS)," Proceedings of the Fourth Annual Conference on Urban Plan ag Information Systems, University of California, 1966.

19. Home Interview Manual, Louisville Metropolitan Comprehensive Transportation and Development Program, 1965.

20. Truck and Taxi Manual, Louisville Metropolitan Comprehensive Transportation and Development Program, 1965.

21. External Survey Manual, Louisville Metropolitan Comprehensive Transportation and Development Program, 1965. 
22. Land Use Manual, Louisville Metropolitan Comprehensive Transportation and Development Program, 1965.

23. Road and Street Inventory Manua 1, Louisville Metropolitan Comprehensive Transportation and Development Program, 1965.

24. Flow Characteristics Manual, Louisville Metropolitan Comprehensive Transportation and Development Program, 1965.

25. Accident Study Manua1, Louisville Metropolitan Comprehensive Transportation and Development Program, 1965.

26. Parking Study Manua1, Louisville Metropolitan Comprehensive Transportation and Development Program, 1965.

27. Routes and Termina1s Manual, Louisville Metropolitan Comprehensive Transportation and Development Program, 1965.

28. Transportation Facilities Standards, Louisville Metropolitan Comprehensive Transportation and Development Program, 1965.

29. Population Econoelic Base Manual, Louisville Metropolitan Comprehensive Transportation and Development Program, 1965.

30. Planned Transportation Facilities, Louisville Metropolitan Coaprehensive Transportation and Development Program, 1965.

31. Public Transit Study, Louisvilie Metropolitan Conprehensive Transportation and Development Program, 1965.

32. Development Data, Louisville Metropolitan Comprehensive Transportation and Development Program, 1965.

33. Maxanan, Robert J., "Data Collection for a Comprehensive Environmental Health Plan," an unpublished term paper submitted for CE 697, Purdue University, 1967.

34. Planning Methodology and Techniques, class notes for CE 697, Prof. W. L. Grecco, Purdue University, 1966. 
GENERAL REFERENCES

(Not cited in text)

1. A Regional Data System, Baltimore Regional Planning Council, June, 1963.

2. Barraclough, R. E., "Information for Land Use Models," Highway Research Record 194, 1967.

3. Becker, Joseph and R. M. Hayes, Information Storage and Retrieval: Tools, Elements and Theories, John Wiley and Sons, New York, 1963.

4. Beshers, James M. (ed), Computer Methods in the Analysis of Large Scale Social Systems, M. I.T. Press, Cambridge, Mass., 1965.

5. Block, Carelton, "Data Bank Implications for City Planning," Report to Leland M. Swanson, Los Angeles, California, 1963.

6. Calkins, H. W., "Ottawa Street Address Conversion System," Highway Research Record $194,1967$.

7. Campbe11, R. D., and H. L. LeBlanc, An Information System for Urban Planning, Urban Planning Data System Project, George Washington University, 1962.

8. Cook, Robert N., "A Comprehensive Unified Land Data System," A Report given to the Conference on A Comprehensive-Unified-Land-Data-System, December, 1966.

9. Cottre11, Norman, "How Do You Actually Start an Information System?" A Paper for the American Society of Tool and Manufacturing Engineers Seminar, March, 1967.

10. Devaney, F. John, "The Use of Computers in City and Regional Planning," Iraffic Quarterly, October, 1966.

11. Dial, Robert B., Street Address Conversion System, Urban Data Center, University of Washington, 1964.

12. Dueker, Kenneth, "Application of Information Systems Concepts to Transportation Planning," Paper given at the 46th Annual Highway Research Board Meeting, January, 1967. 
13. Grecco, William L., "The Continuing Transportation Study for the Small City," Proceedings of the 49th Annual Road School, Purdue University, 1963.

14. Gregory, Robert H., and R. Van Horn, Automatic Data Processing 2nd Edition, Wadsworth Publishing House, Belmont, California, 1963.

15. Hamilton, Calvin, "The Development of a Land Use Data Bank for Transportation Planning," Highway Research Record $64,1965$.

16. Hansen, M., and R. B. Voight, "Availability of Census Data for Urban Areas," Highway Research Record 194, 1967.

17. Hayes, Robert M., "Simulation and Modeling in the Information Sciences," Urban Information and Policy Decisions, University of Pittsburgh, September, 1964.

18. Hearle, Edward, and Raymond Muson, A Data Processing System for State and Local Governments, Prentice Hal1, Englewood Cliffs, N. J. 1963.

19.. Information Base, Bay Area Transportation Study Commission, Association of Bay Area Governments, Berkeley, California.

20. Los Angeles City Planning Information Process ing System, Systems and Data Services Division Los Angeles City Planning Department, Los Angeles, California, May, 1966.

21. Rude, Ronald G., "Formulation of a Technique for Evaluating Urban Highway Needs," A Thesis submitted to the faculty of Purdue University in partial fulfillment of the requirements for Master of Science in Civil Engineering, October, 1964.

22. Sharp, Harold S. (ed) Readings in Information Rerieval, Scarecrow Press, New York, 1964.

23. Standard Land Use Coding Manual, Housing and Home Finance Agency and the Bureau of Public Roads, January, 1965. 24. System $\frac{\text { Development }}{\text { Center }} \frac{\text { and }}{\text { Project, Tulsa, }} \frac{\text { Performance, Metropolitan Data }}{\text { Oklahoma. }}$ 
25. Trilling, Donald, "Notes on the Possible Queries of Data Bases and the Use of Network Analysis by Urban Planners," Urban Information and Policy Decisions, University of Pittsburgh, September, 1964.

26. Urban Planning Data System, Metropolitan Data Center Project, Tulsa, Oklahoma. 
APPENDIX I 


\section{APPENDIX I}

DATA ITEMS: DESCRIPTION, USE, SOURCE, SERVICE, FORMAT, AND SYSTEM NAME

\section{Section A: General Data Items}

The general Data File contains all of the information on the parcel. The 01 and 02 cards contain information about the land itself. The 12 card contains supplementary information . on street and right-of-way parcels. The 11 card contains supplementary information when the parcel has more than one land use, zoning classification, or comprehensive plan use. The 03 card contains information on each building on a parcel. The 04 card contains information on each establishment to within a building.

\section{$\underline{01 \text { Card }}$}

Co1. 1-6, Parcel Number

Each parcel in the data system is given a unique number. This number is used to identify the parcel within the system. Parcel numbers require no $\log i c$ in their assignment other than the fact that each parcel must be assigned a unique number.

The use of the parcel number is internal bookkeeping in the data system.

The source of the number is internal to the system. The system name is PNO, and the format is I6. 
Co1. 7-8, Card Code

Each data card is identified by a card code, on this card the code is 01 . The card code identifies what data is placed on this card. Card code 01 and 02 denote parcel information, card code 03 denotes building information; card code 04 denotes establishment information. Card code 11 denotes supplemental parcel information; card code 12 denotes right-of-way information. There will be one 01 card for each parcel, one 03 card for each building on a particular parcel, and one 04 card for every establishment within the buildings on a parcel.

The use of the card code is to tell the system what kind of data is placed on this data card.

The source of the card code is internal to the system. The system name is CRDTYP, and the format is I2.

Col. 9-12, Change Date

The number of the month and last two digits of the year of the most recent data change are placed here. Each time the data is updated or changed on this particular card, a new change date is placed in these four columns.

This data is used to tell how recent the information on the card actually is.

The source of this data is internal to the system.

The system name is CHANGE, and the mat is I4. 
Co1. 13-14, Transaction Code

The transaction code indicates which data were changed during the last updating cycle.

The use of the transaction code is to help explain changes in data items and describe the updating that takes place.

The source of the transaction code is internal to the system.

The system name is TRANCD and the format is I2.

Col. 15-20, 01d Parcel Number

The old parcel number is used to keep continuity in the parcel records. If parcels are split or joined, the old parcel number gives the number that the data was previously associated with.

If a parcel is subdivided into smaller parcels, one of the new parcels is given the parcel number of the previous larger parcel and the same parcel number is placed in the old parcel number columns. This, then indicates that this parcel has the same number as a parcel which previously had different information. The other subdivided parcels are given new parcel numbers which were not yet used in the system. The number of the parcel with which they were previously associated is put in the old parcel number columns. If parcels are joined to make one 
new large parcel, then the new parcel takes the number of one of the parcels which will be joined and the old parcel number is recorded. This gives a similar indication to that previously explained; this parcel has the same number but since an old parcel number exists, this tells the system user that this parcel number was previously associated with a different physical entity. The other parcels that are joined take on a new parcel number and their previous numbers go in the old parcel number columns.

The source of the old parcel number is internal to the system.

The system name is OLPNO, and the format is I6.

Col. 21-28, Land Use

The present land use is coded in columns 25-28; the previous land use is coded in columns $21-24$. The land use will aid in: determining actual land use trends, the coordination of zoning and actual land use, the coordination of Comprehensive Plan use and actual land use, and estimating traffic generation characteristics. If more than one land use exists on the parcel a (1) is placed in column 72 and the multiple land uses are coded on data card 11 . The source of this information is existing land use maps, assessors cards and field check. 
The system name for the present land use is NULUSE: the system name for the previous land use is OLUSE, and the format for each is I4.

Co1. 29-31, Ownership

The type of ownership that exists on this particular parcel is coded here. This code tells whether the ownership is private, public, corporate, state owned, etc. This information will give indication of tax status of land and extent of types of ownership.

The source of this information will be assessor's cards. The system name is OWNER, and the format is I3.

Col. 32-35, Frontage

The linear feet of frontage on a traveled road or $R / W$ is defined as the frontage; this does not include the frontage on an alley, it does include the frontage on both streets adjoining a corner lot.

These data will be used to compute linear feet of curb, linear feet of streets, and will aid in density computations. The source of these data will be the assessor's cards and Sanborn maps.

The system name is FRONT, and the format is F4.0. 
Col. 36-41, Areas

The area of the parcel in tens of square feet is placed here. This is the physical area of the parcel from boundary to boundary. Calculations for intensity of use, areas of each land use, etc., will be based on this figure.

The source of this information will be the assessor's cards.

The system name is AREA, the format is F6.0.

Col. 42-44, Year of Subdivision

The last three digits of the year of parcel subdivision are placed here. The year that this parcel was created by subdivision is indicated here to give an indication of residential growth. This will indicate a magnitude of growth and a direction of growth.

The source of this information will be assessor's cards, zoning records and maps.

The system name is YRSUB and the format is I3.

Col. 45-49, Assessed Value of Land

The assessed value of the parcel land as listed on the assessor's card is placed here. This figure will be used in economic analysis computations, and computations of the effects of certain environmental factors on land value. 
The source of this information is the assessor's cards. The system name is ASVAL, and the format is F5.0.

Col. 50, Easement

Any easement that exists on this parcel is coded in col. 50. The code explains the type of easement that exists scenic, utility, recreational, etc. This gives an indication of any encumbrances on the land that may hinder development.

The source of these data will be the utility companies, deeds and plat books.

The system name is EASEMT, and the format is I1.

Co1. 51, Landmark

This data item indicates whether there exists any special historically or architecturally significant structures on the parcel. This information will be used in determining the suitability of the parcel for redevelopment or other proposed projects.

The source of this information will be a field check, and residents' opinions.

The system name is LNDMK, and the format is I1.

Co1. 52, Neighborhood Characteristics

The extent of blight in a neighborhood will be coded to aid in determining the effect of blight on this parcel. Cost, maintenance, etc. can be viewed in a more clear context when 
neighborhood characteristics are known.

The source of this information will be a field check and the area redevelopment plan.

The system name is NEIGH, and the format is I1.

Col. 53, Land Appearance

The appearance of the landscaping and maintenance of the land itself will be coded here to help establish the effect of land appearance on land value and other blight factors.

The source of this information will be a field survey. The system name is LND, and the format is I1.

Co1. 54-55, Number of Structures

The number of structures that exist on this parcel is placed here to indicate to the system how many building data cards exist in this data record. This information will be used to insure internal consistency in the data.

Source of this information will be the assessor's cards and Sanborn Maps.

The system name is NOSTRT, and the format is I2.

Col. 56-57, Year of Zone Change

The last two digits of the most recent zoning change on this parcel are recorded here to give an indication of 
land use changes and to coordinate the data bank information with the zoning files.

The source of this information will be the zoning files. The system name is YRCH, and the format is I2.

Col. 58-61, Zoning

The present zoning that exists on this parcel is coded in columns 52-53. The previous zoning for the parcel, if a change has occurred, is coded in columns 50-51. The zoning will give an indication of 1 and use trends and the correlation that exists between actual land use and zoning. If the parcel is split by land use zones a (1) is placed in column 72 and the description of the multiple zones is placed on data card 11 (explained below).

The source of this information is the zoning maps and records.

The system name for the present zoning is NUZON, and the system name for the previous zoning is oLzON. The format for each is I2. 
Co1. 62-65, Zone Change Request Number

The most recent zone change request number for this parcel is placed here to aid in the coordination of data bank and zoning records.

The source of this information is the zoning records. The system name is ZONREQ, and the format is I4.

Col. 66-69, Zone Variance and Special Exception Number The number of the most recent zone variance or special exception request number for this parcel is placed here to aid in coordination of data bank and zoning records.

The source of this information is the zoning records. The system name is ZONVAR, and the format is I4.

Col. 70-71, Comprehensive Plan Use

The use that the comprehensive plan outlines for this parcel is coded here to indicate the land use growth patterns for the area. This information will enable a direct correlation to be studied between existing land use, existing zoning, and future use as outlined by the comprehensive plan. If the comprehensive plan splits the parcel into multiple land uses, a (1) is placed in col. 72 and the multiple uses are coded on data card. 11 .

The source of this information is the comprehensive plan maps . 
The system name is COMUSE, and the format is I2.

Col. 72, Flag

This column is used to indicate whether multiple zoning, comprehensive plan, or land use exists on the parcel, a (1) in col. 72 indicates that a 11 data card exists to explain the multiple categories.

The source is internal to the system from zone, comprehensive plan and land use information.

The system name is FLAG, and the format is I1.

Col. 73, Water System

The type of water system that exists is coded here.

This information will tell whether the water supplied to the parcel is from a public system, a private system or no system. The existence of a water well is indicated elsewhere. This information will aid in determining the extent of service provided by local water systems, and potential areas of need can be deternined.

Public and private utility records, field check, both are sources of information.

The system name is WATER, and the format is I1. 
Col. 74, Sewer System

It is indicated here whether or not a public sanitary sewer or a private sanitary sewer exists on this parcel. The existence of a storm sewer is also incorporated into this code. This information gives an indication of areas served by storm sewers; this will aid in determining areas of potential need.

Public utility records, city engineer records, field checks, will be sources of this information.

The system name is SEWER, and the format is I1.

Co1. 75, Electricity

This information will tell whether or not electricity is available to this parcel. This gives an indication of areas of potential need for this service. A (2) in col. 75 indicates existence of this service; a (1) indicates the absence of this service.

Field check and public utility records are sources of this information.

The system name is ELECT, and the format is I1.

Col. 76, Gas

This informacion indicates whether natural gas is piped to this parcel. This will indicate not whether gas is used 
by the parcel but whether it is available to the parcel. The areas of potential need can be investigated using this information. A (2) in col. 76 indicates existence of this service; $a(1)$ in col. 76 indicates the absence of this service.

Public utility records and field check are sources of this information.

The system name is GASS, and the format is I1.

Col. 77, Water We11

To give an indication of the utilities available to a parcel, the existence of a water well is coded here. This will help obtain a picture of the type of utilities serving each parcel. A (2) in col. 77 indicates the existence of a water well; a (1) in col. 77 indicates the absence of a water we11.

The source of this information will be a field check. The system name is WELL, and the format is I1.

Col. 78, Septic Tank

The existence of an on the premise septic system is coded here to complete the picture of the utilities serving each parcel. A (1) in col. 78 indicates the absence of a septic tank; a (2) in column 78 indicates the presence of 
a septic tank.

The source of this information will be a field check. The system name is SEPTIC, and the format is I1.

$\underline{02 \text { Card }}$

Col. $1-14$

These are all bookkeeping items indicative of all data cards and are explained under the 01 card description.

Col. 15-18, Employee Parking

The number of parking spaces for employees of establishments on or near the parcel is stated here. This will aid in parking needs studies and traffic generation figures.

A field check will be the source of this information. The system name is EMPARK, and the format is I4.

Col. 19-22, Customer Parking

The number of parking spaces for customers of specific establishments on or near the parcel is noted here to aid in parking needs, studies, and traffic generation calculations. The source of this information will be a field survey. The system name is CUPARK, and the format is I4.

Col. 23-26, Residential Parking

The number of parking spaces on this parcel for residents of establishments on or near this parcel is noted here. This 
information will aid in parking surveys and in traffic generation computations.

A field check will be the source of this information. The system name is RESPK, and the format is I4.

Co1. 27-30, Commercial Parking

The number of parking spaces on this parcel, free or for hire, available to the general public, is noted here. This will aid in parking surveys and traffic generation computations .

The source of this information will be a field check. The system name is COMPK, and the format is 14 .

Co1. 31-33, Off-Street Loading Area

The number of square feet of area devoted to the loading and unloading of goods on this parcel is noted here. This information will be used to establish traffic generation estimates for this parcel.

The source of this information will be a field survey. The system name is LDAREA, and the format is F3.0.

Col. 34-38, Assessed Value of Improvements

The assessed value in hundreds of dollars of the improvements on this parcel is noted here. This information will give an indication of the worth of this parcel and the 
economic health of the region. This will also be a growth indicator of the region.

The source of this information will be the assessor's cards.

The system name is VAL.IMP, and the format is F5.0.

Co1. $39-43$, Total Assessed Value

This will be the sum of the assessed value of the land and the assessed value of the improvements, and will give a total worth flgure for the parcel. This information will be used in basically the same context as the other assessed values described above.

The source of this information will be the assessor's cards ,

The system name is TOTVAL, and the format is F5.0.

Co1. 44-45, Sale Date

The last two digits of the year of the last sale of the parcel are noted here. This will give an indication of property turnover and will indicate the validity of the sale price figure.

The source of this information will be the tax records. The system name is SALEDT, and the format is I2. 
Co1. 46-50, Sale Price

The price paid for this parcel, in hundreds of dollars at the last sale is noted here. This will give a market worth of parcels in the area, and will help give a sales versus price relationship.

The source of this information will be the tax stamps. The system name is SALEPR, and the format is F5.0.

Co1. 51-59, Nuisances

The existence of nuisances wi11 be indicated here to analyze the influence of the factors on sale price, neighborhood characteristics, blight, and health. A (1) will indicate the absence of the nuisance and a (2) will indicate its presence; the column for each nuisance category is listed below, with fornat and system name:

\begin{tabular}{|c|c|c|c|}
\hline$\frac{\text { Columin }}{51}$ & $\frac{\text { Information }}{\text { Glare }}$ & $\frac{\text { Format }}{\text { I1 }}$ & $\begin{array}{l}\text { System Name } \\
\text { GLARE }\end{array}$ \\
\hline 52 & Heat & I1 & HEAT \\
\hline 53 & Vibration & I1 & VI BRA \\
\hline 54 & Sme11 & I1 & SMELL \\
\hline 55 & Gas & I1 & Gas \\
\hline 56 & Radiation & I1 & RADIAT \\
\hline 57 & Noise & I1 & NOISE \\
\hline 58 & Electrical Interference & I 1 & ELINT \\
\hline 59 & Smoke & I1 & SMOKE \\
\hline
\end{tabular}


The source of this information will be a fleld survey.

\section{Card}

Col. $1-14$

These coluans contain data bank bookkeeping items which occur on every card. The explanation of these items is under the 01 card description.

Col. 15, Intersection

This indicates whether this right-of-way is an intersection. This will give meaning to the following information. The source of this information will be the base maps.

A (1) in col. 15 indicates that this is not an intersection;

a (2) in col. 15 fndicates that this is an intersection.

The system name is INTER, and the format is II.

Col. 16-19, Length of this Parcel Segment

Each right-of-way will be broken dowa into sections 500 feet long or less. The block length will be used to determine the parcel length when this is convenient. This information will enable the determination of total length of street, and total length of streets by characteristic. For an intersection, the longest dimension will be used as length of the segment and the shortest will be used as rightof way width. 
The source of this information will be base maps and a field check.

The system name is LENGTH, and the format is F4.0.

Col. 20-22, Right-of-way Width

The width of this right-of-way segment in linear feet, to the nearest foot, will enable the determination of street potential for improvement and reclassification and give an indication of area of land being used as rights-of-way.

The source of this information will be base maps, field check, and the city engineer.

The system name is ROWID, and the format is F3.0.

Col. 23-25, Pavement Width

The width of the paved portion of this right-of-way segment (curb to curb) in linear feet, to the nearest foot, will give an indication of potential and need for improvement and help indicate the level of service being required. This will also aid in street classification and maintenance.

The source of this information will be base maps, field check and the city engineer.

The system name is PAVWID, and the format is F3.0. 
Co1. 26, Functional Class

The level of servic that this street segment provides is noted here. It is noted whether this street now functions as a local, collector, arterial, etc. This information will be useful in determining the efficiency and potential of the existing street system.

A field survey will be the source of this information. The system name is FUNCLS, and the format is I1.

Co1. 27, Structura1 Composition

The structural characteristics of this street segment will be coded to aid in street improvements planning, traffic routing, and transportation planning. This code will describe the actual physical construction of this street segment indicating base and wearing coarse.

The city engineer and-field survey will be the source of this information.

The system name is STRCOM, and the format is 11 .

Co1. 28, Per Cent Grade

This data item notes the number of feet that this street segment rises or falls vertically per 100 feet horizontally. This figure is described as a per cent giving an indication of needed improvements and street potential, and aiding in street classifir.tion. 
A field survey will be the source of this information. The system name is GRADE, and the format is I1.

Col. 29-33, ADT

The average daily traffic that traverses this street segment is noted here. This information will be used to determine street use and potential and aid in street classification.

The traffic enginec and field survey will be the sources of this information.

The system name is ADT, and the format is F5.0.

Col. 34-35, Accidents

The number of accidents that have occurred on this street segment will be recorded to determine high accident areas and aid in improving safety.

The traffic engineer and police records will be the sources of this information.

The system name is ACCID, and the format is I2.

Col. 36-39, Traffic Control Signs and Signals

The type of traffic control that exists on this street segment or intersection will be coded here to indicate specifically what type of traffic control exists. This information will aid in inventory and maintenance and will help in 
accident and capacity research. If two traffic controls exist on this segment, e.g. traffic light and "No Left Turn" sign, the primary control will be coded in columns $36-37$ and the secondary control will be coded in columns 38-39. If only one control exists, this will be coded in columns 36-37. The source of this information will be a field survey. The system name is TRCONT, and the format is I4.

Col. 40-41, Speed Limit

The speed limit on this street segment will be noted here to aid in street classification, capacity and accident computations.

The source of this information will be the traffic engineer and a field survey.

The system name is SPDLMT, and the format is I2.

Col. 42-43, Curb Parking Regulations

The curb parking regulations that exist on the north or east side of this street segment are coded in column 42 . The parking regulations that exist on the south or west curb are coded in column 43. This information will aid in parking surveys, parking demand versus capacity regulations, safety computations and flow capacity calculations.

The source of this information will be a field survey. 
The system name for the north or east side is NEPKG; the system name for the south or west side is SWPKG, and the format for each is I1.

Co1. 44, Curb Type

The type of curb that exists on this street segment will be coded here to aid in the inventory of existing facilities.

The source of this information will be the city engineer and a field survey.

The system name is CRBTYP, and the format is II.

Co1. 45, Sidewalks

The type of sidewalk that exists on this street segment will be coded here. Information on the width, and existence on one or both sides of the street will be incorporated into the code. This will aid in inventory of existing facilities and provide information on pedestrian safety and capacity. The source of this information will be the city engineer and a field survey.

The system name is SIDWLK, and the format is I1.

Co1. 46, Number of Lanes

The number of lanes that exist on this street segment will be noted here to aid in capacity computations and 
determination of street improvement potential.

The source of this information will be the city engineer, traffic engineer and a field survey.

The system name is NOLANE, and the format is I1.

Col. 47, Loading Zone

The existence of a curb-side loading zone will be noted to aid in determination of street volume capacity, parking capacity, and safety computations. The presence of a loading zone is noted by a two (2) in col. 47; the absence of a loading zone is noted by a one (1) in col. 47 .

The system name is LOAD, and the format is I1.

Co1. 48 , Bus Route

The existence of a local bus route along this street segment will be noted here to aid in determining extent of service provided, and in computing street volume and capacity. The existence of a bus route is noted by a (2) in col. 48 ; the absence of a bus route is noted by a (1) in col. 48 .

The source of this information will be a field survey. The system name is BUSRT, and the format is Il.

Col. 49, School Route

The existence of a school walking or bus route along this street segment will be noted here to aid in correlation 
to the facilities provided for walking and for safe bus pick up for school children. The presence of a school route is noted by a (2) in col. 49; the absence of a school route is noted by a (1) in col. 49 .

The school board and field survey will be the sources of this information.

The system name is SCHRT, and the format is II.

Co1. 50, Access Control

The type of access control that exists on this street segment will be coded to aid in capacity and safety calculations to determine areas of potential need for change in access control and aid in determination of existing levels of service.

The source of this information will be the traffic engineer and a field survey.

The system name is ACCESS, and the format is II.

Co1. 51, Condition

The condition of this street segment from the point of view of maintenance needed will be coded here to aid in the determination of required maintenance and to aid in computations of existing level of service provided.

The source of this information will be the city engineer and a field survey.

The system name is COND, and the format is II. 


\section{Card}

Col. 1-14

These columns contain data bank bookkeeping items which occur on every card and are explained under the 01 card description.

Co1. 15-16, Primary Zoning

The zoning for the most prominent use on the parcel or largest area (whichever most significant) is coded here. The significance and source of this data item is described under the 01 card explanation.

The system name is PRIZON, and the format is I2.

Co1. 17-18, Secondary Zoning

The second most important zoning on this parcel is coded here.

The system name is SECZON, and the format is I2.

Col. 19-20, Tertiary Zoning

The third most important zoning that exists on this parcel is coded here.

The system name is TERZON, and the format is I2.

Col. 21-22, Main Comprehensive Plan Use

The most important land use on this parcel as determined by the comprehensive plan is coded here. The importance of 
the land use can be determined either by area or significance to the study area. The significance and source of this data item is described under the 01 card explanation. The system name is MNCOMP and the format is I2.

Co1. 23-24, Second Comprehensive Plan Use The second most important land use (as determined above) outlined by the Comprehensive Plan is coded here.

The system name is SCCOMP, and the format is I2.

Col. 25-26, Third Comprehensive Plan Use

The third most important land use as outlined by the Comprehensive Plan is coded here.

The system name is TDCOMP, and the format is I2.

Col. 27-30, Main Land Use

The primary land use (either by area or significance) now existing on the parcel is coded here. The significance and source of this data item is described under the 01 card explanation.

The system name is MNLUSE, and the format is I4.

Col. 31-34, Second Land Use

The second most important land use on the parcel is coded here.

The system name is SCLUSE, and the format is I4. 
Co1. 35-38, Third Land Use

The third most important land use that exists on the parcel is coded here.

The system name is TDLUSE, and the format is 14 .

\section{$\underline{03 \text { Card }}$}

Col. $1-14$

These are data bank bookkeeping items and are the same for each card. A detailed explanation of these items can be found under the 01 card explanation.

Col. 15-18, Building Number

Each building on a parcel is numbered consecutively in order to uniquely identify each building. The present building number is entered in columns 17-18; if the building number has changed, the number that previously identified the building is placed in columns $15-16$.

The source of this information is internal to the system.

The system name for the present building number is

NUBLDG: the system name for the previous building number is OLBLDG; and the format for each is I2.

Col. 19-21, Year Built

The last three digits of the year of construction of this building are entered here to aid in developing community 
growth trends. This will aid in determining potential blight and suitability for redevelopment.

The source of this information will be the tax assessor's cards.

The system name is YRBLT, and the format is I3.

Co1. 22-25, Type of Construction

The materials used in the construction of the foundation, frame, siding, and roof of this structure are coded here to enable determination of potential redevelopment and suitability for new uses. The codes are placed as follows:

$\begin{array}{ll}\text { Foundation - Column } 22 \\ \text { Frame } & \text { - Column } 23 \\ \text { Siding } & \text { - Column } 24 \\ \text { Roof } & \text { - Column } 25\end{array}$

The source of this information will be the assessor's cards and a field survey.

The system names are as follows: foundation - FND; frame - FRAME; siding - SIDING: roof - ROOF; the format for each is I1.

Co1. 26-27, Type of Structure

The basic characteristics of the structure are coded here to enable determination of exactly what type of structures exist, e.g. detached building, arcade, attached building, etc. 
This will aid in establishing exact use and suitability to present and future use. .

The source of this information will be a field survey. The system name is STRTYP, and the format is I2.

Co1. 28, Building Condition

The extent of maintenance needed is coded here to aid in determining areas of blight and potential redevelopment. This information should enable the determination of potential blight before wholesale renewal is required.

The source of this information will be a field survey. The system name is BLDCON, and the format is I1.

Col, 29-30, Year of Latest Building Permit

The last two digits of the year that the most recent building permit was issued for this building is entered here. This will give a determination of extent of upkeep and growth occurring in this building and will aid in the determination of blight and need for redevelopment. This will also show areas of growth in the study region.

The source of this information will be the city engineer. The system name is YRPRMT, and the format is I2. 
Col. 31-36, Cumulative Cost of Building Permit

The cumulative costs of construction and improvement as reflected by all of the building permits issued for this structure in hundreds of dollars is noted here to give extent of construction and growth occurring in the study area.

The source of this information will be the city engineer. The system name is COSTPR, and the format is F6.0.

Co1. 37-38, Number of Floors

The number of floors, including the basement if one exists, in this structure is noted here. This information will aid in intensity of use calculations and aid in size computations for structures in the study area.

The source of this information will be a field survey. The system name is NOFLR, and the format is I2.

Col. 39-45, Total Floor Area

The total floor area of the building, including the basement, in square feet is noted here to obtain intensity of use figures. The square feet of floor space in each land use category will also be a product of this information.

The source of this information will be a field survey. The system name is TOTARE, and the format is F7.0. 
Col. 46, Basement

The presence of a basement is noted by a (2) in col. 46; the absence is noted by a (1) in col. 46. This information gives insight into the number of floors and total square feet previously mentioned, since these include a basement if one exists.

The source of this information will be a field survey. The system name is BASMNT, and the format is I1.

Co1. 47-52, First Floor Area

The area of the first floor of the building in square feet is noted to indicate the land coverage of the building. This is an intensity of use indication, and will aid in determining land coverage by buildings.

The source of this information will be a field survey The system name is FSTARE, and the format is F6.0.

Col. 53-55, Number of Dwelling Units

The number of complete dwelling units (number of kitchens) that exist "his building are noted. This is an indication of residential inccm.ty of use and aids in determining traffic generation figures.

The source of this information will be a field survey. The system name is NODU, and the format is I3. 
Co1. 56-58, Building Setback

The number of feet that the building is set back from the front lot line; this is measured from the corner of the building closest to the front lot line, and measured perpendicular to the lot line. This information indicates the legality of the building location and possible interference with right-of-way activities.

The source of this information will be a field survey. The system name is SETBK, and the format is F3.0.

Co1. 59-61, Required Setback

The building setback requirements, as defined above, that exist for this parcel are noted here. This gives the legality of the actual setback.

The source of this information will be the zoning records. The system name is REQBK, and the format is F3.0.

Co1. 62-64, Rehabilitation Cost

The cost, in hundreds of dollars, of rehabilitating this building to a condition needing only upkeep maintenance. This information gives an indication of extent of blight and cost for rehabilitation.

The source of this information will be a field survey. The system name is RECOST, and the format is F3.0. 
Col. 65, Type of Building, Code Violation

The type of the most recent building code violation is coded here to indicate problem areas with this structure. This information will yield areas of potential blight and negligence of maintenance.

The source of this information will be the building inspector's records.

The system name is VIOL, and the format is II.

Co1. 66-67, Number of Code Violations

The total number of building code violations that have existed in this structure is coded here. This gives an indication of extent of violations that have existed and will aid in determining chronic maintenance problems. This will also be useful in determining potential blight.

The source of this information will be the building inspector's records.

The system name is NOVIOL, and the format is I2.

Co1. 68-69, Number of Establishments

The number of establishments that exist within this building is noted here. This is a bookkeeping item to indicate how many establishment data cards exist for this structure.

The source of this information will be a field survey. 
The system name is NOEST, and the format is I2.

\section{Card}

Co1. 1-14,

These columns contain data bank bookkeeping items which occur on every card. The explanation of these items can be found under the 01 card description.

Co1. 15-16, Building Location Key

Al1 buildings on a parcel are numbered consecutively, giving each building on the parcel a unique number. The Building Location Key is the number of that building in which this establishment exists. This information is used to uniquely locate each establishment.

The source of this information is internal to the system. The system name is BLDKEY, and the format is I2.

Col. 17-20, Establishment Location Code

All establishments within a building are numbered consecutively, giving each establishment a unique number. This number, along with the building location key and parcel number, is able to uniquely identify every establishment in the data system.

The present establishment number is placed in columns 19 and 20. If the establishment number has changed for any reason, the previous establishment number is placed in columns 17 and 18 . 
The source of this information is internal to the system.

The system name of the present location is NULOC; the system name of the previous location is OLOC, and the format for each is I2.

Col. 21-28, Space Use Code

The particular use that exists in this establishment is coded here. This tells specifically what type of activity exists in this establishment. This information will aid in traffic generation analysis and analysis of various types of activities on an area or number basis. The present space use will go in columns 25-28; the previous use will go in columns $21-24$.

The source of this information will be a field survey. The system name of the present use is NUSUSE: the system name of the previous use is OLSUSE, and the format for each is 14 .

Col. 29-32, Total Number of Employees

The total number of full time employees that are employed ty this establishment is noted here. This information will aid in traffic generation analysis, economic forecasting and employment analysis.

The source of this information will be the employment securities division. 
The system name is TOTEMP, and the format is I4.

Col. 33-36, Peak Shift Number of Employees

The number of employees working at this establishment during the peak shift (the shift requiring the greatest number of employees) is noted here. This information will aid in traffic generation computations, in parking demand determinations and economic evaluations.

The source of this information will be a field survey and the employment securities division.

The system name is PEAKEM, and the format is I4.

Col. 37-40, Optimal Total Employment

The number of people that this establishment would like to have employed under present conditions using existing facilities is entered here to determine to what extent more workers are needed in the study area.

The source of this information will be a field survey. The system name is OPTEMP, and the format is I4.

Col. 41-42, Number of Rooms for Rent

The total number of residential sleeping units for rent (that is a unit excluding kitchen, as in hotels, motels, or rooming houses) in this establishment is noted here. This information enables determination of residences, temporary 
and permanent, that would not be considered under the "dwelling unit" classification. This information will be useful in residence computations, economic analysis, and traffic generation computations.

The source of this information will be a field survey. The system name is NOROOM, and the format is I2.

Co1. 43-52, Number of Male Residents

The number of male residents residing in this establishment is noted here. This information will be used in population forecasting, work force determination and traffic generation computations. The population by age group is recorded as follows:

$\begin{array}{llll}\text { Column } & \text { System Name } & & \text { Age Group } \\ 43-44 & \text { MOT5 } & & 0-5 \text { years } \\ 45-46 & \text { M6T18 } & 6-18 \text { years } \\ 47-48 & \text { M19T25 } & 19-25 \text { years } \\ 49-50 & \text { M26T64 } & 26-64 \text { years } \\ 51-52 & \text { MGT64 } & \text { over } 64 \text { years }\end{array}$

The source of this information will be the Bureau of Census .

The format for each age group is I2. 
Co1. 53-64, Number of Female Residents

The number of female residents residing at this establishment is recorded here. This will be used in population forecasting, work force determination, and traffic generation computations. The population, by age group, is recorded as follows :

$\begin{array}{lll}\text { Column } & \text { System Name } & \text { Age Group } \\ 53-54 & \text { F0T5 } & 0-5 \text { years } \\ 55-56 & \text { F6T18 } & 6-18 \text { years } \\ 57-58 & \text { F19T25 } & 19-25 \text { years } \\ 59-60 & \text { F26T62 } & 26-62 \text { years } \\ 61-62 & \text { FGT62 } & \text { over } 62 \text { years } \\ * 63-64 & \text { F14T44 } & 14-44 \text { years }\end{array}$

*child bearing age, especially useful in population forecasting.

The source of this information will be the Bureau of Census .

The format for each age group is I2.

Co1. 65-67, Family Income

The total income of the family that resides at this establishment is recorded here in thousands of dollars. This information will be used in economic analysis, and traffic generation computations. 
The source for this information will be a field survey. The system name is INCOME, and the format is F3.0,

Co1. 68-69, Vehicles Owned

The total number of vehicles owned by the establishment (e.g. a business) or by residents of the establishment (e.g. a private home) is recorded here to aid in traffic generation computations. This figure would include all cars, trucks, and buses.

The source of this information will be vehicle registration records.

The system name is VEHOWN, and the format is I2.

Col. 70-71, Police Calls

The total numberof police calls made to this establishment during an update period (probably one year) will be recorded here to aid in determining police needs and help in crime research.

The source of this information will be the police records. The system name is POLCAL, and the format is I2. Col. 72-73, Fire Calls

The total number of fire calls made to this establishment during an update period (probably one year) is noted here to aid in determining fire protection needs and aid in fire hazard research. 
The source. of this information will be the fire department records.

The system name is FIRECAL, and the format is I2.

Col. 74, Welfare Payments

If welfare payments are made to this establishment a (2) is placed in column 74 ; if no welfare payments are made to this establishment a (1) is placed in column 74. This information will aid in welfare research and extent (on an area basis) of payments made.

The source of this information will be the city and county welfare records.

The system name is WELFAR, and the format is I1.

Co1. 75, Number of Communicable Diseases

The number of communicable diseases reported at this establishment during an update period (probably one year) is noted here. This information will aid in disease research and aid in determining the health characteristics of the study area.

The source of this information will be the city, county and state Boards of Health.

The system name is NODIS, and the format is II. 
Col. 76-77, Type of Communicable Disease

The type of communicable disease last reported at this establishment will be coded here to aid in disease research and give further insight into the health characteristics of the study area.

The source of this information will be the city, county and state Boards of Health.

The system name is DISEAS, and the format is I2.

Col. 78-80, Rent of this Establishment

The monthly rent paid for this establishment is recorded here to aid in determining the characteristics of the establishment, aid in deriving rental supply and demand, and help in economic analysis of the study area.

The source of this information will be a field survey. The system name is RENT, and the format is F3.0.

\section{Section B: Zone Name-Grid Coordinate File}

The Zone Name-Grid Coordinate File identifies the boundary of all zones in the system. Each data card contains the zone name and three coordinates (the first is mentioned twice). These three coordinates define a triangle which makes up part of the total zone. Each zone is broken up into triangles which exhaustively define the total area covered by the zone 
name and the coordinates for the triangle. There is only one kind of data card for the Zone Name-Grid Coordinate File.

Col. 1-12, Zone Name

The name of the zone being defined is entered or abbreviated into columns $1-12$. If an abbreviation is necessary because of the space available, then a catalog of these abbreviations should be made for further reference. This name, along with the zone number, uniquely identifies the zone. The name should start in column one with one space between each word in the name.

The source of the zone name and boundary will be dependent upon the type of zones being used (school, transportation, etc.)

The system name is $\mathrm{ZON}$, and the format is $2 \mathrm{~A} 6$ (ZON also includes zone numbers).

Col. 13-14, Left Blank

Co1. 15-20, Zone Number

The number of the zone being described is entered into columns $15-20$ This number helps uniquely identify each zone. If a zone (such as a township or city) has no number these columns are left blank. 
The source will depend upon the type of zone being entered.

The system name is $Z O N$, and the format is A6 (ZON also contains zone name).

Co1. 21-80, Boundary Coordinates

The coordinates of the vertices of the triangle are placed in columns 21-80. A parenthesis is used around each pair of coordinates with a comma between coordinate pairs.

$\underline{\text { Column }}$

21

$22-27$

$\mathrm{X}$-Coordinate of point one

28

$29-34$

Y-Coordinate of point one

Comma

35

36

Right parenthesis

Left parenthesis

37-42 X-Coordinate of point two

43

$44-49$

Y-Coordinate of point two

Comma

50

Right parenthesis

51

Left parenthesis

52-57 X-Coordinate of point three

Comma

$59-64$

Y-Coordinate of point three

58

\section{System Name Format}

$\mathrm{X}(1) \quad \mathrm{I} 6$

$\mathrm{Y}(1) \quad \mathrm{I} 6$

$X(2) \quad I 6$

$Y(2) \quad$ I 6

$X$ (3) $\quad$ I6

$Y(3) \quad I 6$ 
$\underline{\text { Column }}$

65

66
Data Item

Right parenthesis

Left parenthesis

67-72 X-Coordinate of point one

73

$74-79$

Y-Coordinate of point one

80

$$
\text { Right parenthesis }
$$

\section{Comma}

$x(4)$

I6

$x(4)$

I6

System Name Format

The source of this information is the coordinate digitizer and conversion to the base system.

\section{Section C: Parcel Number-}

\section{Grid Coordinate-Address File}

The Parcel Number-Grid Coordinate-Address File relates each parcel in the development area to a particular location (grid coordinate) and a particular street address. This file gives the system the facility of locating data for a parcel on a name or location basis. Each parcel in this file should have the same number as a parcel in the General Data File where the actual data is stored. There is only one type of card in the Parcel Number-Grid Coordinate-Address File.

Col. 1-6, Parcel number

The unique number which identifies this parcel is placed in columns 1-6. This number need have no logic attached to 
it, other than being unique - the parcel number in the General Data File which refers to this particular parcel should, of course, be the same.

The source of this number is internal to the system. The system name is PNO, and the format is I6.

Col. 7, Left Parenthesis

Co1. 8-20, Parcel Coordinates

The grid coordinates of the approximate centroid of this parcel are entered here. The X-Coordinate is placed in Columns 8-13. A comma is placed in Column 14. The YCoordinate is placed in Columns 15-20.

This information is obtained from the coordinate digitizer and conversion to the base system.

The system name for the X-Coordinate is XCOORD, for the Y-Coordinate it is YCOORD, and the format for each is I6.

Col. 21, Right Parenthesis

Co1. 22-28, Street Number

The street or rural route number of this parcel is entered into Columns 22-28. If the parcel is a street segment, the number of the block (in even hundreds) is placed in Columns 22-28 and a "B" is placed in Columns 29. In the case of a regular parcel, Column 29 is left blank. This 
number, along with the street name, gives a name tag to the parcel information.

The system name is ADDRES. (ADDRES also contains street name and type), and the format is A6.

Co1. 30-69, Street Name

The name of the street, as listed in the town directory is placed here. One column is placed between each word in the street name. If the address of this parcel is a rural route number, then "rural route" is placed here instead of a street name. A street'segment still has the name of the street entered into these columns. This name, along with the street number, block number, or rural route number will give a name tag to the parcel information.

The source of this information will be the town directory. The system name is ADDRES (ADDRES also contains street number and type), and the format is 7A6 (includes Col. 29).

Co1. 70-72, Street Type

The type of street, as listed in the street directory is coded here. Common entries here will be "Lane," "Street," "Path", etc. This information completes the street address as 1 isted in the directory and also completes the name tag for the parcel information. 
The source of this information is the town directory. The system name is ADDRES (ADDRES also contains street number and name), and the format is $A 3$. 
APPENDIX II 


\section{General Notes on Data Coding}

Whenever a data item is a number (e.g., police calls, rent, sale price, etc.) and this data has not been checked, that is, not yet entered into the systen, each colunn of this number should have a nine (9) punched to indicate that the iten has not yet been entered into the systen. Any code (e.g., Building Type, Foundation Type, etc.) not entered into the system would have a zero $(0)$ punched in the column.

If a numbered data item has been checked and the actual number is $9,99,999 \mathrm{etc}$, then enter one less than this number is entered to indicate that this is a verified entry (e.g., 99 would be entered as 98 ).

\section{Code So. 1-Land Use}

\section{Coc. Generalized Land Use Code}

Code

Description

0 Residential

00 Single Fanily fincluding detached, semi-detached, triple-attached and row, plus individual mobile homes)

01 Multi-Family (two or more dwellings in a single building, including apartments and residential hotels)

02 Rooning and Boarding Houses 


\section{Code}

\section{Description}

03 Membership Lodgings

04 Residence Halls and Dormitories

05 Retirement Homes, Orphanges and Religious Quarters

06 Seasonal Housing (including sunner cottages and farm labor camps)

07 Nobile Hone Parks or Courts

08 Hotels, Motels and Tourist Acconanodations

09 Other Residential

\section{Industrial}

11 Sanufacturing and Processing

12 Research and Testing

15 Wholesale, Warehousing and Storage

14 Contract Construction

19 Other Industrial

2 Utilities (operating facilities not including offices)

21 Electric Utility

22 Gas Utility

23 Water Utility

24 Sewage Utility

25 Solid Kaste Disposal

26 Telephone and Telegraph Comnunications

27 Radio and Television Comnunications

29 Other Utilities 
Code

Description

3 Transportation

30 Railroad

31 Rail Rapid Transit

32 Bus and Streetcar

33 Taxi

34 Notor Freight Transportation

35 Street and Highway Rights of Way

36 Automobile Parking

37 Air

38 Marine

39 Other Transportation

4 Consumer Services

40 Stores

41 Shopping Centers.

42 Gas Stations, Auto Repair, Automobile Dealers and Auto and Truck Rentałs

43 Repair Services (not auto repair)

44 Personal Services

45 lating and Drinking

46 Nedical and Dental C1inics, Centers, and Laboratory Services

49 Other Consuner Services

5 offices

$\$ 1$ Comnercial offices

52 Professional and Irade Associations

53 Institutional offices 
Code

Description

54 Federal Government Offices

55 State and Local Government offices

56 Foreign Governments and International Organizations including embassies, chanceries, etc.

59 Other Offices

6 Public Services

60 Cemeteries

61 liospitals

62 Nursing Hones

63 Other llealth Facilities (except Clinics)

64 Police stations

05 Fire and Rescue Stations

66 Correctional Institutions

67 Military Installations

68 Welfare and Charitable Services

69 Other Public Services

7 Cu1tura1, Educational and intertainment Services

70 Churches, Synagogues, and other places of worship

71 Civic, social and fraternal associations

72 Libraries

73 Permanent exhibitions, including museums, art galleries, monuments, planeteria, aquariuns, and urban historic sites

74 Places of public assembly, including theaters, stadiuns, auditoriums and exhibition halis

75 Nursery Schools 
Code Description

76 Elementary Schools

77 Secondary Schools

78 Colleges and Universities

79 Coanercial Schools

Parks and Recreation

80 Indoor recreation, including recreation centers, indoor swiming, gyanasiuns, ice and roller skating rinks, bowling, and penny arcades

81 Outdoor Anusenents, including fairgrounds, race tracks, go-cart tracks, miniature goif, golf driving ranges, and amusenent parks

82 Private outdoor Recreation, including tennis, swimming, country clubs, and yachting clubs, limited to nembers and guests

$\$ 3$ Commercial Outdoor recreation, including resorts, riding academies, ski runs, organized camps, and marinas

84 Public Golf Courses

85 Play lots, playgrounds and playfields

86 Parks- leisure and ornamental

87 Parks-General recreation, including individual camping and picnicing as well as areas for the preservation and enjoynent of nature, including zoos, botanical gardens, arboretums and national parks

88 Outdoor Courts and pools open to the public (tennis, basketball, swinning, etc.)

$\$ 9$ Other Parks

9 Resource Uses and Undeveloped Areas

90 Agriculture

91 Agriculture Related Activities 
Code

Description

92 Forestry Activities and Related Services

93 Mining Activities and Related Services

94 Permanent Conservation Areas

95 Other Resource Production and Extraction

96 Undeveloped and Unused Land Area

97 Water Areas

98 Vacant Floor Area

99 Under Construction

\section{Code No. 2-ownership}

Code

Description

Private

100 Individua 1

110 Condominium

120 Cooperative

130 Partnership

140 Corporation, Profit

150 Corporation, Limited Dividend

160 Corporation, Non-Profit

170 Unicorp Organization

180 Trust

190 Other or unknown type of private ownership 
Code

Description

Townships

310 Tippecanoe

320 Washington

321 Penny

322 Fairfield

323 Sheffield

324 Lauranic

325 Randolph

$326 \mathrm{Jackson}$

327 Kayne

328 Union

329 Kea

330 Wabash

331 Shelby

Municipalities

410 Lafayette

420 West Lafayette

430 Co1burn

431 Americus

432 Battle Ground

433 Nontmorenci

434 Buck Creek

435 Monitor

436 Pettit

437 Shadeland 
Code Description

438 Dayton

439 West Point

440 Ode 11

441 Concord

442 Stockwel1

443 Monroe

444 Clarks Hill

445 Romney

446 otterbein

Special Districts

510 School Board

520 School Board

etc.

State Government

610 Indiana

611 Purdue

Federal Government

710 United States

Code No. 3-Easement Code

Code

Description

1 Scenic Easement

2 Utility

3 For Recreational Trails or Access to Recreation 
Code

Description

9 Other Easenents

Code No. 4-Landmark Code

Code Description

1 Historical Significance

2 Unusual Architectural Merit

3 Both

\section{Code No. 5-Neighborhood Characteristics}

Code

Description

4 Less than 105 blight

3 10-20s blight

2 20-50s b1ight

1 Greater than 50 s of neighborhood blighted

Code No. 6-Land Appearance

Code

Description

9 We11 landscaped, no maintenance required

7 Cood landscaping, some maintenance and/or clean-up needed

5 Fair landscaping, considerable maintenance and/or clean-up needed

3 Poor or no landscaping, extensive naintenance, clean-up and grading needed to inprove the land 


\section{Code No. 7-Zoning Code}

Code

Description

1 Agriculture " $A$ "

2 Glood Plain Districts FP

3 Forestry Conservation Districts FC

4 Residential Low Density RI

5 Residential Mediun Density R1A

- Residential High Density R1B

7 Residential Medium and 2 Family $R 2$

8 Residential Multiple Fanily R3

9 Residential All Types R4

10 Acconmodations Business $\mathrm{AB}$

11 Local Business LB

12 Local Business Filling St, LBS

13 General Business GB

14 Centra1 Business CB

15 Shopping Center SC

16 Industrial Districts 1

17. Industrial Reserve Aid IR

\section{Code No. 8-Comprehensive Plan Use Code}

Code Description
01 Agricultural
02 Low Density Residential
05 Mediun Density Residential
04 High Density Residential 
Code

Description

05 Conmercial, (CBD and Neighborhood Shopping Districts)

06 Industrial (Mfg., Reserve)

07 Industrial Research

08 Public and Quasi Public (Schools, Parks, Recreation and 0 ther)

09 Purdue

10 Flood Plain

11 Wildcat Reservoirs

\section{Code No. 9-Water Systen Code}

Code

Description

1 Public Water Systen

2 Private Water System

9 No Water System

Note: Definition of water system is water provided from an off parcel source.

\section{Code No. 10-Sewer System Code}

Code

Description

1 Private Sanitary Sewer Systen, no Storm Sewer

2 Private Sanitary Sewer System, and Storm Sewer

3 Public Sanitary Sewer System, No Storm Sewer

4 Public Sanitary Sewer System, and Storn Sewer Separate

5 Public Sanitary Sewer and Storm Sewer, Combined

9 No Sanitary or Storn Sewer System.

Note: A private system is defined as one owned and operated by any persion, group or corporation other than a city, municipal, county, state or federal government. 


\section{Code No. 11-Functional Street Class Code}

Code

Description

1 Loca1, Two Way

2 Collector, Two Kay

3 Minor Arterial, Two Way

4 Major Arterial, Two Kay

5 Expressway

6 Local, One Kay

7 Collector, One Nay

8 Minor Arterial, One Way

9 Najor Arterial, One Way

\section{Code No. 12-Structural Conposition}

Code

Description

1 Grave 1

2 Asphalt, Soil Cement Base

3 Concrete, < 8" Thick

4 Concrete, $\geq 8$ " Thick

5 Asphalt, Brick Base

6 Asphalt, Concrete Base

7 Asphalt, Sand and Gravel Base

8 Brick

9 Asphalt, No Formal Base 


\section{Code No. 13-Traffic Control Signs and}

Signal Codes

Code

Description

1 Stop Sign

2 Yield Sign

3 Traffic Light (red, yellow, green)

4 No Right Turn

5 No Left Turn

6 No Turns

7 One Kay

8 Parking Regulations Sign

9 Traffic Light, Flashing Blinker

0 Route Signs

Code No. 14-Curb Parking Regulations Code Code Description

1 No Parking

2 Parking $1 / 2$ Hour or Less

3 Parking 2 Hours or Less

4 Parking No Restrictions

5 Bus or Taxi Stop

6 Fire Zone

7 Parking Metered, Less than $1 / 2$ Hour

8 Parking Metered, Longer than 1/2 Hour.

9 No Parking, Standing or Stopping 


\section{Code No. 15-Curb Type Code}

Code

Description

1 Concrete Sloping Mountable Curb

2 Concrete Rectangular Mountable Curb (1ess than $5^{\prime \prime}$ high)

3 Concrete Rectangular Barrier Curb (greater than $5^{\text {" }}$ high]

4 Asphaltic Curb

9 No Curb

\section{Code No. 16-Sidewalk Code}

Code

Description

I Commercial Sidewalk One Side, No Sidewalk Other Side

2 Commercial Sidewalk One Side, Residential Sidewalk other Side

3 Comnerical Sidewalk, Both Sides

4 Residential Sidewalk One Side, No Sidewalk Other Side

5 Residential Sidewalk Both Sidos

9 No Sidewalks Either Side

Note: A commercial sidewalk is defined as greater than six feet in width.

\section{Code No. 17-Access Contro1}

Code

Description

1 Partial Control of Access

2 Ful1 Control of Access

9 No Access Control 
Code No. 18-Roadway Condition Code

Code

Description

9 Very Good Condition, Little or No Maintenance Required

7 Good Condition Some Light Maintenance Required

5 Fair Condition, Considerable Naintenace Required

3 Poor Condition, Extensive Maintenance Required

1 Very Poor Condition, Reconstruction and/or Resurfacing Necessary

\title{
Code No. 19-Foundation Construction Code
}

\author{
Code \\ 1 Concrete \\ 2 Stone \\ 3 Brick \\ 4 Concrete Block \\ 5 Piers
}

Description

\section{Code No. 20-Frame Construction Code}

Code

Description

1 Wood Frame

2 Brick

3 Stone

4 Concrete

5 Aluminum

6 Metal, Steel Sk1t., Joist 


\section{Code No. 21-Siding Code}

Code Description

1 Common Brick, Face Brick, Glazed Tile, Tile, Stone

2 Concrete

3 Stucco

4 Aluninun Siding

5 Siding, Shingles, Other Than Kood or Aluninun

6 Wood Siding, Shingles

7 Metal

8 Glass

2 Concrete Block

\section{Code No. 22-Roof Code}

Code

Description

1 Composition

2 Asphalt Shingle

3 Metal

4 S1ate

5 Tile

6 Tin

7 Tar and Grave1

8 Wood Shingles

9 Rolled Roofing 
Code No. 23-Type of Structure Code

Code Description

10 Detached Building (free standing)

11 Attached Building (at least one wall in comnon with another building)

20 Poles

21 Lines, Power, Telephone, Telegraph

22 Tower

23 Pipelines

24 Tank

31 Piers, Wharf

31 Trestle

40 Fence

41 Wal1

42 Signs, Billboards, and Other Outdoor Advertising Structures

50 Platform

51 Drying Bed

52 Swimming Pool

60 Arcade

70 Pavenent

80 Open Structure (Spectator Stands, Outdoor Theatres, storage)

90 Other Structures, N.E.C. 
Code No. 24-Building Condition Code

Code

Description

9 New Building, No Maintenance Required

7 Good Building, Ninor Naintenance Needed

5 Fair Building, Sone Maintenace Neoded

3 Poor Building, Extensive Naintenance Needed

1 Dilapidated Building, Reconstruction May Be Warranted

Code No. 25-Type of Building Code Violation

Code

Description

Not available at present tine due to small anount of information available.

\section{Code No. 26-Space Use Code}

Code

Description

See Standard Land Use Coding Manual by HHFA and BPR.

Use the four (4) digit code.

Note: Instead of Code 6813 representing secondary schools let Code $68: 3$ represent funjor high schools, let Code 6814 represent senior high schools.

Code No. 27-Type of Communicable Disease

Code

Description

01 Anebiasis

02 Aseptic Meningitis

03 Bruce11osis

04 Chickenpox 


\section{Code}

Description

05 Diphtheria

06 Dysentery, Bacillary

07 Dysentery, Unspecified (Amebic)

08 Encephalitis

09 Helninthic Infestations

10 Inpetigo

11 Infectious Hepatitis

12 influenza

13 Neasles (Rubeola)

14 Meningococcic Infections

15 Meningitis, other

16 Mumps (1nfectious Parotitis)

17 Pertussis

18 Pnoumonia

12 Rabies in Animals

20 Rhoumatic Fever

21 Rebe11a (German Measles)

22 Salmonellosis, Other Than Typhoid

23 Scarlet Fever

24 Streptococcic Sore Throat

25 Tinea Capitis (Ringworm of the Scalp)

26 Tularenia

27 Typhoid Fever

28 Anthrax

29 Botulisn 
Code

Description

30 Cholera

31 Conjunctivitis (Pink-eye)

32 Eastern Equine Encephalonyelitis

33 Gonococcal Ophthalnia

34 Gonococcal Ophthalmia Prophylaxis

35 Histoplasmosis

36 Infectious Jaundice

37 Infectious Mononucleosis

38 Malaria

59 Meningococcenia

40 Influenzak

41 Pneumococcal

42 Streptococeal

43 Syphilitic

44 Tuberculosis

45 Viral (Aseptic)

46 Meningococeic Meningitis

47 Ophthalmia Neonatorum

48 Gonococcal

49 Pediculosis (Lousiness)

50 Pertussis (Whooping Cough)

51 Poliomyelitis

52 Prophylaxis Ophthalmia Neonatorum

53 Psittacois

54 Q Fever 
Code

\section{Description}

55 Rheumatic Fever

56 Rocky Mountain Spotted Fever

57 Scabies

58 Silver Nitrate Prophylaxis, Ophthalmia Neonatorum

59 Snallpox

60 Tetanus

61 Trachona

62 Trichinosis

63 Tulareaia

64 Typhoid Fever

65 Typhoid (Endericlflea-borne] and Epidenicllouseborne])

66 Venereal Disease

67 Western Equine Encephalonyelitis

68 Syphilis

69 Granuloma Inguinale

70 Gonorrhea

71 Lymphopathia Venereum

72 Chancoid

73 Ophthalmia Neonatorum (of gonococcal etiology)

74 Erysipelas

75 Yellow Fever

76 Lyaphocytic chorioneningitis

77 Animal Bites 


\section{Code No. 28-Street Type}

Code

Description

ST Street

L.N Lane

B1.V Boulevard

PTH Path

AVE Avenue

DR Drive

CT Court

RD Road

TR Trail

CR Circle

TER Terrace

PL Place

Note: A north, south, east or west designation is coded by preceding the street name by an

$\mathrm{N}, \mathrm{S}, \mathrm{E}$ or $\mathrm{W}$ respectively; followed by one biank space.

Code No. 29-Transaction Code

Code

Description

1 First piece of data on card has been changed

2 Second piece of data on card has been changed

3 Third piece of data on card has been changed

4 Etc.

98 General, but incosplete, update. Xore than one piece of data has been changed but not all data has been exanined for its present accuracy

99 General update, all data on the card has been made current 
APPENDIX III 


\section{APPENDIX III}

\section{PROGRAM DESCRIPTION AND LISTING \\ Progras 1: Initialize the Parcel Number - \\ Grid Coordinate-Address File}

This program reads the data cards for this file and places the data on tape. The tape to be used must be specified in the control cards for the program. Once this program has been used to initialize the file, any operation can be performed on the data. Sample data follow the main body of the program. 
PROCipan 1

INITIALIZE PARCEL NUNBER - GRID COORDINATE - aDOEESS FILE

$36=6$, Warken.

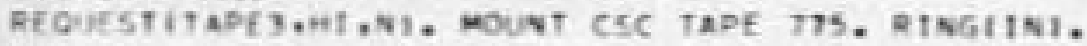
Rusisi.

167.

PMOCRAN COORIINPUT , OUTPUT.

1 TADES + INPUT . TAPE 6*OUTPUT . TAPE3)

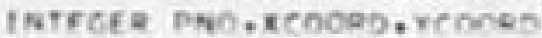

Dincsion sonefsion

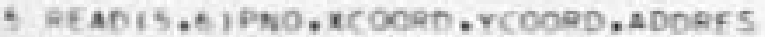

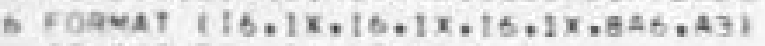

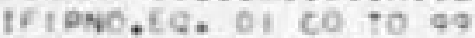

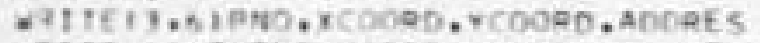

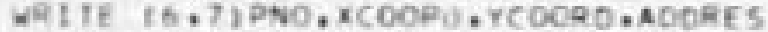

7 foamat $(5 x+16 \cdot 1 x+13 \cdot 1 x+16 \cdot 1 \times \cdot 846 \cdot 43)$

rio 10.

99 controut

ENO EILE ?

atwiNo 3

$F+10$

$999(444646,555555) 947654$ to00 6665558777777 , ABA

$1191111111,273727)$

IIT JENNTFER 
Program 2: Read more information for the Parcel Number-Grid Coordinate-Address File

This program reads data cards and adds this information to an existing Parcel Number-Grid Coordinate-Address File. This program can be used as more parcels are digitized; it eliminates the necessity of initializing the entire file at one time. Sample data follow the main body of the program. The tape used for the file must be noted on the program control cards. 
PROGRAN 2

DEAD WOAE INFOENATION FOQ PARCEL NUNAER - GRID COOEDTNATE - ADDRESS FILE

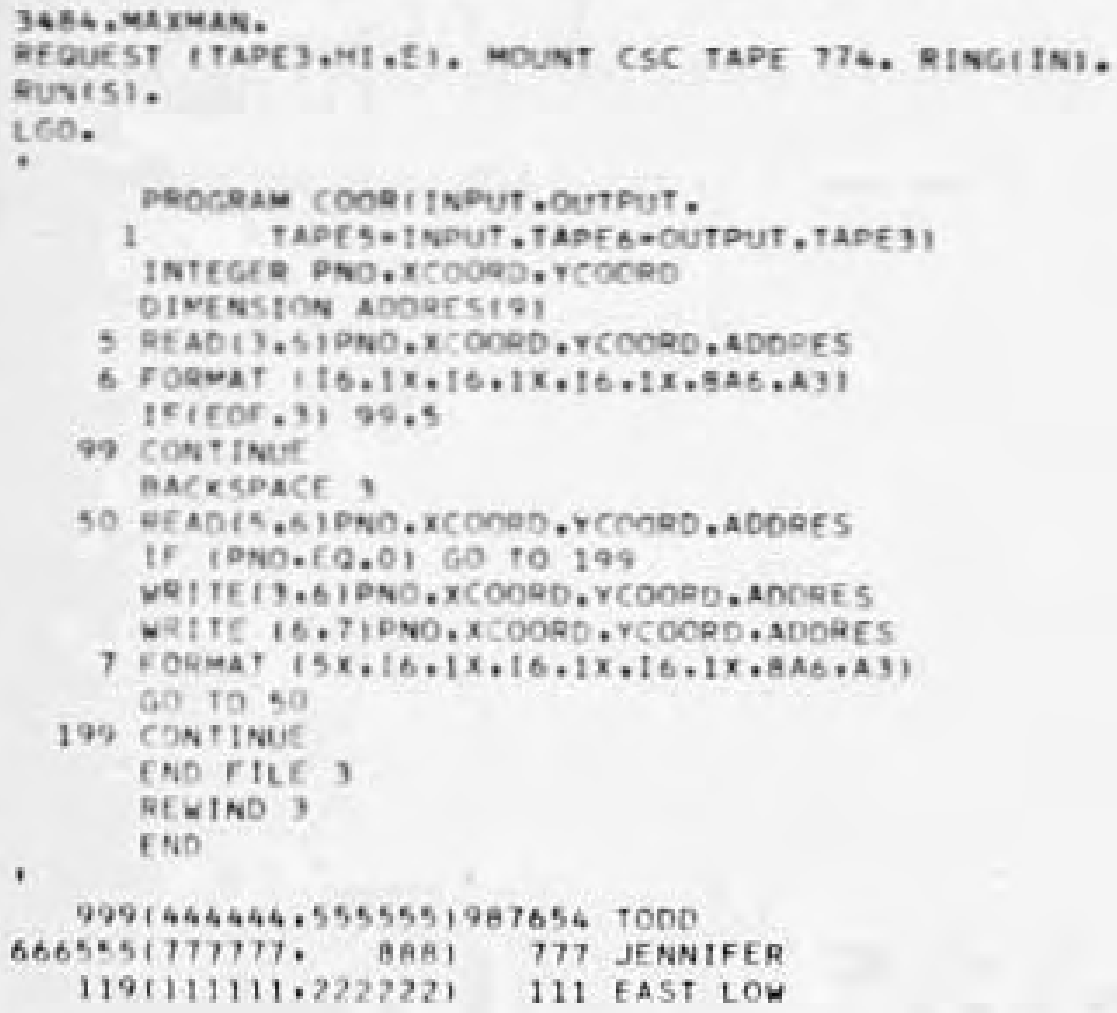


Program 3: Initialize the General Data File

This program reads data cards for the General Data File and then writes this information on tape. The tape number must be specified in the control cards for the program. After the information has been put on tape by this program, the data are ready to be utilized by the other programs. Sample data follow the main body of the program. 
DARTIRAM 3

INITIALIZE GENERAL DATA FILF

3656, vaxmav, 070000 .

REQUFSTtTaDEI,HI, Ni, HOUNT CSC TADE 774. RINGITNI. Duntsi.

t.6.

peocinan mativitinfut, OutPut.

1 TAPES-1NDUT, TAPES-OUTPUT , TAPE1 1

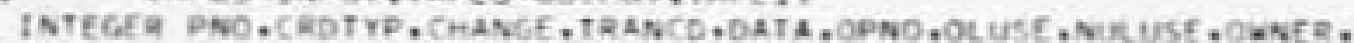

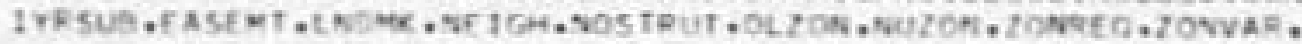

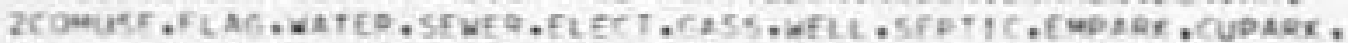

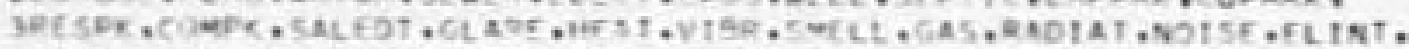

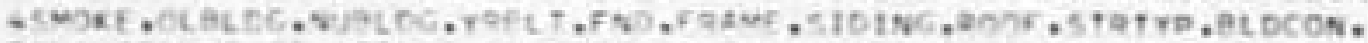

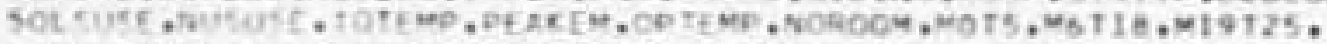

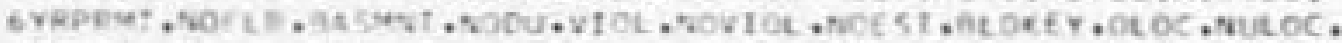

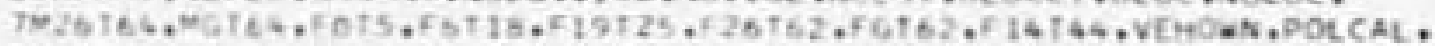

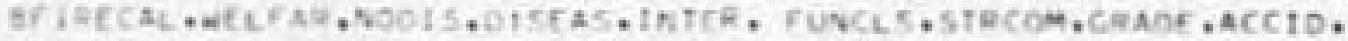

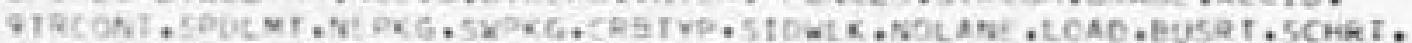

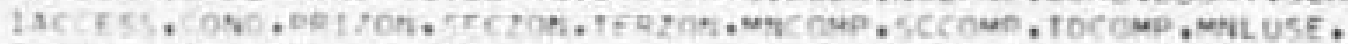

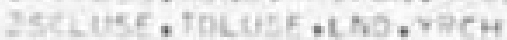

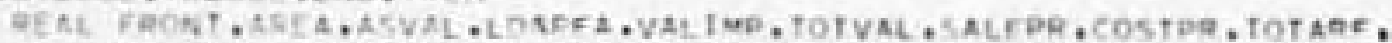

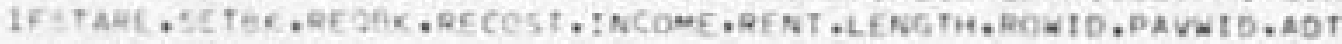
aturnetos CAtati

5 FIAB IS.E) PNO,CADTYP, CHANGE, TRANCD, DATA

6 roamat $116,12,16,12,6.210,461$

II I COPTYB eEg. It no to 3

if ichotra eER. 21 ro to 17

II I CaDtrp efo. 3) 60 T0 27

If ICROTYo. EQ. 4 ) 60 to 37

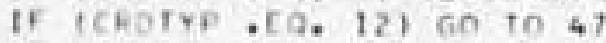

if ICROTYO.ED, 11) 00 to 57

II I cantre,E0.99) 60 to 99

on to 6.7

3 cantinut

7 DECODE $16 B$, A, DATAIOL PNO . OLUSE, NULUSE, OWRER, FRONT, AREA , YRSUA, ASVAL

I.EASTNT, LADMF, NE IGH, LND, NOSTOT, YRCH, OLZON, NUZON,ZONREQ,ZONVAR.

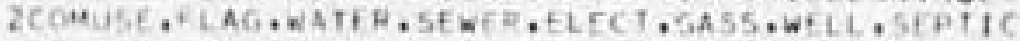

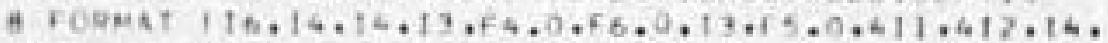

$116,12+711 x$

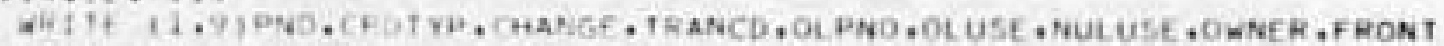

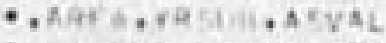

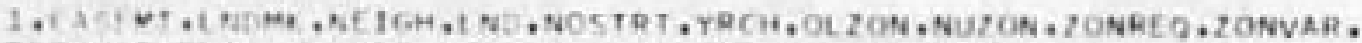

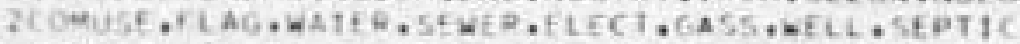

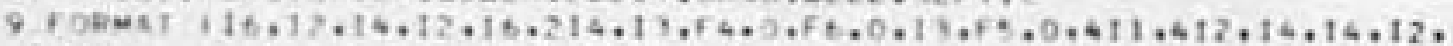

$17+1)$

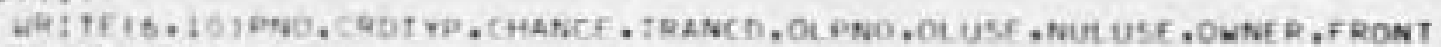

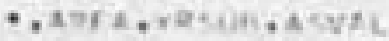

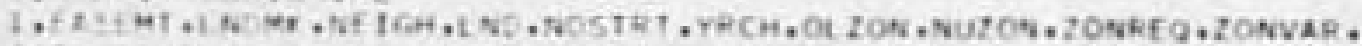

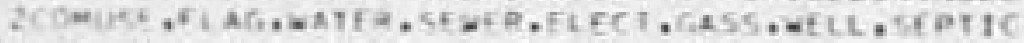

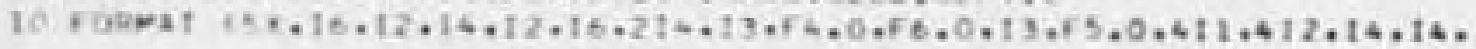


peogran 3, CONTINUEO

\section{$1+2,7111$}

60 10 5

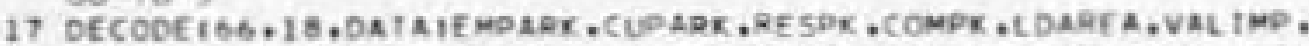
1 TOTVAL, SALEDT, SALEPR, CLAQE, HEAT, VIER, SNELL, 5AS, NAOIAT, NOISE, 2ELINT, SUaces

19 Foesat $\{616,53,0,2 F 5.0,12.55 .0 .9111$

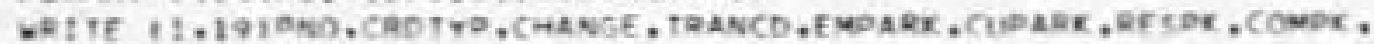
- bapra, valimo,

ITOTVAL, SAL FDT, KAL FPR, GL ARE, NEAT, VIED, SMETL, CAS, NAOTAT, NOISE. zELINT. SwoKE

19 Foevat it $16,12,16,12,616,53,0,255 \cdot 0,12,55,0,9111$

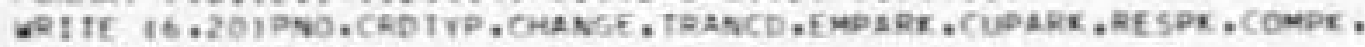
- Daefa, valime,

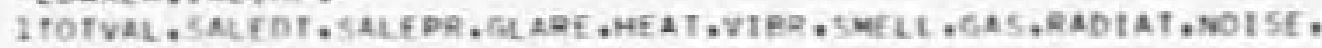

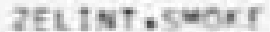

20 foevat $15 x+16,12,14,12,416,73 \cdot 0,255,0,12,55,0,9111$ 50 to 5

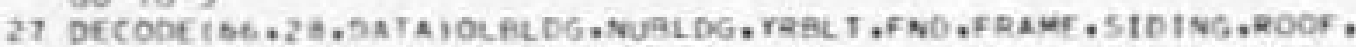

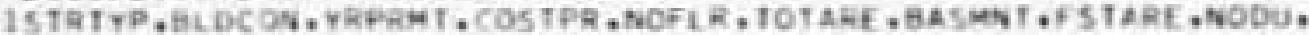

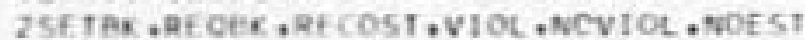

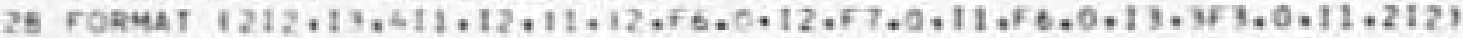

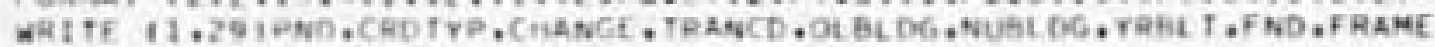
- sintwinanoor.

ISTATYP, AL DCON, YRPRMT, COSTPR, NOFLR, TOTARE, AASNENT , FSTARE, NODU, 2SETEK, RFOBK, RECOST, VIOL, NOVIOL, NOEST

29 format $116,12,16,12,212,13,611,12,11,12,56,0,12,57,0,11,56,0,13$. $\cdot 353 \cdot 0,11,2121$ WRI TE 16,301 PNO, CRDTYP, CHANGE, TRANCD, OLBL OF, NUUAL DG YRALT , F ND, FRAME - stoing, Hoor. ISTRTYP, ALDCON, YRPRMT, COSTPR, NOFLR, TOTARE, BASMNT, F STAHF, NODU. 2SE TAK, AE GEK, RECOST, VIOL, NOVIOL, NOEST

30 FORMAT $15 x, 16,12,14,12,212,13,411,12,11,12,56,0,12,57,0,11,56,0,13$

$\because$, $35,0,11,2121$ 60 To 5

37 DECOOE 166,95 .DATAIELDKEY,OLOC.NULOC,OLSUSE, NUSUSE, TOTEMP. IPF AKEM, OPTE UP, NCROOM, UOT5, N6T18,M19T25, M26,T64, MGT64,FOT5, F6T18. $2 F 19 T 25, F 26162, F G 162$, F $14 T 44$, INCOME, VEHONN, POL CAL, F TRECAL, WELFAR, 3 MODTS, DISEAS, RENT

39 FORMAT $1312,414,1212,53,0,312,211,12,53,01$ WRITE $11.39,1$ NO . CRD TYD, CHANIE, TRANICD, BLDKFY, OL OC. NULOC, OL SUSE, -NUSUSE, TOTEMP. IPEAKEM, OPTEMP, NOROOM, MOT5, MBT18, M19T25,M26T64, MGT64,FOTS, FGT1A. $2 F 19125, F 26762,76 T 62$, F14T44, INCOME, VEHOWN, POLCAL, FIRECAL, WELFAR, $3 N O 0$ IS , DISEAE, QRENT

32 foMmat $116,12,14,12,312,514,1212,53,0,312,211+12,53,01$ WRTIE $16.40 I P N O$, CRD TYP. CHAMGE, TRAKCD, ELOKEY,OLOC, NULOC, OL SUSE, -wususe, totems.

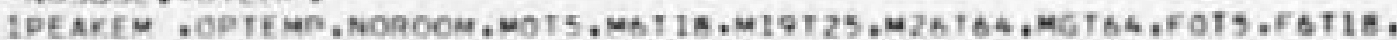

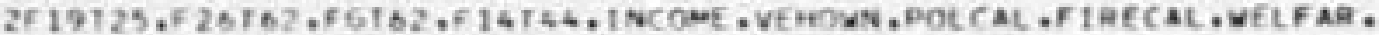
$3 N 0015,015 E A 5$, RENT

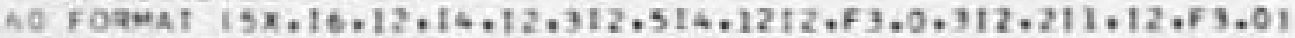
60 to 5 


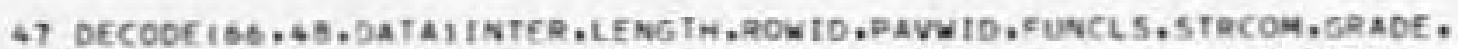

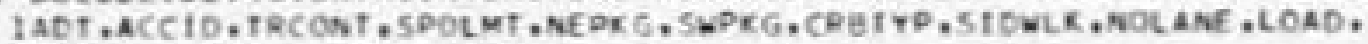
zausat o 5 CHet a ACESS, COND

49 roemat $111,54.0 .253 .0 .311,55.0 .12,14.12+10111$

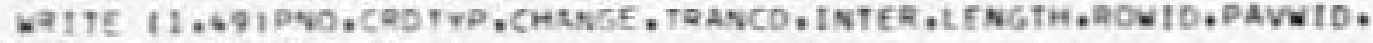
-FunCL 5 , stacon, cikabe.

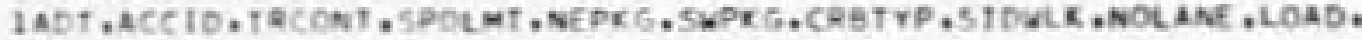
zEUSOT, ECHET a ACESS, COND

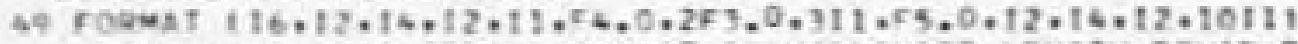

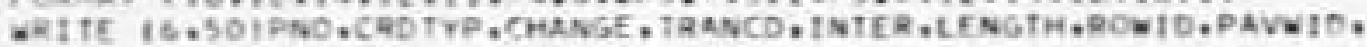

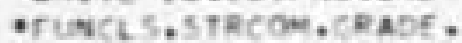

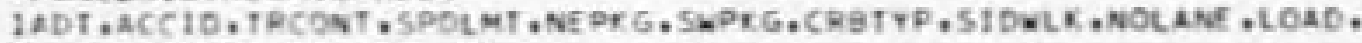
zeuset, scret a access + cond

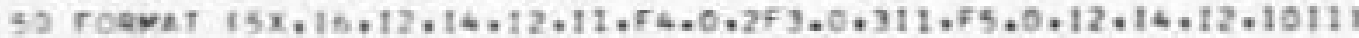
60 Te 5

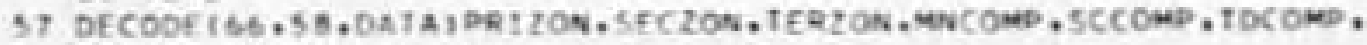
Iuveuse, sclukf, toliker

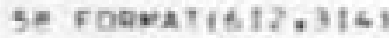

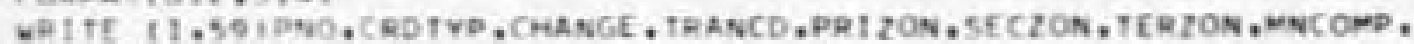
- sccont, tocons. imuluse scluse, toluse

So FOPNAT $116,12,16,12,612,3161$

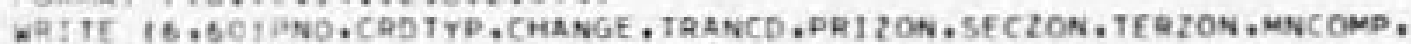
- ecCONP, TOCONP. IMra use. SCLuSe, TDLuSE

SD FORNAT $15 x, 16.12 \cdot 14,12.612,314)$ Go 109

67 WRTTE 16.691 PNO

68 FDRMAT IIIH PARCEL NO , $16,61 H$ HAS A DATA CARD WITH AN INCORRECT NU IMAER)

60705

99 CONTtNuE: END FILE 1 REWIND 1 END

1501000000000000000000110012345678901234567890123456789012345678901234567890 1502000000000000000025 A ABA $1234567890123456789012345+789012345678901234567890$ $1101000000000 n n 0000000110012345678901234567890123456789012345678901234567890$ 99 


\section{Program 4: Read more information for the General Data File}

This program reads data cards and adds the information to the existing General Data File. This program can be used as information is assembled for additional parcels. This enables the General Data File to be initialized in stages so that the data file can be checked as initialization takes place. Sample data follow the main body of the progras. The tape used for the file must be noted on the program control cards. 


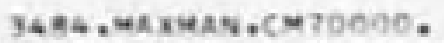

EEQUESTITAPEI.41,NI.MOUNT CSC TADE 776. RTNGIINI. BuNisi.

160.

DROCRAN MatNithPut, OUTPUT.

1 TADES NINDUT, TADF 6 =OUTDUT, TADF 11

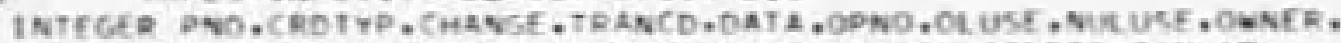

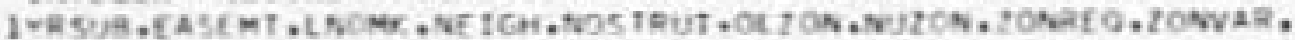

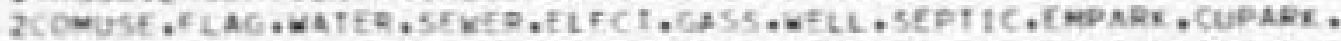

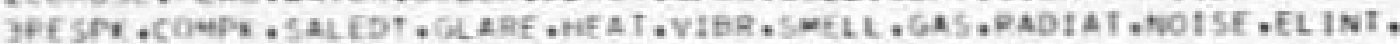

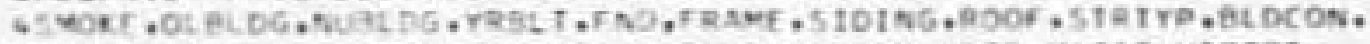

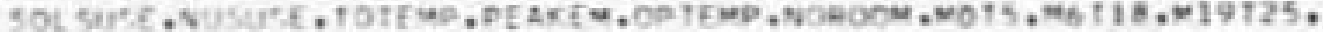

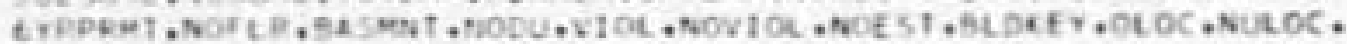

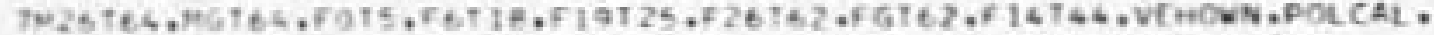

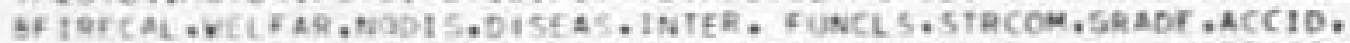

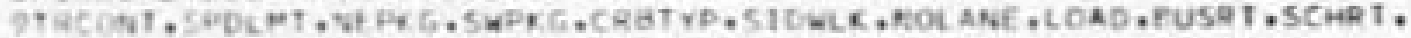

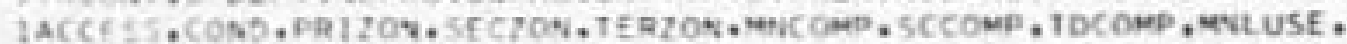
2 iscluit, toluse, No, rech

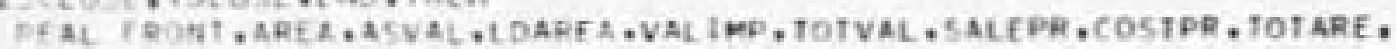

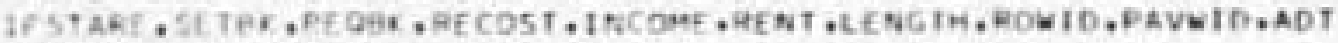
DivrsitinN DATAI?

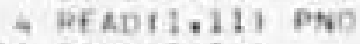

11 F OBNatif 161

if trat, 1112,6

12 CONTINUL

BACKSPACE 1

5 READ $(5,6)$ PNO, CRDTYP. CHANGE, TRANCD,DATA

6 FORMAT $116,12,16,12.0 \mathrm{~A} 10 . \mathrm{AB})$

IF I CADTYP ofO. 11 GO TO 3

If iruntYo.ED. 21609017

IF I CAOTYR .EO. 3160 TO 27

If ICROTYP. EQ. 4) GO TO 37

If ICPOTYP. EQ. 121 GO TO 47

If ICNOTYP. EQ. 111 GO TO 57

IFICHOTYP. FQ.99)60 TO 99

60 to b?

3 continie

7 DFCOOE 1 B6, B, DATAIOL PNO, OL USE, NUL USE, OWNER , FRONT, APEA, YR SUE, ASVAL

1. FASEMT + LNOMK, NE TGH, LND, NOSTRT, YHCH,OLZON, NUZON , ZONREO .ZONVAR,

ZCOAUSE, FLAG, WATER, SEMER, ELECT, GASS ,WELL, SEFTIC

a Foevat $116,14,16,13,54,0,55,0,13,55,0,411,4,12,14$.

$114,12,7111$,

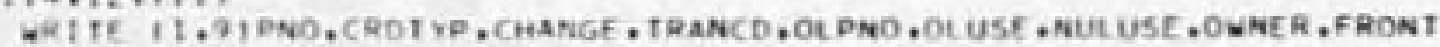

D,AERZ,YRSUA , ASVAL.

I, HASEMT , LNDWK, NEIGH, ND, NOSTRT, YRCH, OL ZON, NUZON, ZONAEO, ZONVAR.

ZCOWUSE, FLAG , WATER, SEUER, ELECT, CIASS , WELL, SEDT TC

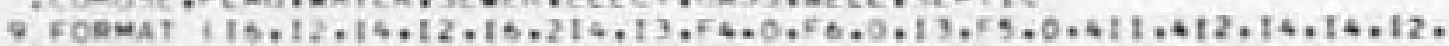
17111 
PFOCRAM 4 . CONTINUFD

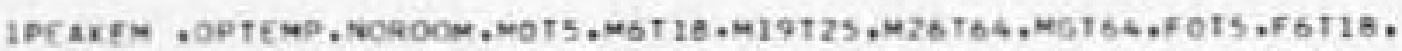
2F19T25, F26T62, FGT62, F16T44, INCONE, VFHOWN, POLCAL of IRECAL , WELFAR.

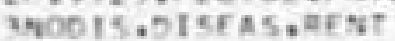

40 roput $15 x+16,12 \cdot 16,12 \cdot 312,516,1212,53 \cdot 0,712,211+12,53 \cdot 01$ co 10.5

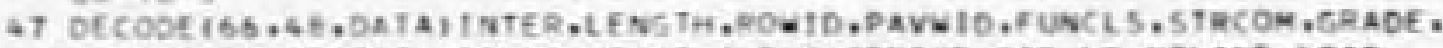

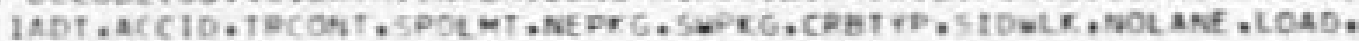
zeuspt, sriat, access, cont

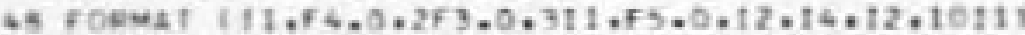

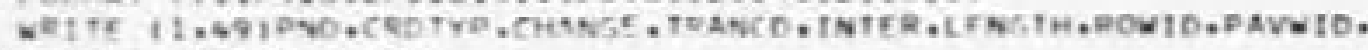

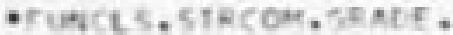

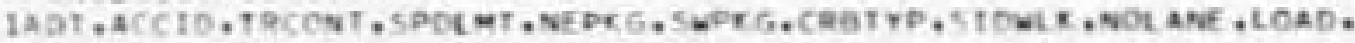
2 Fus at, sCheit, acCFss, COND

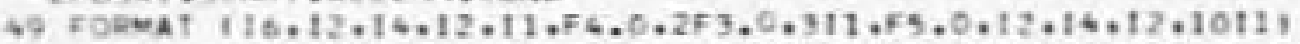

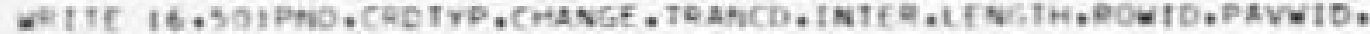
- runclsotincon, coabe.

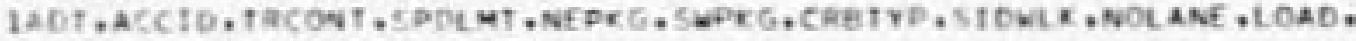

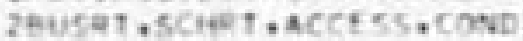

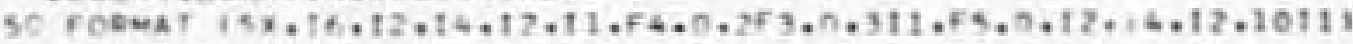
(6) 10,5

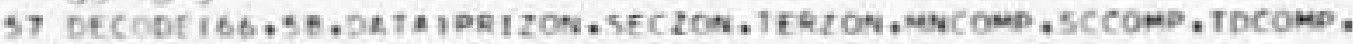
INEL USF, SCLULE, TOLUSE

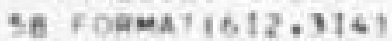

WRTTE I1.59IDNO.CNDTYP, CHANGE, TRANCD,V IZON, SECZON, TEGZON, MNCOMP.

- icconp. tocomp.

IMNLUEF, STLUEF, TDLUSE

59 FODAA I I $16,12,14,12,512,3141$

WRITE 16.603 PNO, CPDIYP, CHANGE, TRANCD, PRIZON, SECZON, TERZON, MNCOND,

- scCOAP, TOCOMO.

IMNI USE, SCLUSE, TDLUSE

60 Fopuat $15 x, 15,12,14,12,6 \pm 2,314)$

60 10 5

67 WR: If 16,6 . A IPNO

6A FORMA! IIIH PARCEL NO 16.41 H HAS A DATA CARD WITH AN INCORRECT NU IMHF Q) 60 to 9

99 CONIINUE ENO TILE I AENTRB 1 END

$00000101000000000000000 n+00010000900008109600543162543136563246220000045431100$ 00000102012345674901274567890123456789012345678901234567000 onnooin4012345674901234567890123456749012345678901234567001234567890123456780055 99 
Program 5: Initialize the Zone NameGrid Coordinate File

This program reads the data cards for this file and writes the information on tape. The tape to be used must be specified on the control cards for the program. Once this program has been used to initialize the file, any operation can be performed on the data. Sample data follow the main body of the program. 
34 et. MAXMAN.

PROGRam s

REQUESTITADE2,HI, NI. MOUNT CSC TAPE 7TL. RTNGTINI.

Ruvist.

L6.

.

GROCANE TONIINPUT, OUTPUT,

1 TADES * INPUT , TAPE 6*OUTPUT + TAPE2I

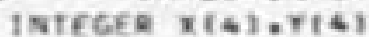

DIMENStON zON(4)

RENTNO 2

5 READts, $6120 \mathrm{~N}, \mathrm{x}(1), \mathrm{rt} 1 \mathrm{1}, \mathrm{x}(2), \mathrm{r}(2), \mathrm{x}(3), \mathrm{r}(3), \mathrm{x}(6), \mathrm{Y}(6)$

6 ropmat $1246,42,26,1 x+16,1 x, 16,2 x+16,2 x, 16,2 x, 16,1 x, 16,2 x, 16,1 x+16)$ if $\{x \in 2\} \cdot\{0.0) 60$ to 99

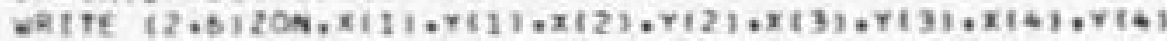

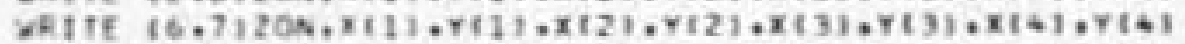

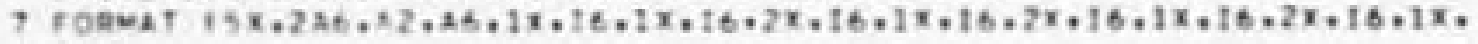

1161

CO TOS

90 contInue

tNo fILE?

DENTND 2

ENo

CENSUS TRACT 100456(111111.123456)(987656,666555)(555123,3392151(321568.3625147 CENSUS THACT 1234551111111.12345611987654.665555)(555123.333215)(321568.3625141 $20 \mathrm{NF}$ $1111561123797.656321)(666559.213456)(373256.25167811235689 .6532471$ 
Program 6: Read more information for the Zone Name-Grid Coordinate File

This program reads data cards and adds the information to the existing Zone Name-Grid Coordinate File. This enables the file to be initialized in stages and more information added as the need becomes apparent. Sample data follow the main body of the program. The tape used for the file must be noted on the program control cards. 


\author{
PPOGRAN o \\ REAO WOQE INFONMATION FOR ZONE NAME - GRTB COONDINATE FILE
}

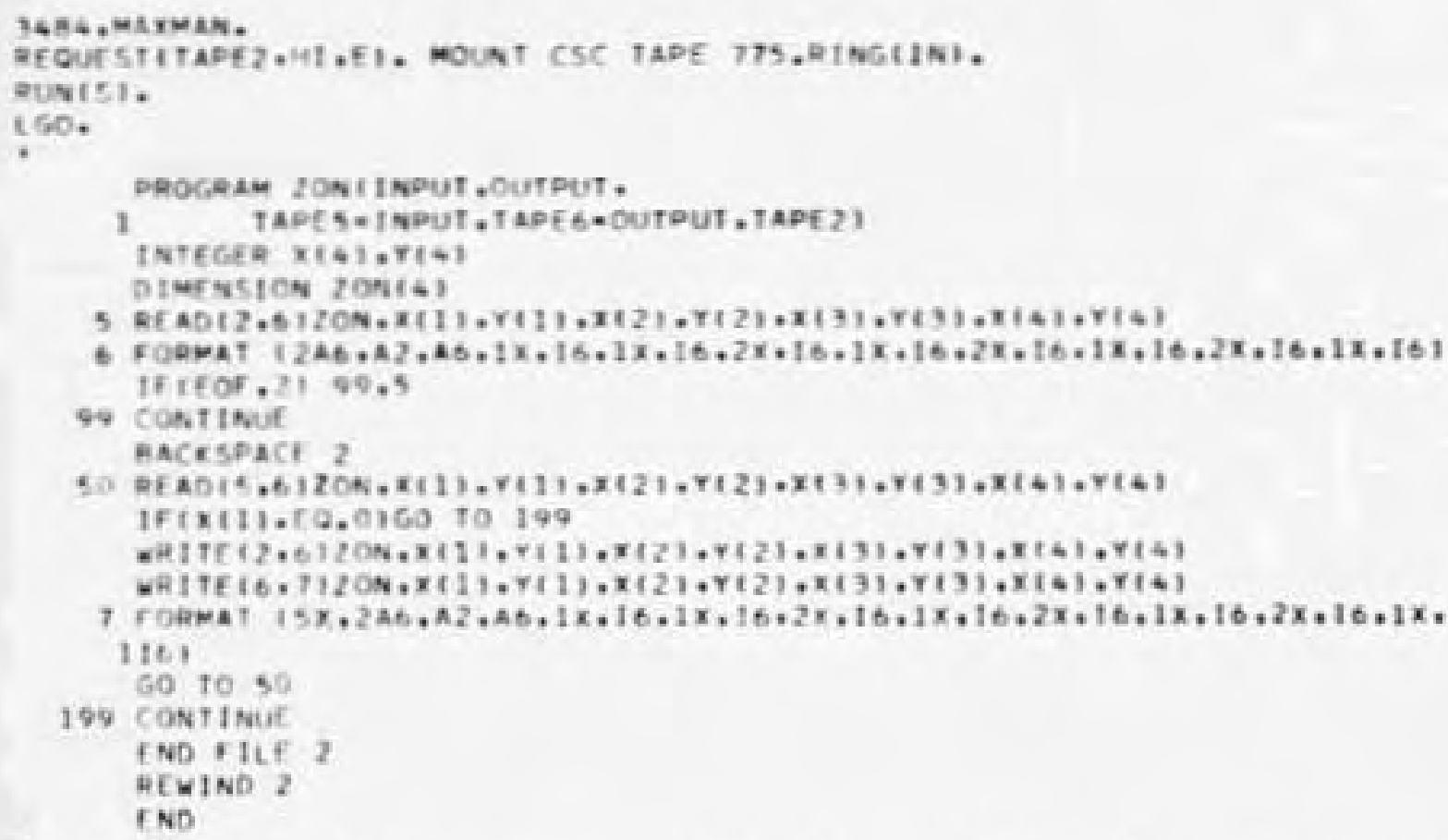




\section{Program 7: Read the Parcel Number- Grid Coordinate-Address File}

This program reads the Parcel Number-Grid CoordinateAddress tape file and gives a complete printed listing of the file. The listing can be used to check the accuracy of the data and the completeness of the file. The tape used for the file must be noted on the program control cards. 
DeOGrav 7

READ TADE. DETNT CONPLETE LIST FOR

DARCEL NUWAER - GRTD COONDINATE - ADORESS FILE

3456,0 HXNAN.

aEOUEST ITAPE3,Ht ,E I. NOUNT CSC TAPE 776. RINGTOUTI. Runte1.

too.

,

peocan coopitinput, Output.

1 TAPES - INPUT, TADES=0UTPUT, TAPE 3 ,

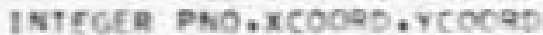

Dtwriston anoorstar

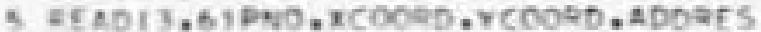

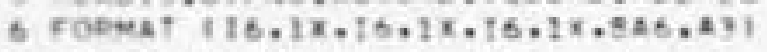

iftrof, $7,69,6$

4 wette is, 7 , pNo, xCOORD, rCOCAD, moDkES

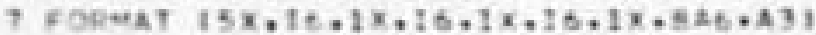

on 10.

9e conttwue

DE $=1 N 0,3$

END 
Program 8: Read the General Data File

This program reads the General Data tape file and gives a complete printed listing of the file. The listing can be used to check the accuracy of the data and the completeness of the file. The tape used for the file must be noted on the program control cards. 
3454, NaxMAN,CN70000.

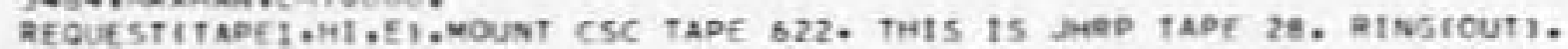
Rukisi.

L.6.

.

phocean markithert output.

1 TADCSNTNDUT, TAPEG=OUTPUT, TADEII

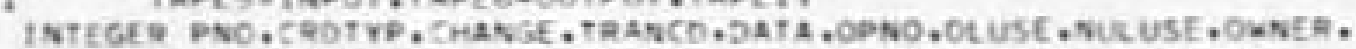

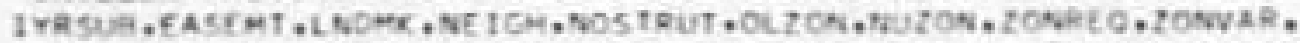

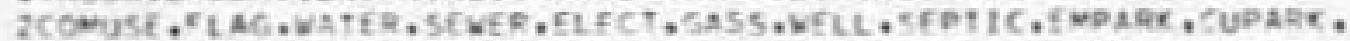

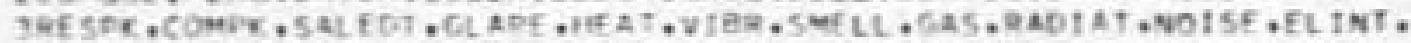

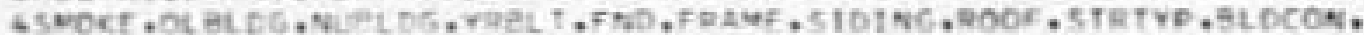

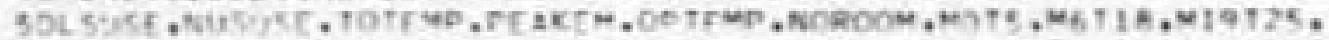

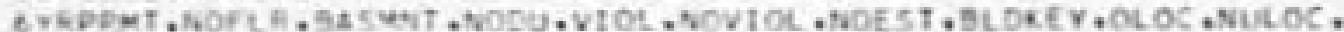

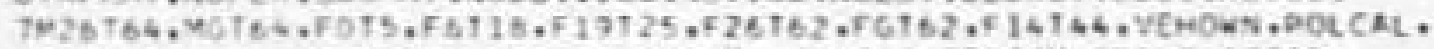

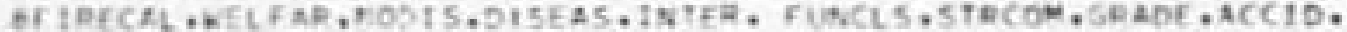

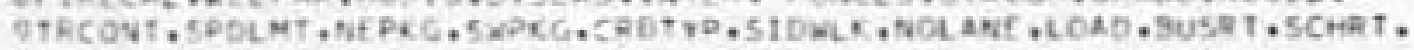

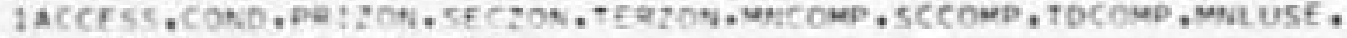
zSCLUSE, TOLUSF, LND, YaCH

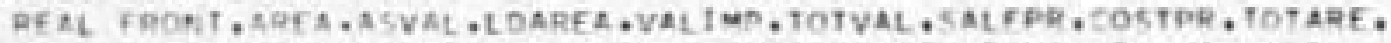

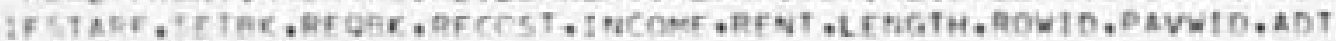
DTNENSION DATAT? of w 1 in 1

5 READI1, STPNO, CROTRD. CHANCE, TRANCD,DATA

B FontA $\{16,12,14,12,6 A 10, A b)$ tritror, $11,09,4$

4 IF I CODTYP. EQ. 11 CO TO 3

IF tCROTYP. FQ. 21 GO 1017

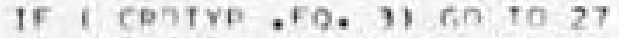

If ICROTYP. FQ. 4 ) 60 TO 37

If ICADTYP. FO. 12160 TO 47

If (CRETYP.EO. 11 , 60 TO 57

60 to 67

3 CONTtMUE

7 DECODE 166 , 6, DATA IOLPNO, OLUSF, NULUSF, ONNER, FRONT, AREA , YRSUR, A SVAL

1. FA SEMT, LNDMK, NET TH, I ND, NOSTRT, YRCH, OLZON, NUZON, ZONRE , ZONVAR,

2CONUSE, FLAC , WATFR, SFWER. FLECT , SA S5, WFEL, SEDTTC

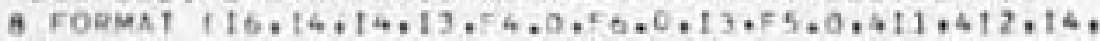

$114,12,7111$

WRTTETE, IOIONO, CROTYP, CHANGE, TRANCD, OL PNO, OL USE, NUL USE , OWNER, FRONT

- vaREA , YRESUA O RSVAL

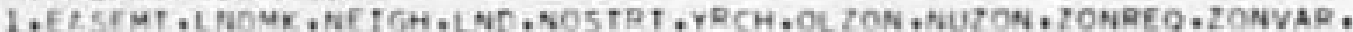

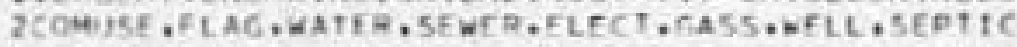

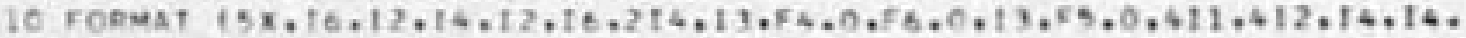

112.7111 00 to:

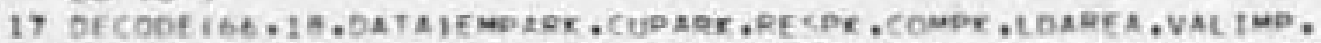

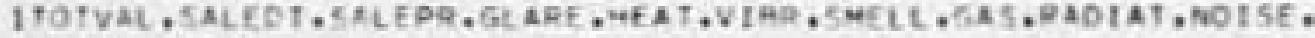
2LCINT, STOKF

18 foevat $(414,53,0,275,0.12,85.0,9111$

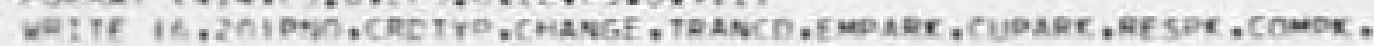


- Donetaval IND.

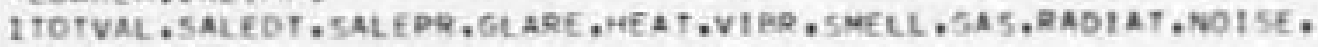

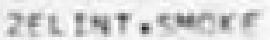

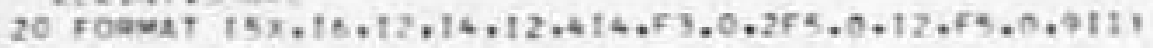

ro to 5

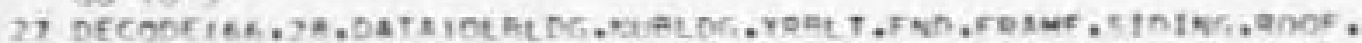

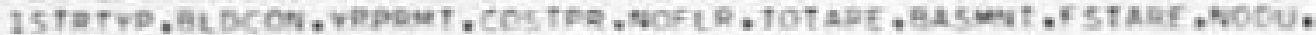

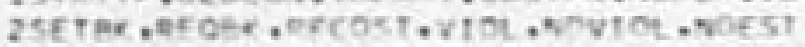

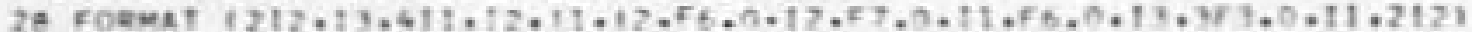

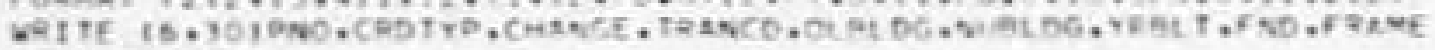

- 5 totnis.a00r.

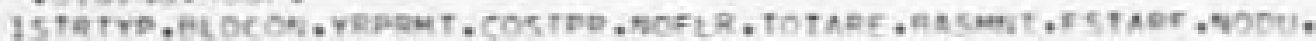

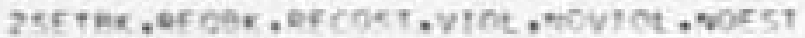

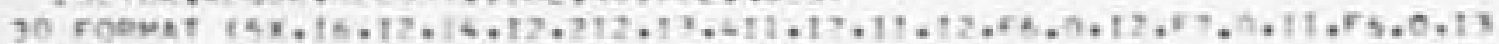

$\bullet, 3+0,11,2121$ $\cos \tan :$

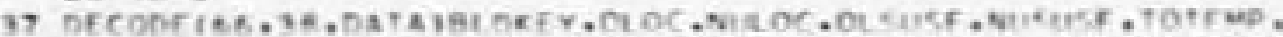

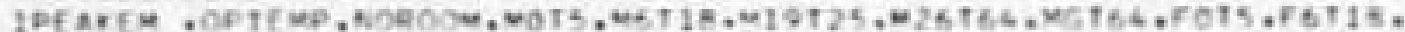

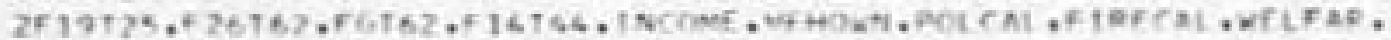
3 vonts ont 5 . A 5 , or $N$ t

3 foevat $1317,416,1312,57,0,312,7+1,17,53,01$

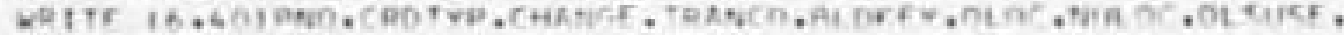

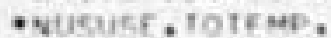

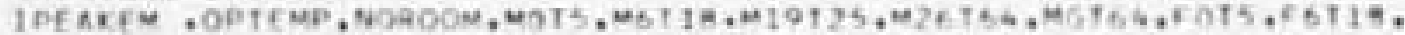

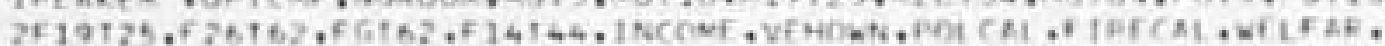

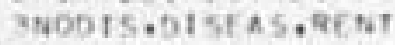

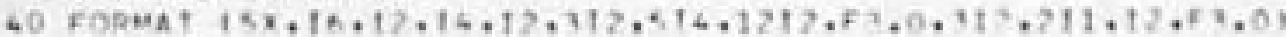
60 to 5

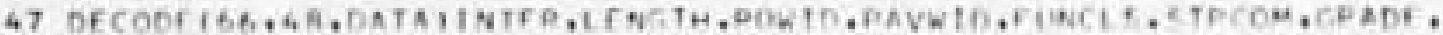

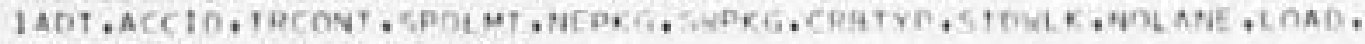
2ALSOT, SCHRT, ACCE KS, CONA

44 KORMAT $111,54.0,253.0,311,55,0.12 .14,12.10111$

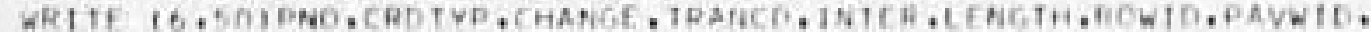
- Funcl s. STRECOM, Cimane.

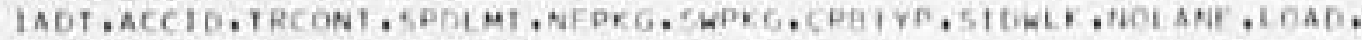

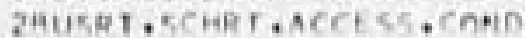

50 FORGAT $15 x, 16,12,14,12,11,54,9,257,0,311,55,0,12,14,12,10111$ 6 ก to 5

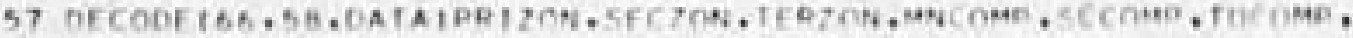
TWNIISE. SCIUSF, TBLHSE

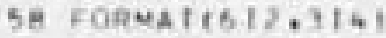

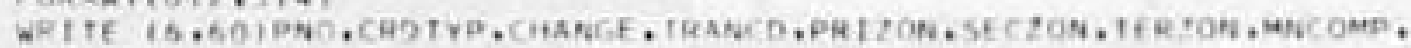
esccomp, tocome.

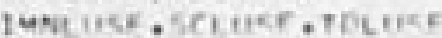

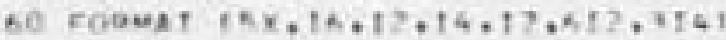
in th 5

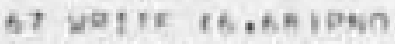

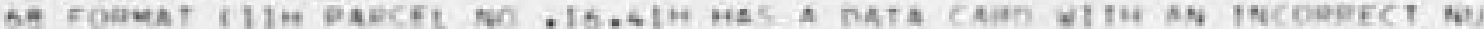
IUIER

no to 5

69 contithur efotinn 1 Fin 


\section{Program 9: Read the Zone Name- Grid Coordinate File}

This program reads the Zone Name-Grid Coordinate tape file and gives a complete printed listing of the file. The listing can be used to check the accuracy of the data and the completeness of the file. The tape used for the file must be noted on the program control cards. 
DROGRAM 9

AEAO TADE. PRINT COMPLETE LIST FOR ZONE NAME - GRIO COORDINATE FILE

$3406,02 \times 14$.

DEQUFSTITADE2,HI, E1. NOUNT CSC TADE 775. RTNGIOUTI. RuNtsi.

TGO.

PROCRAN zONITSPT, OUTPUT.

1 TAPES-INDUT +TADEG-OUTPUT, TAPEZ?

integer $x(6), 7(6)$

Divenston zONiti

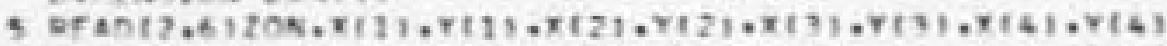

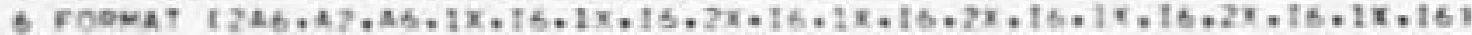
trifor, $2,99.4$

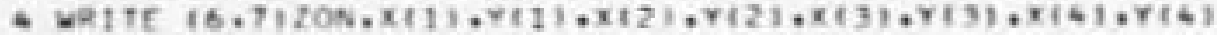

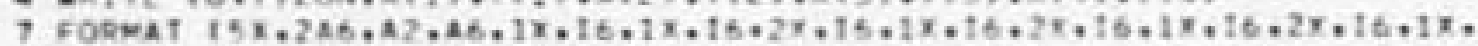
1161

(6) $10 \%$

99 cowtinut

antwis 2

END 
Program 10: Update the Parcel NumberGrid Coordinate-Address File

This program reads new data and changes the information in the existing Parcel Number-Grid Coordinate-Address File to match the new information. The update data cards must be complete; all old and new information must be included. On1y cards that have new information on them need be used in the update cycle. This program enables information to be periodically rendered current without initializing an entire new tape file. The new information must be read onto tape via Program 1 before this program can utilize the information. The tapes used for each file must be noted on the program control cards. 
poocean 10

UPOATE PARCEL NUNEER - GRTO COORDINATE ADORESS FILE

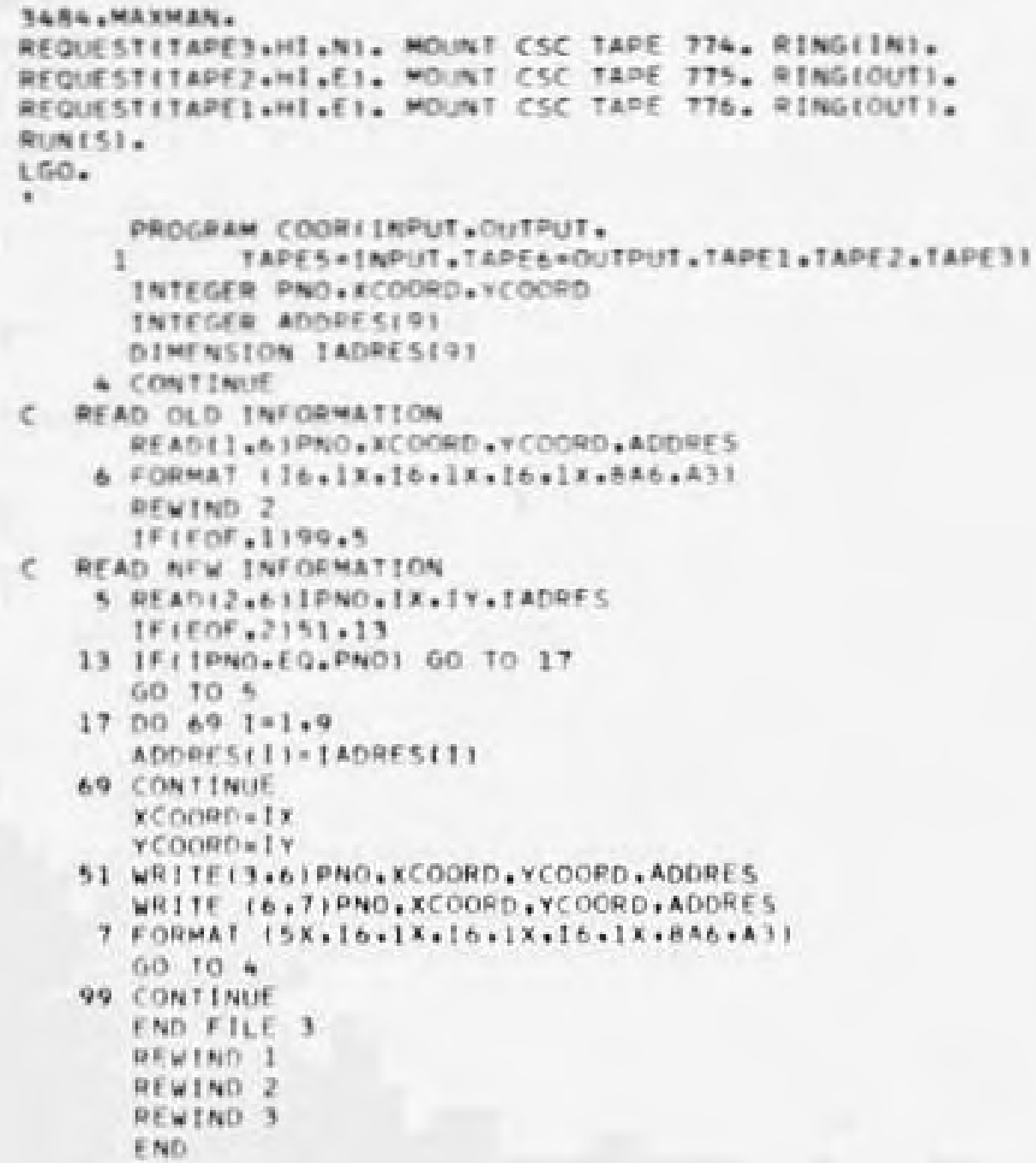

51 WRITE 13.6 IPNO, XCOORD, YCOORD, ADDRES WRITE 16,7$)$ PNO, XCOORD, YCOORD, ADDRES

7 FORMAT $15 \mathrm{x}, 16,1 \times, 16,1 \times, 16,1 \times, 8 \mathrm{~A} 6, \mathrm{~A}, 3)$ 0010 ,

99 continue END FILE 3 REWINT 1 REWIND 2 RENTNO 3 END 
Program 11: Update the General Data File

This program reads new data and changes the information in the existing General Data File to match the new information. The update data cards must be complete; all old and new information must be included. Only cards that have new information on them need be used in the update cycle. This program enables information to be periodically rendered current without initializing an entire new tape file. The new information must be read onto tape via Program 3 before this program can utilize the information. The tapes used for each file must be noted on the program control cards. 
DROGE AN 11

UPDATE GFNFRAL DATA FILF

3646, MAXMAN.CATOOOO.

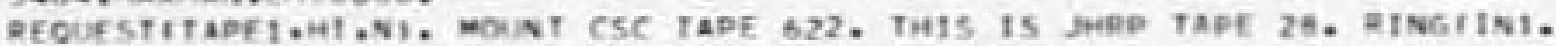
REOUESTITAPEA, +HI, EI. NOUNT CSC TADE 776. RINGTOUTI. RECUESTITAPEZ,HI, EI. WOUNT CSC TAPE 774. PINGIOUTH. munisi.

LGO.

*

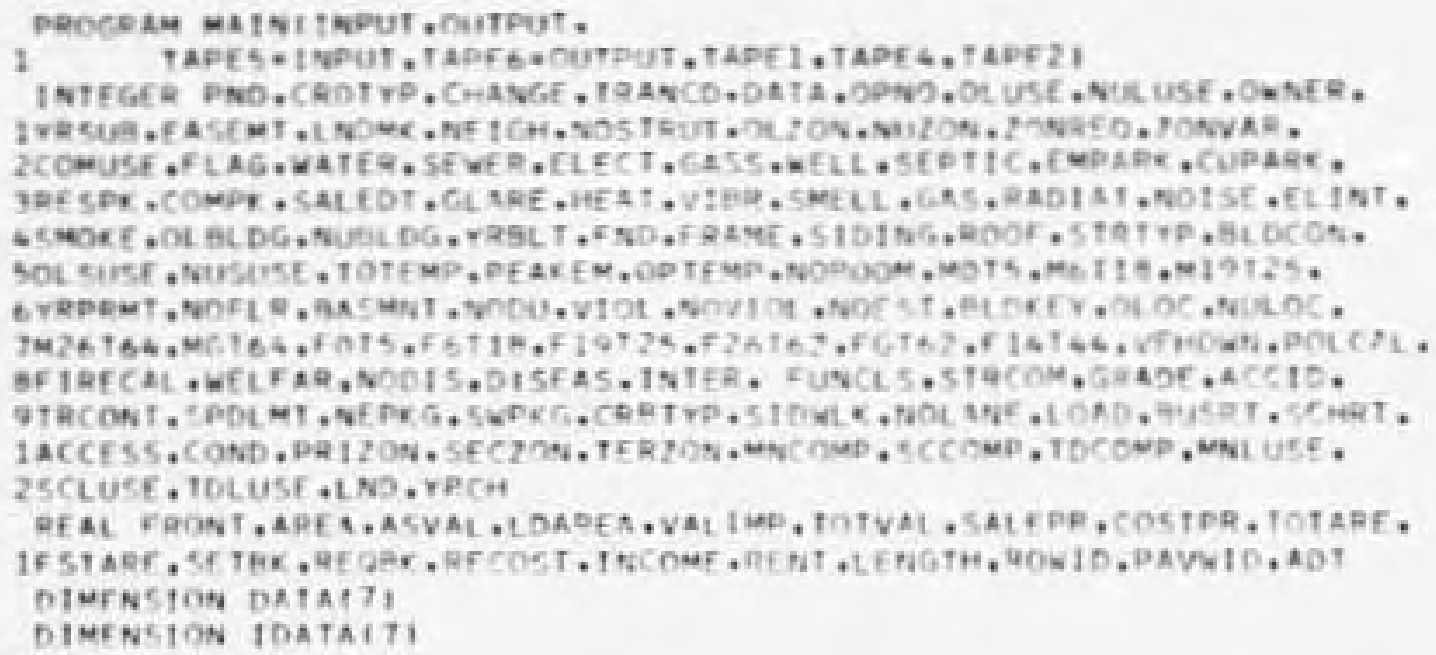

5 READ $(2,6)$ IPNO, TCROTY, ICHANGF, ITRANC, IDATA

6 Fopmat $116,12,14,12,6$ A $10, A B)$

If 1 for, $, 2,51,13$

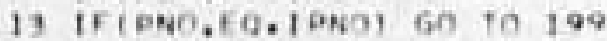
6010.5

199 IftCrotro,fo.tenDtY, 60 10 200 60 to 5

200 PNONTENO

CMOTrEetCHOTY

CHANGE + t CHANGE

toAnChet toanc

DO $11 \quad t=1,7$

Dataffioloatatis

11 contrivie

51 ificatro.fo. II 60 to 3

IF ICNDTV ofO. 2) 60 10 17

it I cootro. 50.3$)$ co ro 27

If ickntro efo. 41 gon to 37

IF tCuntrp. EO. 121 Go to 47

if icantre ofo. II) 50 to 57 


\section{DROGRAM 11, CONTINUFD}

Co. 10.7

3 continut

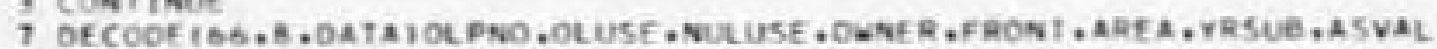

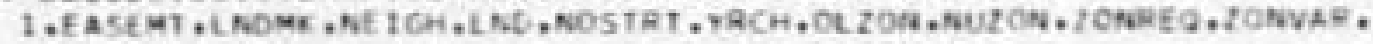

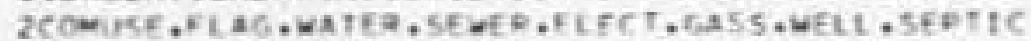

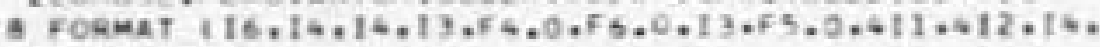

$1+2,12 \cdot 7111$

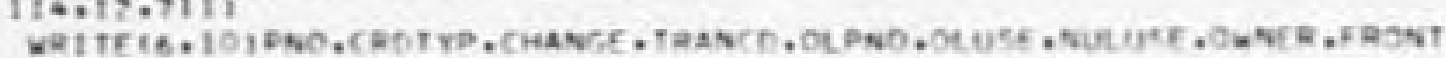

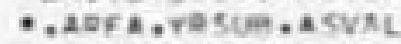

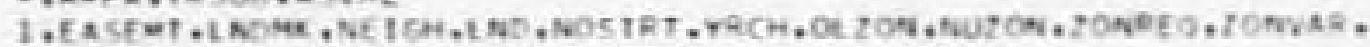

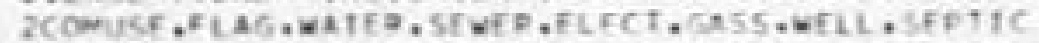

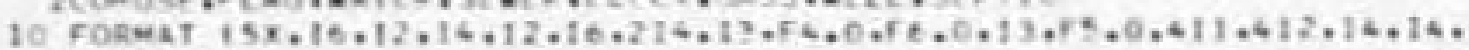

112,7111

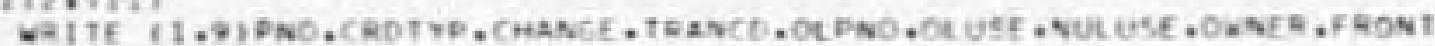

- aneravinsue, asval.

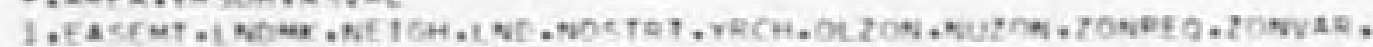

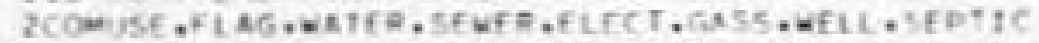

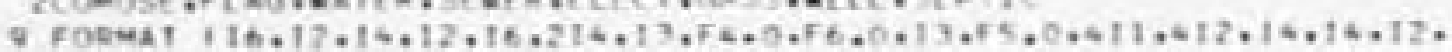

17111

$6070 \%$

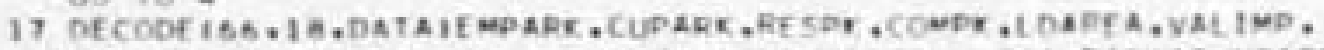

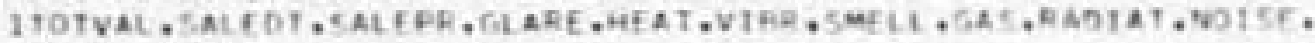

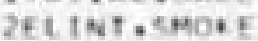

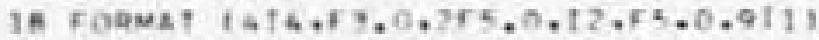

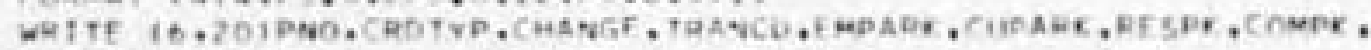

- Tondera, VALTHE.

ITOTVAL, SALFDT, SALEPR, GLARE ,HEAT, VIFD, SNELL, GAS, ARDIAT, NOTSE,

ZELINT, SWOEF

20 FoRMt is $x, 16.12 .14 .12 .414 .53 .0 .255 .0 .12 .55 .0 .9111$

WHT TE 11.19TPNO. CPDIYP, CNANGE, TRANCD, EMDARK, CUDABR, OE SPR, COMPK.

-idoarfa, valimo.

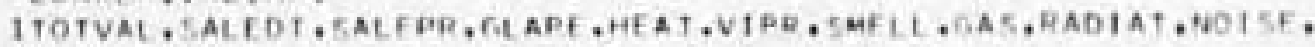
2ELINT, SMOKE

19 FORMAT $116,12,14,17,414,53,0,255,0,12,55,0,911\}$ 6010.4

27 OECOOE $166,25,0$ TAIOLRLDG, NUELOG, VRALT, FND, FRAMF, SIDING, HOOF, 1STRTYP, BL DEON, YRPRMT, COSTPR, NOFLP, TOTARE, HA SUHI, F STARE, NODU, 25ETAK, AEQAK, RECOST, VIOL.NOVIOL.NOEST

2 F FOAMAT $1212,13,411,12,11,12,56,0,12,57,0,11,50,0,13,3,3,0,11,2121$

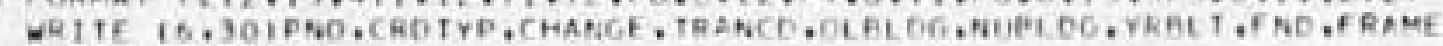
$\because 5 \operatorname{tintho,pOOF.~}$

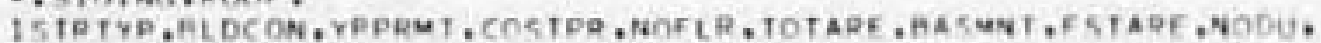

ZSETEK, DECAR, EECOST, VICL, NINVICL.NOEST

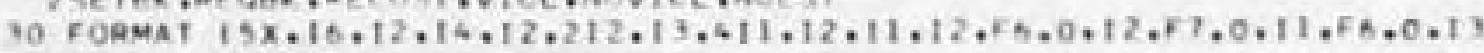

$0,35,0,1+2,21$

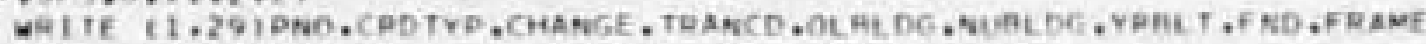

? stotno,poor.

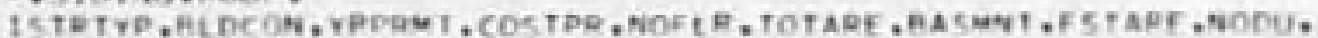

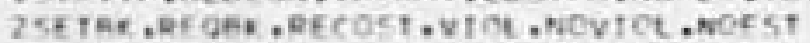

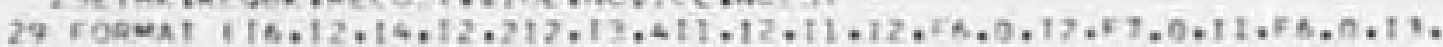

$\because 3+30,11,2121$

$60+0 \div$

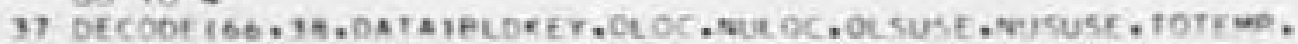

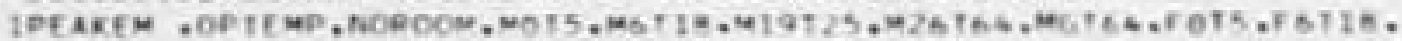


PROGRAN 11. CONT1NUED

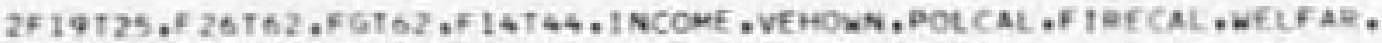
3 NOOTS ontsEas, aENT

38 Foanat $1312,516.1212,53.0 .312,211,12,53.01$

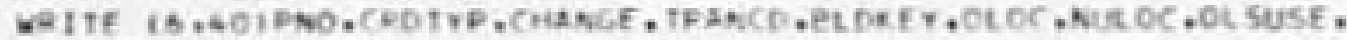

- wususe, TOTENP.

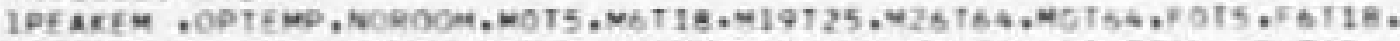

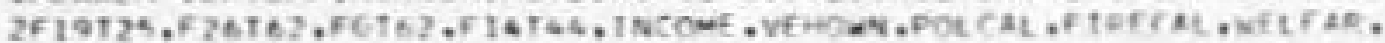
$3500 t 5,015 F a s, 6 F n t$

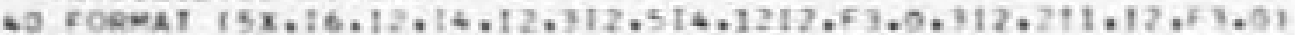

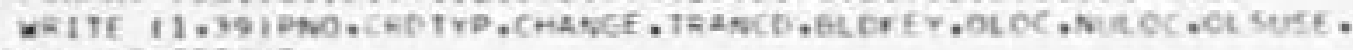
- virsuse, fotemp.

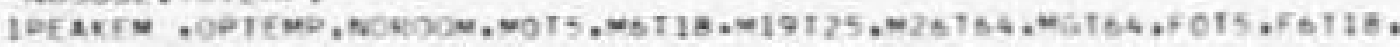

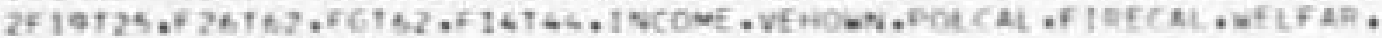

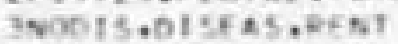

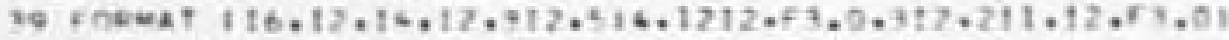
6910.

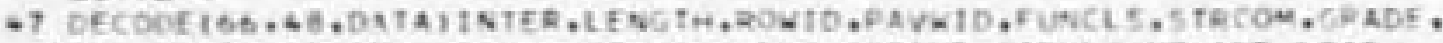

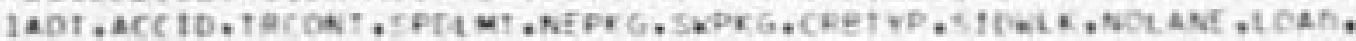
zeusat aschet, accese, cond

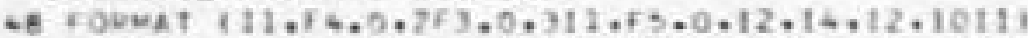

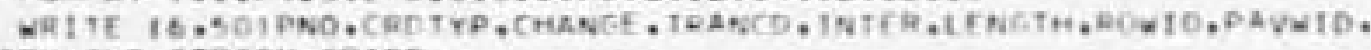
- Funcisostricon. Gerade,

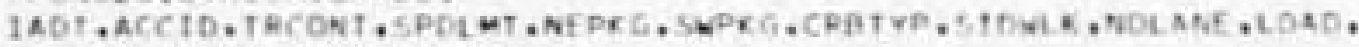

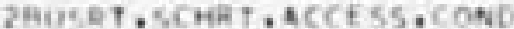

so tormat $15 x, 16+12,16,12,11,54 \cdot 0 \cdot 253,0,311,55,0,12,14,12,10111$

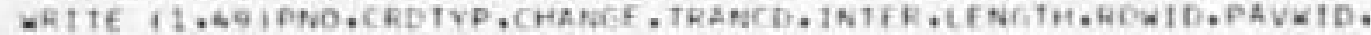
- funcl.s.strcom, chice.

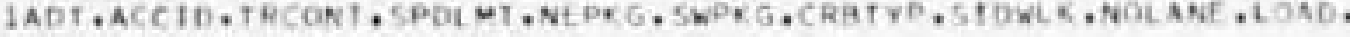
2 PUTRT, SCHET, ACCF SS, COND

49 FOAMAT $116,12,14,12,11,54,0,253,0,311,55,0,12,14,12,10111$ 60 104

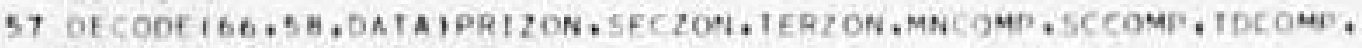
I HFL IISF, SCLUSF, TOLUSF

5 Q FOPMAT 1612.3141

WHITE 16.6 OIPNO, CRETYP, CHANGE, TRANCD,PRIZON, SECZON, IEHZON, MNCOMP, - sc С OMD, TDCOMP, IHFLUSF, SCL UISF, TDLUSE

60 FORMAT $(5 x, 16,12,14,12,812,314)$

WRTIE I 1.59IPNO, CRDTYP, CHARGE, TRANCD , PRTZON,SECZON, TERZON, MNCOMP, - sccomp, toconp. IMNLUSE, SCLUSE, TDLUSE

59 Fonvat $116,12,16,12,612,3161$

$6010 \div$

67 WRTTF 16.6 MIPNO

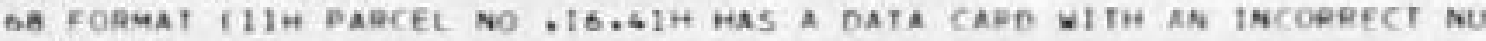
IMAFRI

60 ro +

99 conttinus FNO FILE I

aFU $01 \mathrm{ND} 1$

nertno 2

af who :

ENo 


\section{Program 12: Update the Zone Name- \\ Grid Coordinate File}

This program reads new data and changes the information in the existing Zone Name-Grid Coordinate File to match the new information. The update data cards must be complete; al1 old and new information must be inciuded. Only cards that have new information on them need be used in the update cycle. This program enables information to be periodically rendered current without initializing an entire tape file. The new information must be read onto tape via Program 5 before this program can utilize the information. The tapes used for each file must be noted on the program control cards. 


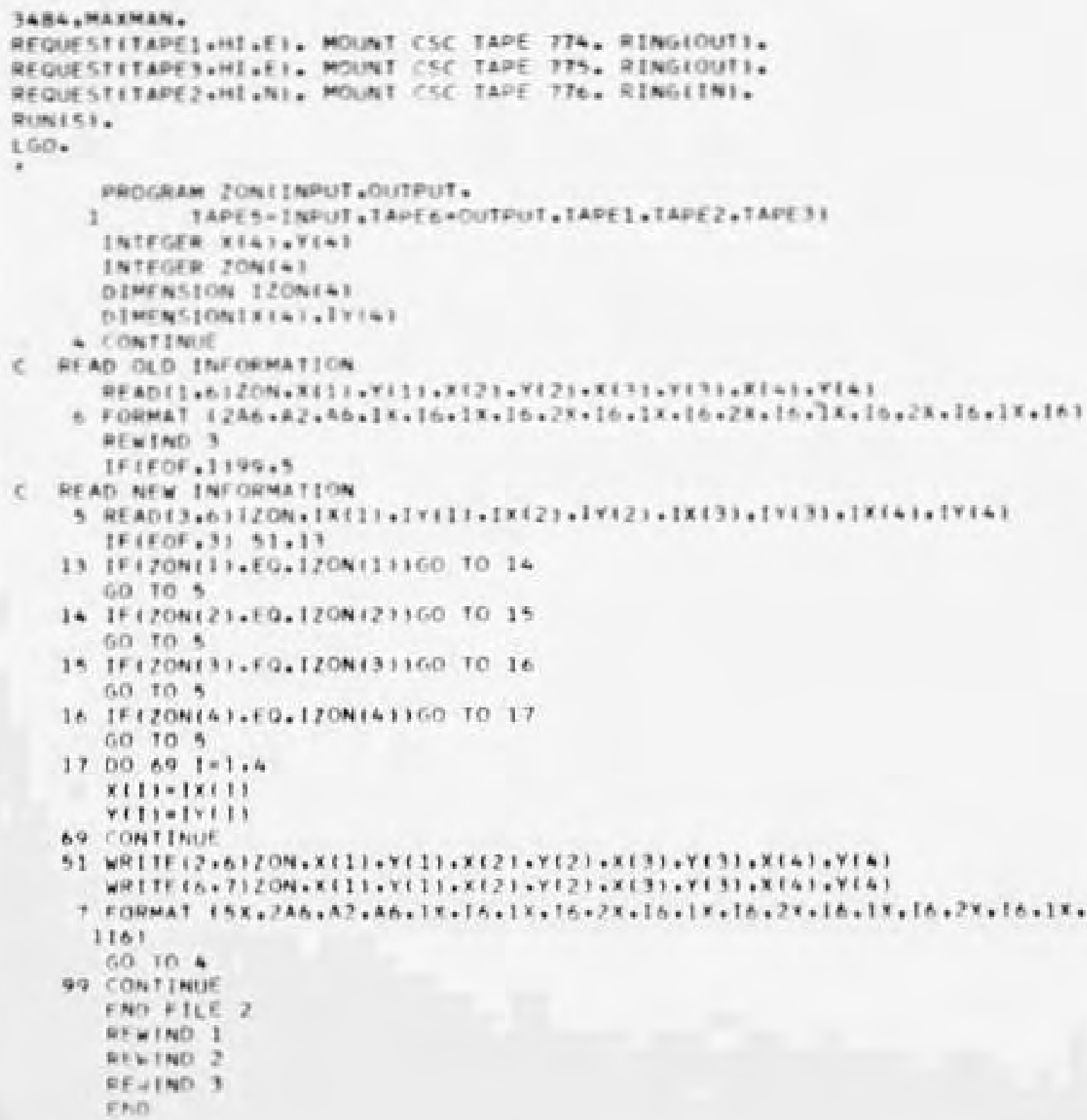




\section{Program 13: Retrieve a List of $\mathrm{X}$ and $\mathrm{Y}$ from the General Data File}

This program will retrieve a list of any two variables from the General Data File. The variables to be listed must be noted in the program, along with the maximum list size and the variable format. The system name for the two variables must also be noted in the program. With this information, this program will yield a list of the two variables on a parcel by parcel basis. The tape to be used must be noted on the program control cards. 


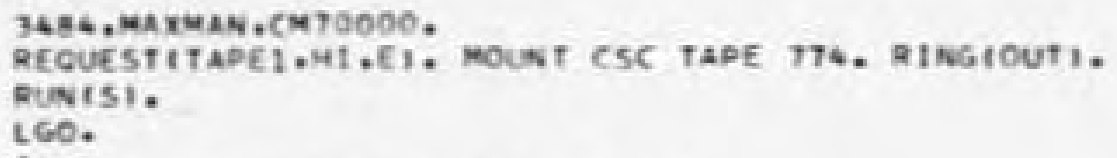


PROGRAN 13 , CONTINUED

$1 F$ renotra ofO. 11160 TO 57

3 cont thue

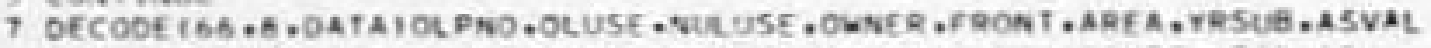

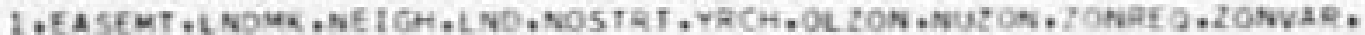

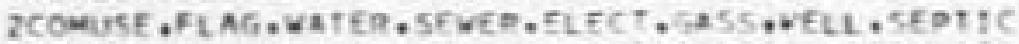

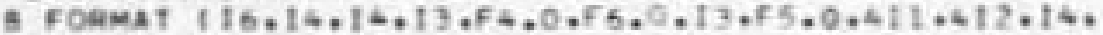

$11+\cdot 12+7111$

6070101

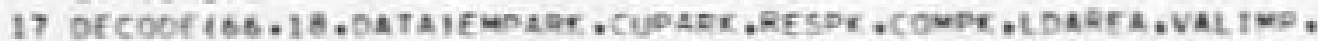

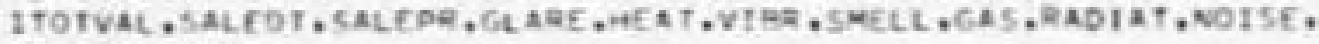
2FLtNT, Sheoke

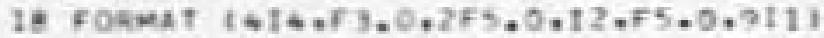
co $10 \quad 101$

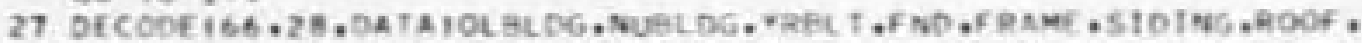

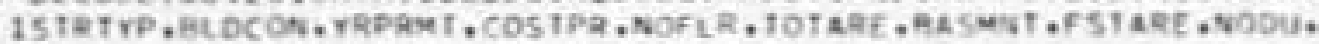

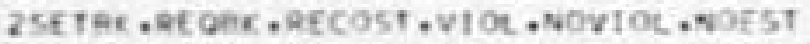

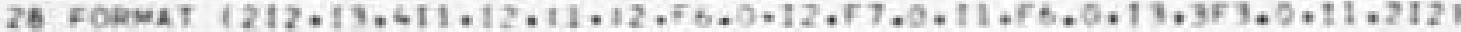
60 To 101

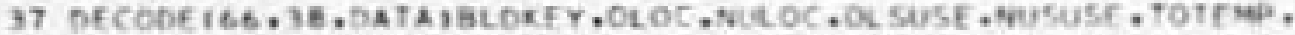

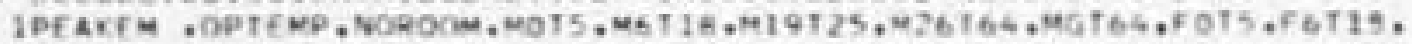

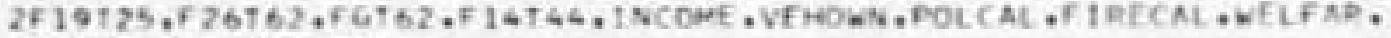

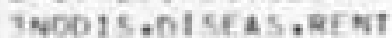

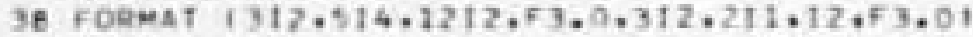
co $10 \quad 101$

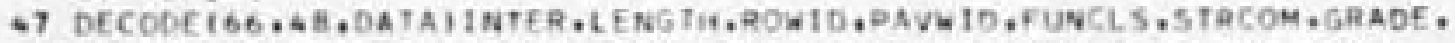

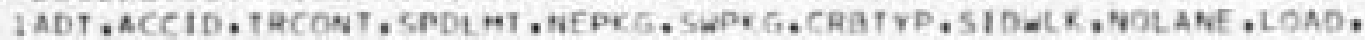
2HUSRT, SCHRT, ACCESS, COND

4A FODNAT $111,54.0 .253 \cdot 0,311,55 \cdot 0,12 \cdot 16,12,10111$ 60 to 101

57 DECODE 166 .5A,DA TAIPRIZON, SECZON.TERZON.MNCOMP, SCCOMP, TDCORP, IMNLUSE, SCLUSE, TDLUSE

56 FORMAT1612,314

$101 \quad \begin{aligned} & 60 \text { To } \\ & x=101\end{aligned}$

IPNO $(K)=$ PNO

$x \times(x) * x$

60 in :

199 CONTINUE AENINO 1

SO REAOH 1 ,6) PNO CADTYP, CHANGE, TRANCD DATA tFIFOF. 11599.200

200 IFICADFYP.EO. II 60 TO 209 fo to 50

$29900399 \quad \mathrm{~L} \cdot 1, \mathrm{~K}$

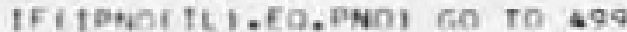

399 CONTINUE

$\sin \operatorname{tos}=0$

499 contline

tricuntre.FO. 11 Go to 603

triceotre.fQ. $2160-70-617$

IFICKOTrP.FQ. 3) GR TO Sz?

IFICNDTVP. EO. 416010637 


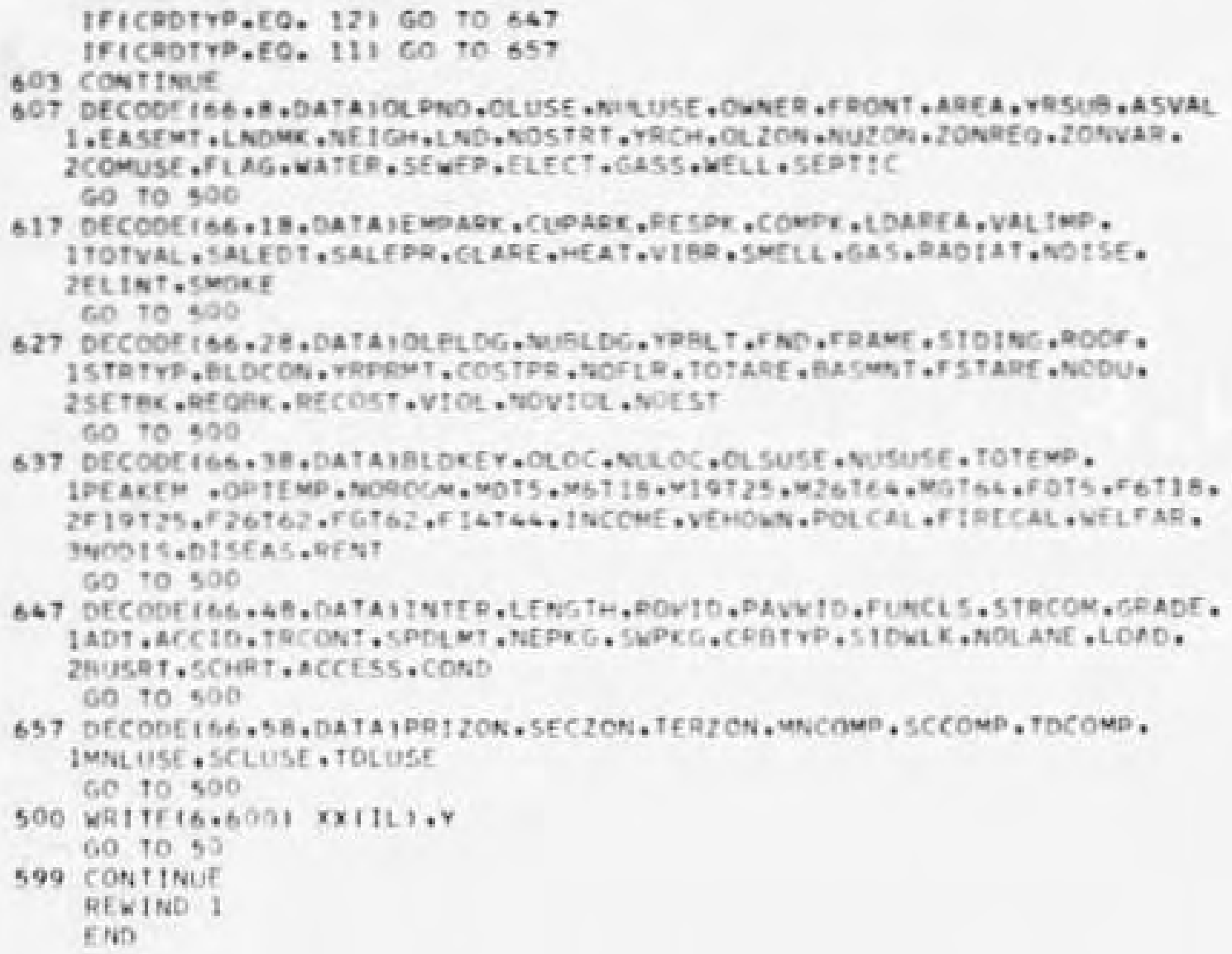




\section{Program 14: Retrieve the Sum of $\mathrm{Y}$ For $\mathrm{X}=$ Test}

This program will sum a variable for a specific value of another variable (from the General Data File). The variable to be summed, the variable the . mmed over, the value to be summed over, and the variable format must be entered into the main program. With this information, this program can sum the values of one piece of data based on a particular value of another piece of data. The tape to be used must be noted on the program control cards. 
DROGRAN 14

AETAIEVE SUN OF Y FOR A SPECIFIC $x$ FRON THE GENERAL DATA FILE

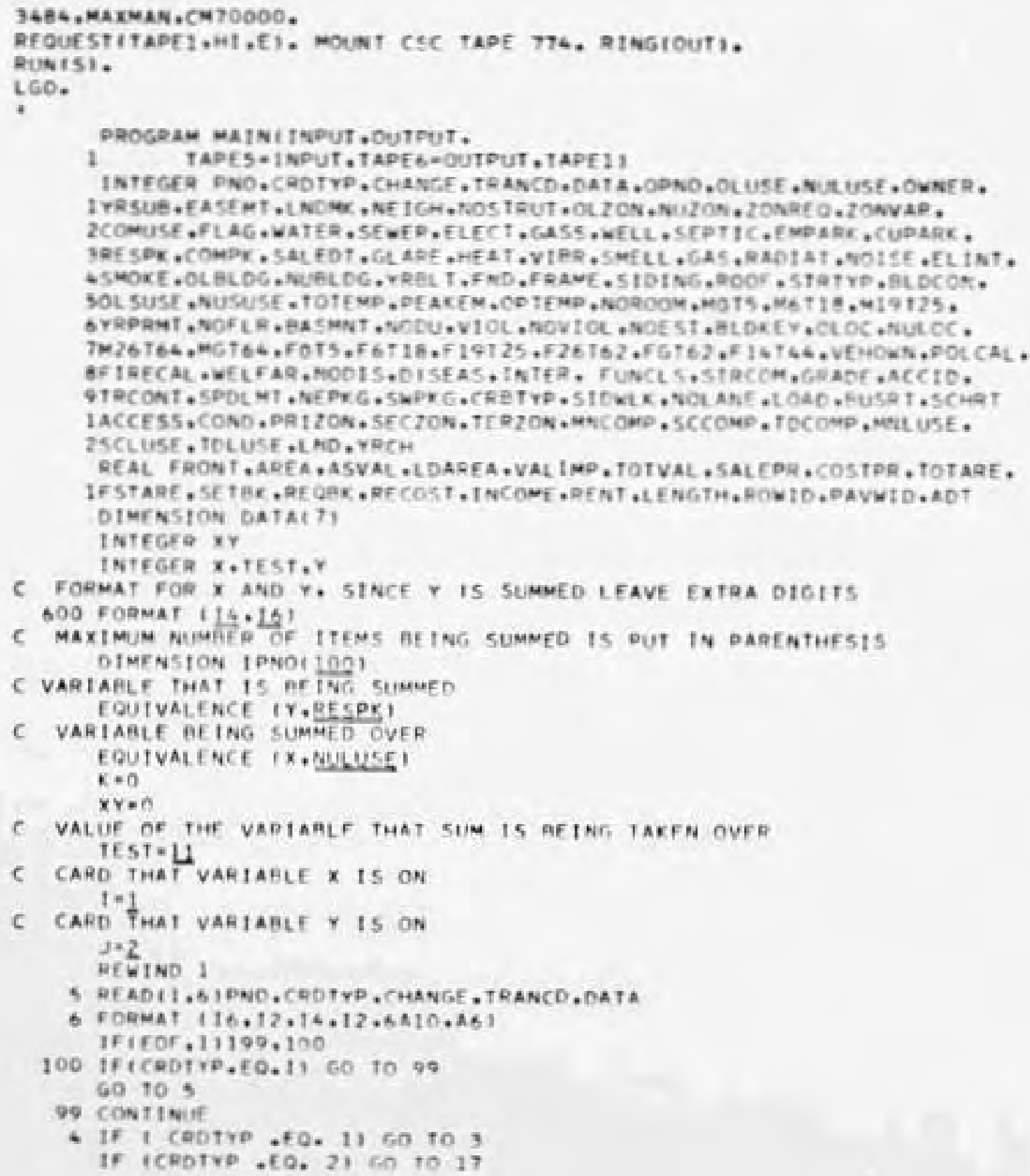




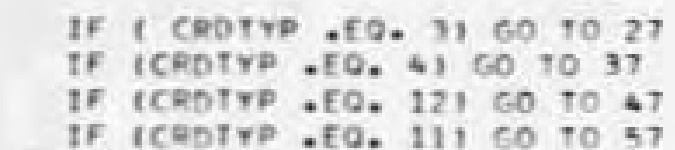

3 continue

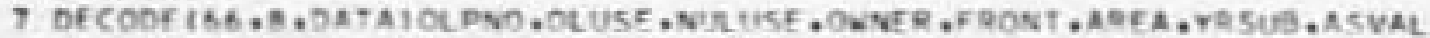

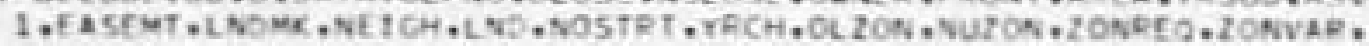

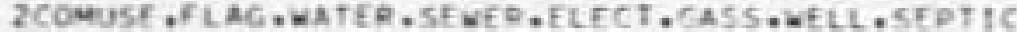

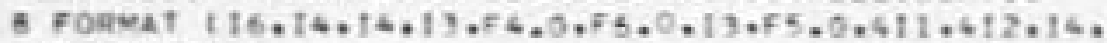

$114 \cdot 12 \cdot 7111$

co 1099

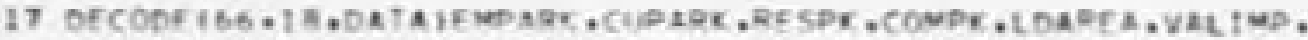

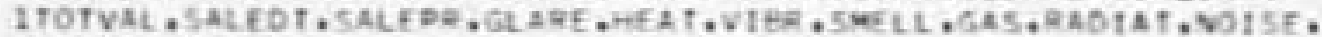
26 LTRT, ENOKE

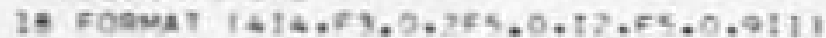
6010999

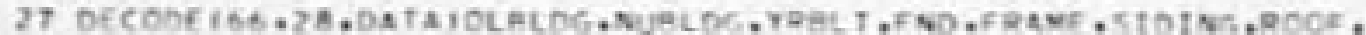

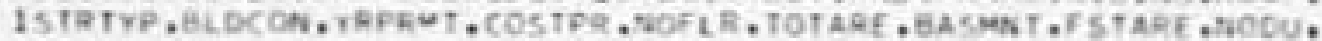

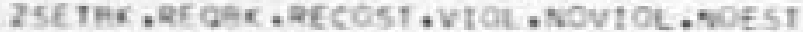

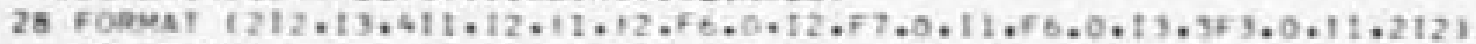
60 to 698

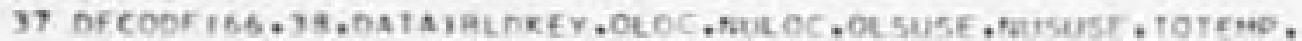

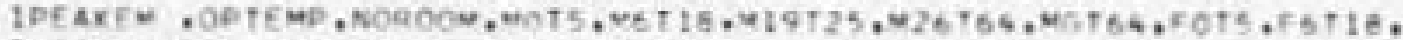

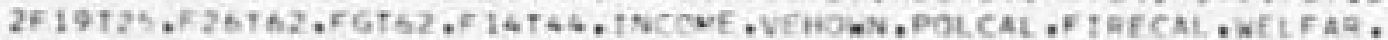

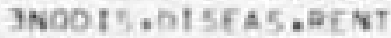

38 FOQNat 1312.514 .1212 .53 .0 .312 .211 .12 .53 .01 60 T0 999

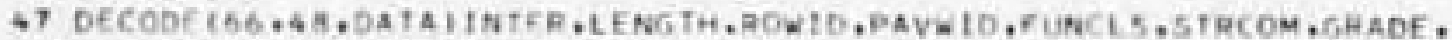

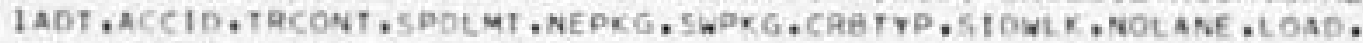
2AIJSRT, SCHAT, ACCF 55 , COND

4G FORNAT I 11, F4.0,2F7.0.311, F5.0.12.14.12.10111 60 To 999

57 DECODE 166,58 , DATA IPRTZON, SECZON, TERZON, MNCOMR, SCCOMP, TDCOMD, 1MNLUSE. SCLUSE. TOLUSE

SA FORMAT $(612,314)$ 60 Tि 999

999 if $(x .50 . t E 5 T)$ to to 101 60 To 5

$101 \times=x+1$

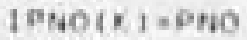
60 to 5

199 costinur QREINO 1

SO READI . 6$)$ DNO. CRDTYP. CHANGF. TRANCD , DATA If tFor. 11599.200

200 IFICRDTYP.EQ.JI 60 TO 299 60 To 50

299. DO $399 \quad 11=1, \%$

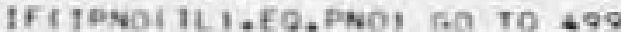

399 contrinut

607050

499 contlaut 
peogran 14. CONTINUFD

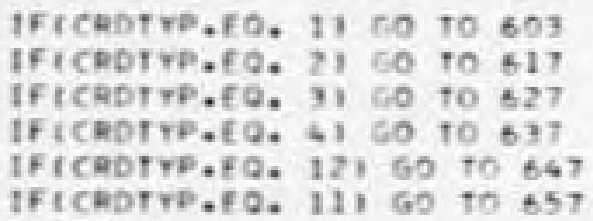

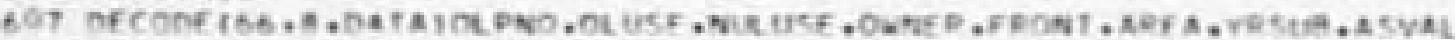

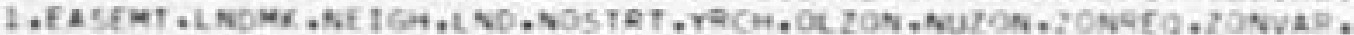

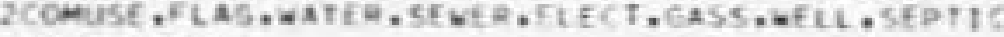
60 to 500

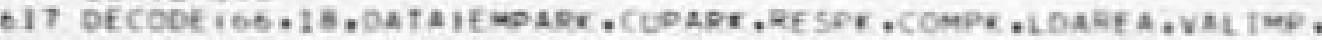

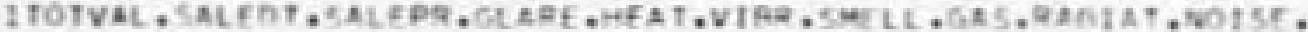
2FLINT. EMenKF

fo 10,500

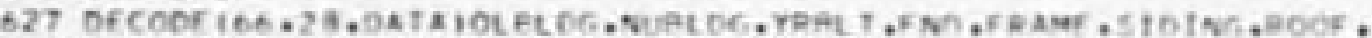

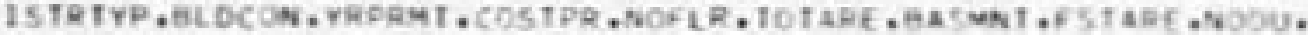

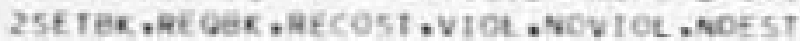

Do 10900

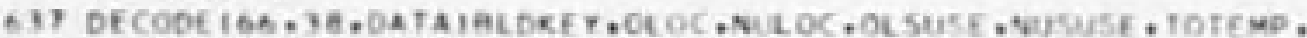

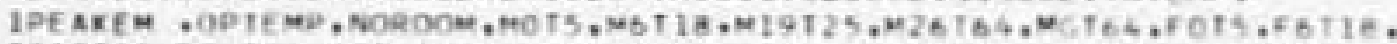

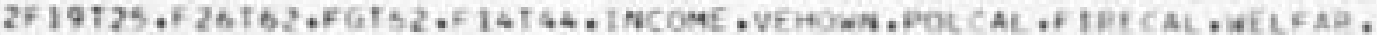
3 NOOIS.0I5FAS.RERT 60 To 500

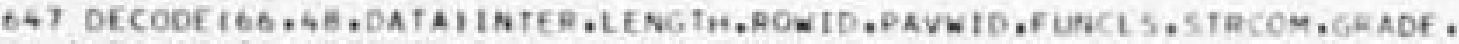
1 ADT, ACCIO, THCONT, SPDEMT, NEPKG. SWPKG. CABIYP, SIDEL K, NOL WHE , LOAD. 2BUSRT, SCHRT, ACCESS, CORD

0010500

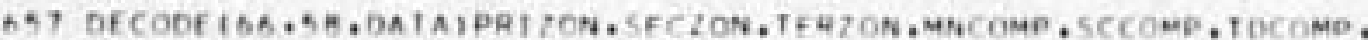
IMNI UISE. SCLUSE, TOLUSE 6010500

$000 \times Y=X Y+Y$ 60 TO 50

599 WRITI $(6,600)$ IEST,XY PE WIND I

FND 
Program 15: Retrieve a List of $\mathrm{Y}$ for $\mathrm{X}=$ Test

This program will list one variable when the value of another variable equals a specified test value (from the General Data File). The variable to be listed, the variable to be listed over, the value of the variable to be listed over, the format for the variables and the maximum list size must be entered into the program. With this information this program can list the values of one data item based on a particular value of another data item. The tape to be used must be noted on the program control cards. 
PROGRAN 15

RETRIEVE LIST OF, FOR A SPECIFIC $x$ FRON THE GENERAL DATA FILE

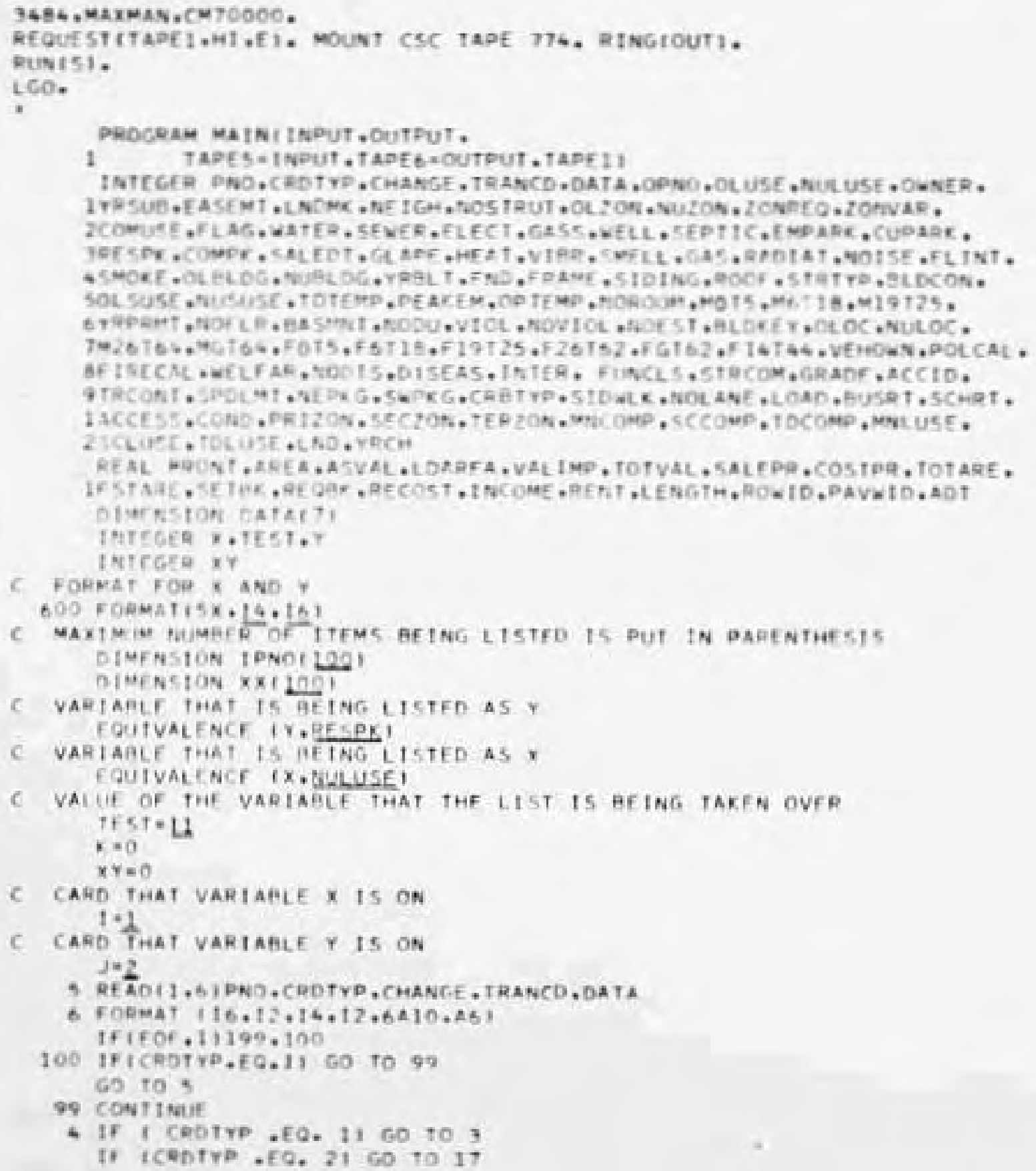


DROCRAN 15 . CONTI IuTO

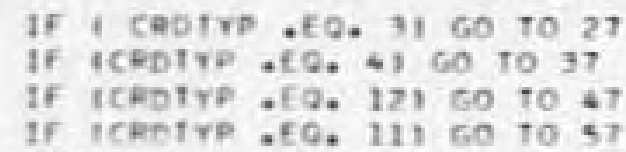

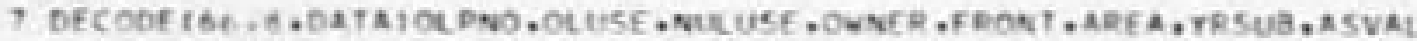

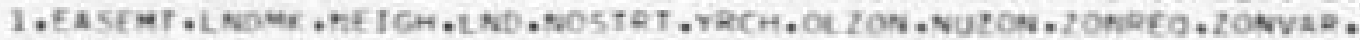

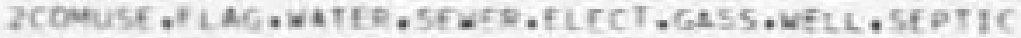

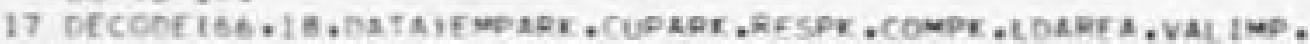

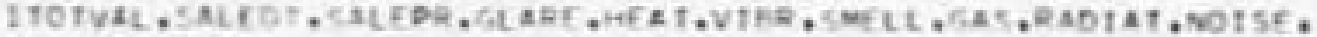
2ELINT. smoef

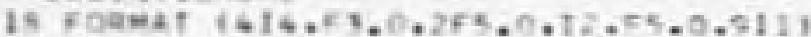
60 to 101

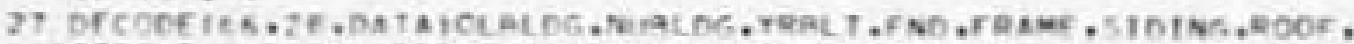

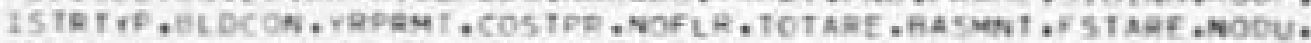

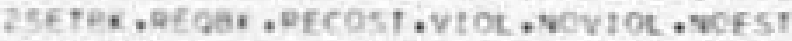

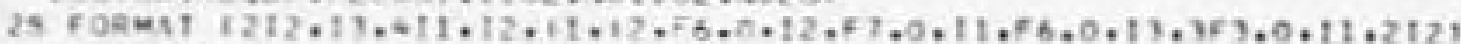
(to to 101

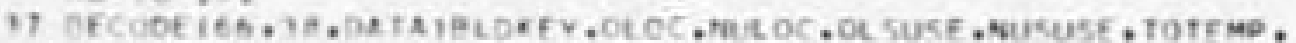

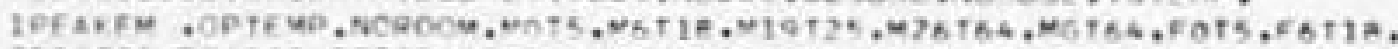

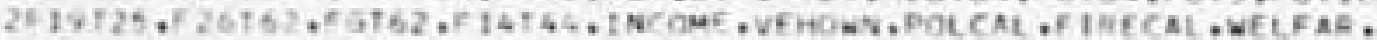

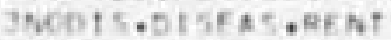

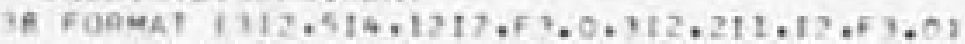
00 to 171

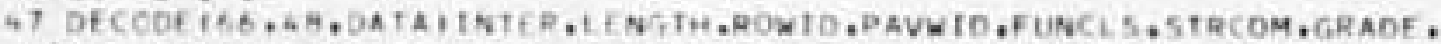

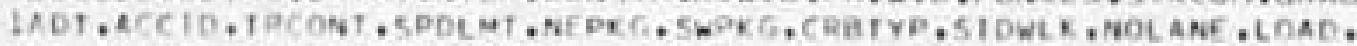
zAUSAT, SCHRT, ACCTSS,COND

4 FOENAT $171,54,0.253,0.711,55.0,12,14,12.10111$ (a) 10101

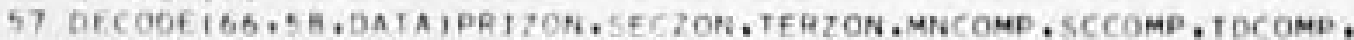
IMNL USE , SCLUSE, TOLUSE

5 H TORMAT $(6,12,314)$
(4) 10101

101 If $(x, E 0 \cdot T E 5$ T) 60 to 102 $60+10 \cdot$

$102 \times \approx r+1$ 1PWOIK, = Pwn 6ot to 5

199 CONTINULE RCw InD ?

SQ READI 2,61 DNO, CRDTYP, CHANGE, TRANCD, DATA If If of , 11599, 200

200 ificatrp.FO. 11 Go th $20 \%$ co to 50

299 no $190 \quad 11-1 \times 4$ IFITPWOI ILY.FO.PNOI Go th 490

399 CON'1nut

CO 1050

69 continut 
PROGRAM 15, CONTINUFD

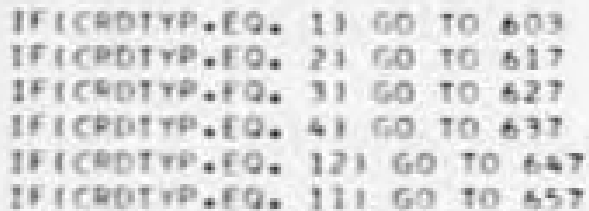

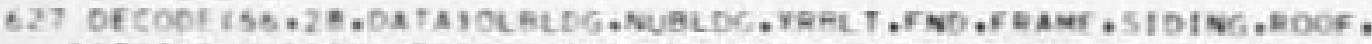

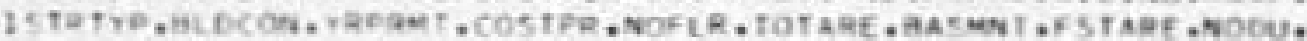

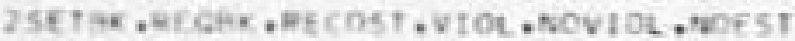

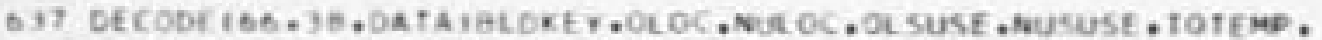

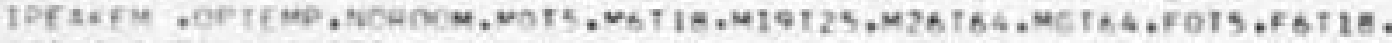

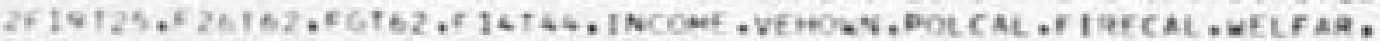
$3 \mathrm{~N} 00 \mathrm{t} 5.015+45$. 0 ent? $60 \% 0 \% 00$

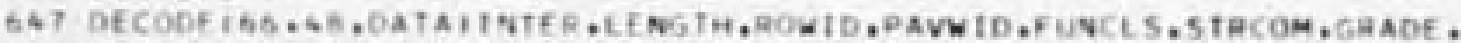

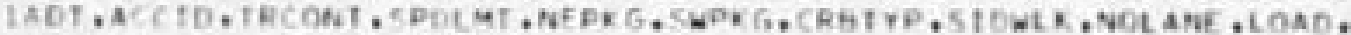

ZAUSRT, SCHET , ACCESC, CONO $6010 \times 10$

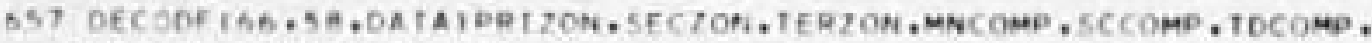
IMNE USE. SCLUSE, POLUES

6010500

500 wettris, 00 to 50

590 continit REWINO FND 
Program 16: Retrieve $\mathrm{X}$ for

Particular Parcel Numbers

This program will retrieve the value of a specified variable for each parcel number read into the program. The program listing contains sample data. This program will read the parcel numbers that are entered as program data, and will retrieve the value of a specified data item for these parcel numbers (from the General Data File). The program will then print a list of the parcel numbers and the value of the specified variable for each parcel number. The variable to be listed, the variable format, and the number of parcel numbers to be considered are entered into the body of the program. The parcel numbers to be considered are entered as data and follow the main body of the program. This program can be combined with Program 17 in order to retrieve data on an address basis, or with Program 18 to retrieve data on a zonal basis. The tape to be used must be noted on the program control cards. 


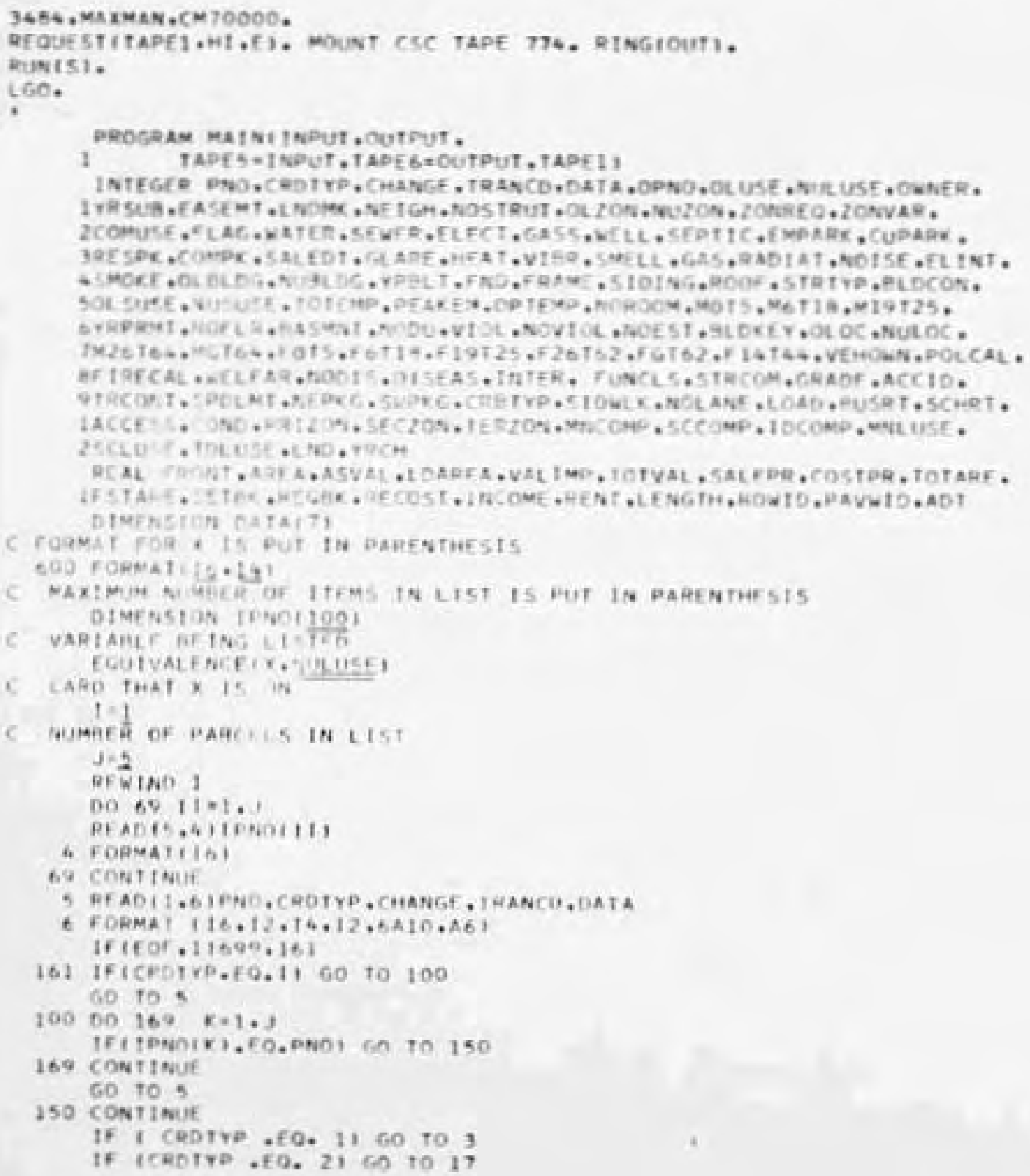


PROGRAN 16, CONTINUED

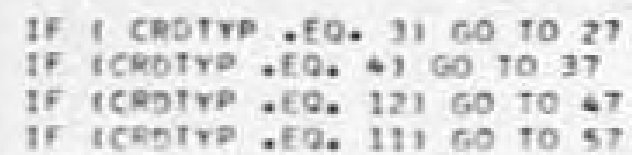

3 continge

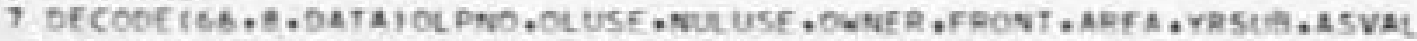

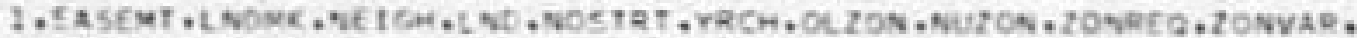

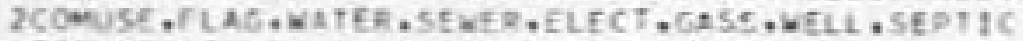

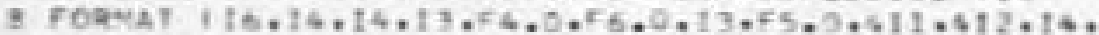

$11+, 12 \cdot 7121$

6010230

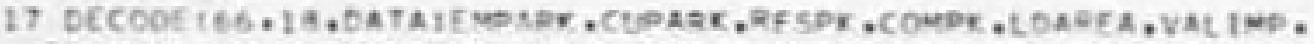

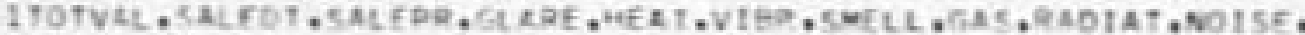
2ELINT, Suroef

IF FONUAT $1414,53 \cdot 0.255 \cdot 0 \cdot 12 \cdot 75 \cdot 0 \cdot 9111$ 00 to 250

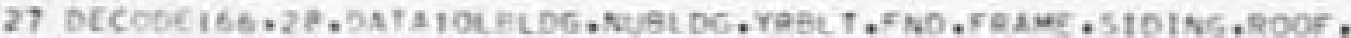

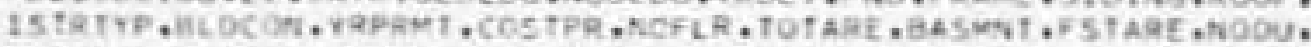

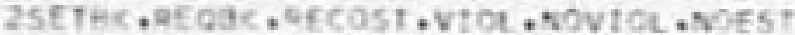

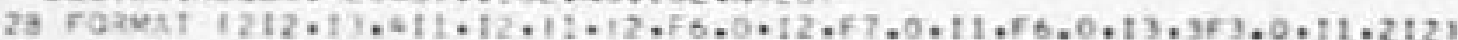
$607025 \mathrm{C}$

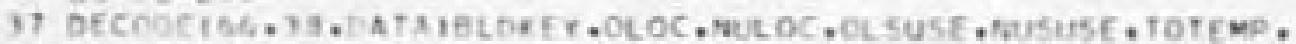

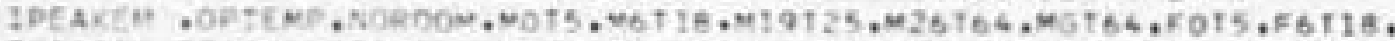

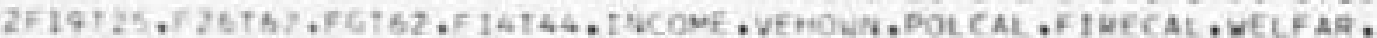

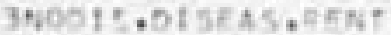

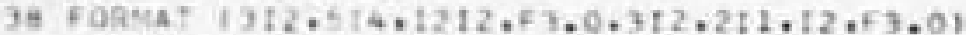
00 to 200

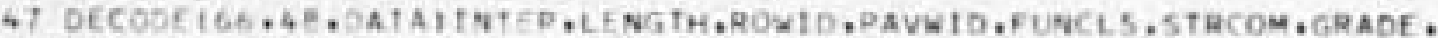
IADT, ACCID, TRCONT, SPDL UT, NEPKG.5WPKG. CRBTYP, SIDWLK, NOL ANE , LOAD. 2AUSRT OSCHRT A ACEFSE, COND

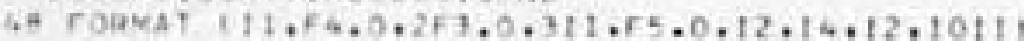
GO $1020 \mathrm{~d}$

57 DECOOE $666,5 \mathrm{~F}, 0 \mathrm{ATAIOR} 12 \mathrm{CH}$, SECZON, TERZON, RNCOMP, SCCOMP, TOCOMP, IMNL JEF. ECLSE, TDLUSE

53 robution: $32,3+1$
$60+0200$

200 Whit 16.0 .00 inNo, x 60105

699 PFVTND 1 Fno 
Program 17: Retrieve Parcel Numbers

for Particular Addresses

This program retrieves the parcel number for given street addresses or street blocks. The addresses are read as data and then the Parcel Number-Grid Coordinate-Address File is searched for the parcel numbers that correspond to the given addresses. The number of addresses to be entered must be noted in the body of the program. The actual addresses to be considered are entered as data and follow the main body of the program. This program can be combined with Program 16 to retrieve General Data on an address basis. This program will yield cards with the parcel number punched on them. These cards can be entered directly as data for Program 16 and thereby yield the General Data on an address basis. The tape to be used must be noted on the program control cards. 
RETRIEVE DARCEL NUMAER FOR GIVEN ADDRESSES FAOM PARCEL NUMAFR - GRTD COORDTNATE - ADDNFSS FILE

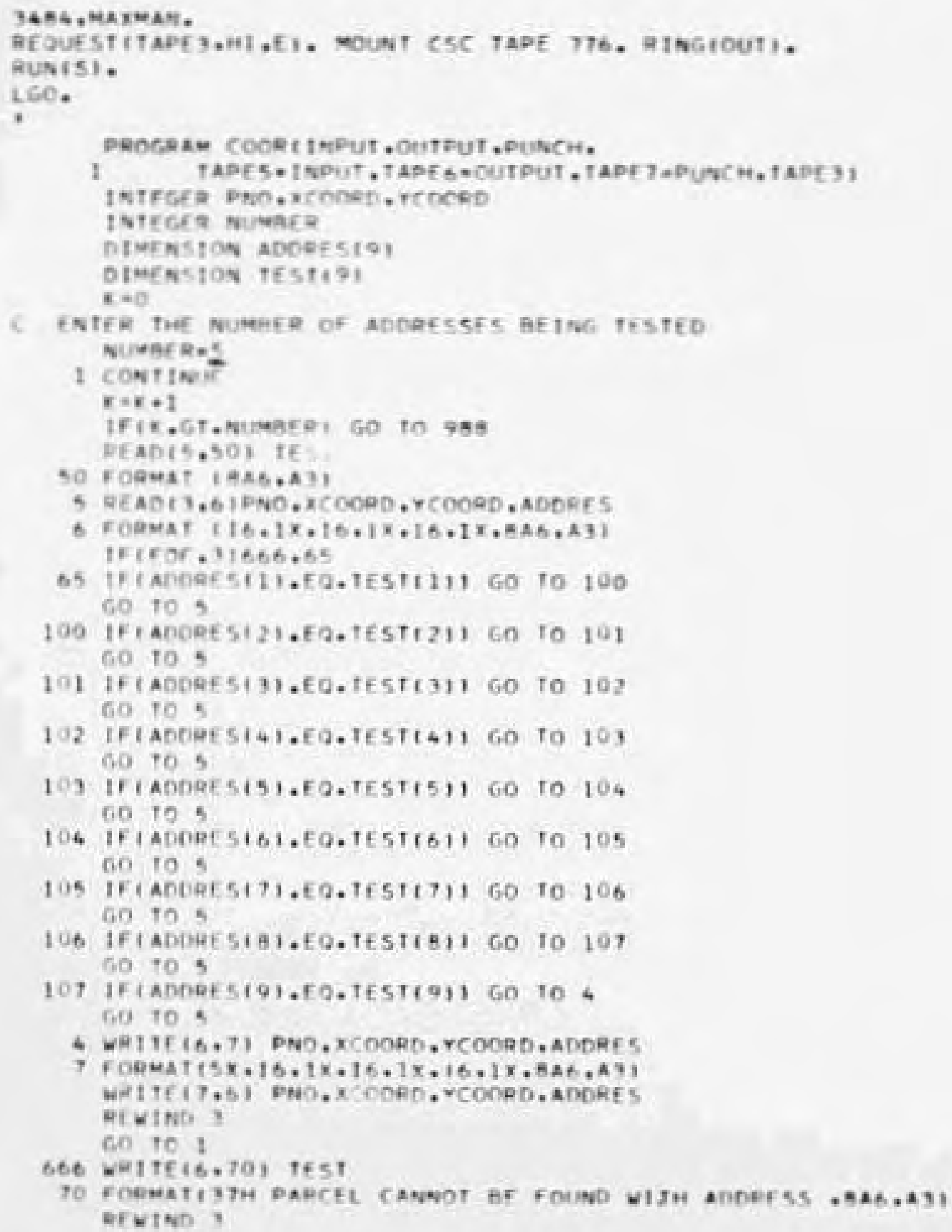

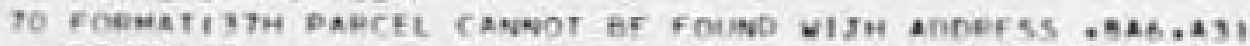
erotan? 
DROGRAN 17, CONT1NUED

60 to 1

ens contrinue

DENIND 3

FND

111 Soutre Matr

555 WEST HTGH

210203 Noeth wats

222 NOETH WATN

999 thanfs 


\section{Program 18: Retrieve Parcel Numbers for Specified Zones}

This program will print a list of the zones and the parcels within each zone. The Zone Name-Grid Coordinate File and the Parcel Number-Grid Coordinate-Address File are utilized. Cards are also punched by this program which can be fed directly to Program 16 and thereby retrieve General Data on a zonal basis. The tapes to be utilized are noted on the control cards for the program.

Note: The Point In Polygon procedure used in this program is an adaptation of the work done by Mr. Robert B. Dial at the University of Washington. 


\author{
PROGRAM 18. \\ RETRTEVE PARCEL NUWAFRS FOR A GTVEN ZONE \\ FRON THE ZONE NAWE - GeIO COODDINATE FILE \\ AND THE DARCEL NUVAER - GRTD COORDINATE - ADOQESS FILE \\ idotent is poercon'
}

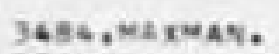

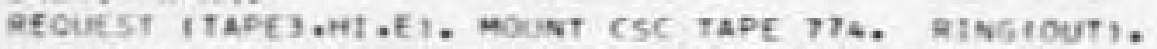

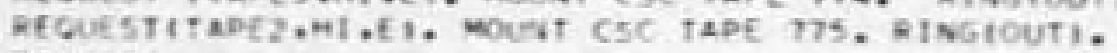
grust5:

L.60.

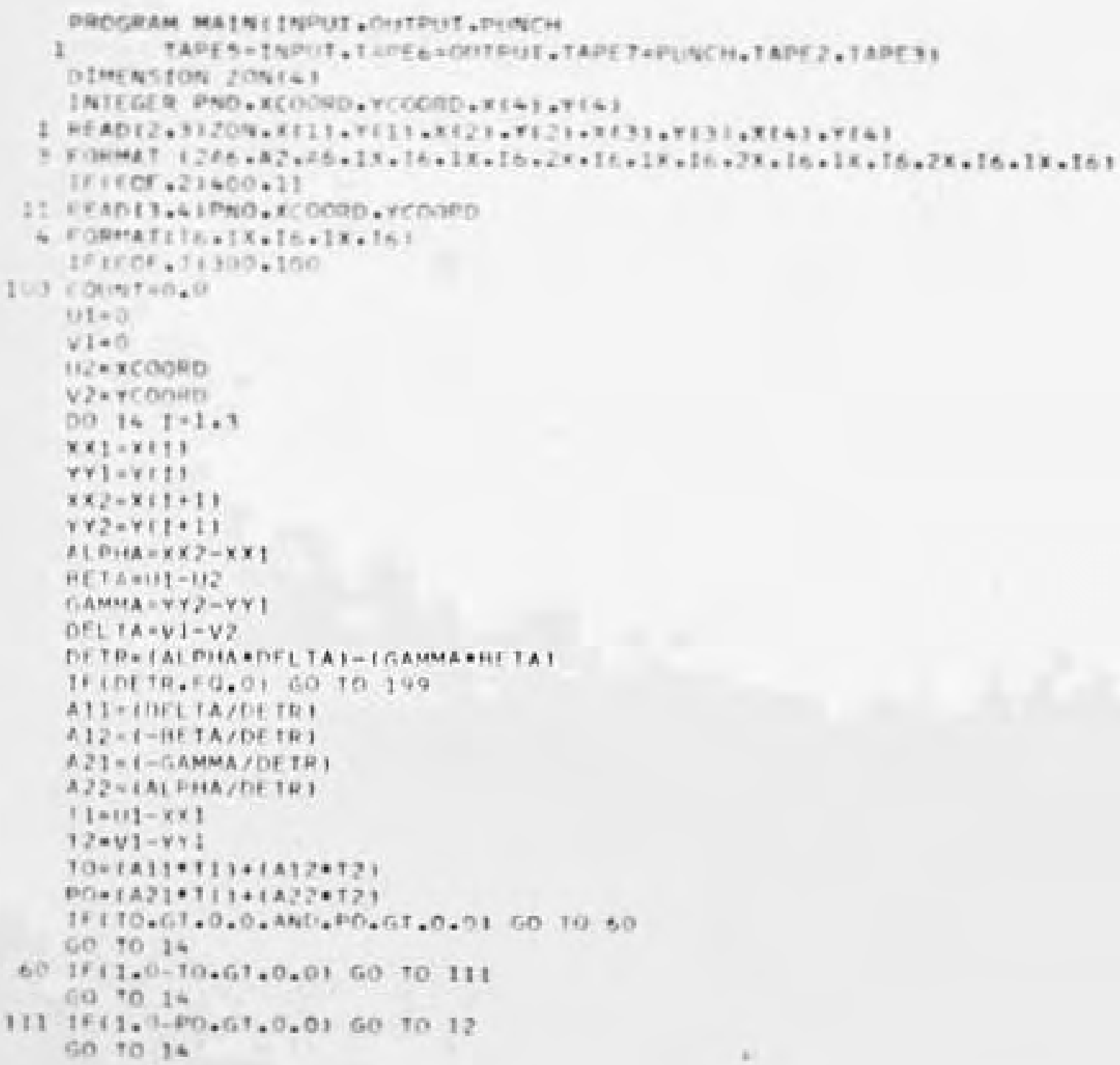


PROGRAM 18, CONTINUFD

12 count * count $+1 \cdot 0$

16 CONTISUE. ICOUNT-COUNT

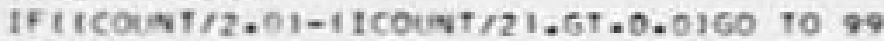

60 10 11

99 conttivie

wat? is 1110 IDNO $20 \mathrm{~N}$

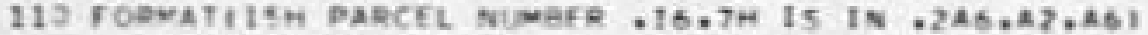

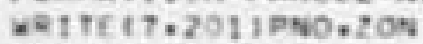

201 rosentit: $6,10 x, 246,42,461$ CO 70 il

300 seNTND 3 60 10 1

400 ofvinh 3 efwinh 2 60 To 500

199 vetteis. 20010No, zon

200 FOEMATI27U CHECK COORD FOR PARCEL NO , I6.10H ANO ZON .2A6.A2,A5. - 3nir tre computations canovot pe conpleteo l 60 to 11

600 continue

rNo 